University of Louisville

ThinkIR: The University of Louisville's Institutional Repository

Electronic Theses and Dissertations

$5-2010$

\title{
"Subject to change" : the composition course syllabus and intersections of authority, genre, and community.
}

Christopher Michael Alexander 1976-

University of Louisville

Follow this and additional works at: https://ir.library.louisville.edu/etd

Part of the English Language and Literature Commons

\section{Recommended Citation}

Alexander, Christopher Michael 1976-, "'Subject to change" : the composition course syllabus and intersections of authority, genre, and community." (2010). Electronic Theses and Dissertations. Paper 28. https://doi.org/10.18297/etd/28

This Doctoral Dissertation is brought to you for free and open access by ThinkIR: The University of Louisville's Institutional Repository. It has been accepted for inclusion in Electronic Theses and Dissertations by an authorized administrator of ThinkIR: The University of Louisville's Institutional Repository. This title appears here courtesy of the author, who has retained all other copyrights. For more information, please contact thinkir@louisville.edu. 
"SUBJECT TO CHANGE" - THE COMPOSITION COURSE SYLLABUS AND INTERSECTIONS OF AUTHORITY, GENRE, AND COMMUNITY

\author{
By
}

Christopher Michael Alexander

B.A., University of Alabama, 1998

M.A., University of Alabama, 2001

\begin{abstract}
A Dissertation
Submitted to the Faculty of the

Graduate School of the University of Louisville in Partial Fulfillment of the Requirements

for the Degree of
\end{abstract}

Doctor of Philosophy

Department of English

University of Louisville

Louisville, Kentucky

May 2010 
Copyright 2010 by Christopher M. Alexander

All rights reserved 
"SUBJECT TO CHANGE" - THE COMPOSITION COURSE SYLLABUS AND INTERSECTIONS OF AUTHORITY, GENRE, AND COMMUNITY

By

Christopher Michael Alexander

B.A., University of Alabama, 1998

M.A., University of Alabama, 2001

A Dissertation Approved on

12 April 2010

by the following Dissertation Committee:

Dissertation Director 


\section{DEDICATION}

This dissertation is dedicated to R. B.

Thanks, for lots of reasons,

but mainly for giving me Another Method of Making Walnut Catsup 


\section{ACKNOWLEDGEMENTS}

I would like to thank my entire dissertation committee and several faculty members at the University of Louisville for their guidance and encouragement. In particular, I would like to thank my director, Dr. Karen Kopelson, for her extraordinary insights on how to shape my project, and for the countless drafts she has read. Dr. Kopelson has been more than a mentor, more than a director and a guide through this entire process; her support and encouragement, her careful attention to every detail of this project, and her ability to recall the "bigger picture" elements of this dissertation as I became bogged down in the more minute details have made me a stronger writer, a better scholar, and a more attentive and compassionate future mentor. I simply cannot thank her enough.I would also like to thank Dr. Bruce Horner, for his incredible support and expertise (especially in helping me develop and engage in historical disciplinary discussions), which was an enormous asset to my dissertation overall. Dr. Horner's incisive and perceptive comments and questions have helped shape this project, and his responses to my writing have influenced not only the quality of my own work, but the processes through which I engage writing in general. He has been an invaluable asset. Dr. Beth Boehm and Dr. Aaron Jaffe have both provided me with integral perspectives for the development of my dissertation, through the more amorphous beginnings of my SRA exam and my original prospectus. Their insights have demonstrated to me the importance of writing as a series of evolutionary processes. I also wish to thank Dr. David Owen from the Philosophy Department at the University of Louisville for being an outside 
reader and taking the time to assist me. I am grateful to have been able to work with all of my committee members, and I appreciate the time and effort everyone has given me.

In addition to my committee, others have contributed directly and indirectly to my work. I would especially like to thank Dr. Debra Journet, who saw this project as a paper for her Narrative Theory seminar in Fall 2005, and during the workshops at the end of the semester, commented, "This would make a good dissertation." Her advice and assistance in shaping the earliest version of this project, the conversations we have had concerning the narrative structure of texts otherwise not traditionally thought of as narratives, and her words of encouragement at a time when I was unsure of my own place in the $\mathrm{PhD}$ program at the University of Louisville have ultimately led to the project you see before you. Dr. Journet is, without a doubt, a signature representative of the supportive, encouraging, and confidence-building faculty at the University of Louisville, and I thank her for giving of herself unconditionally to the personal, intellectual, and professional growth of her students.

I also wish to acknowledge professors from the University of Alabama, particularly Dr. Robert Halli, a true friend, someone who taught me how funny Milton can be, Dr. Richard Rand, who made close reading an art form, and Dr. Sharon O'Dair, for hipping me to this strange place in Kentucky whose only doctoral degree in English was in something called "Rhetoric and Composition." I owe you one.

Finally, thanks to Stephen Neaderhiser and everyone who ever came out to the Granville to enjoy food, libations, conversations ranging from shop-talk to Family Guy, and more libations. Thanks for keeping me (relatively) sane. I owe you more than one. 


\begin{abstract}
"SUBJECT TO CHANGE" - THE COMPOSITION COURSE SYLLABUS AND INTERSECTIONS OF AUTHORITY, GENRE, AND COMMUNITY

Christopher Michael Alexander
\end{abstract}

12 April 2010

This dissertation is an investigation of composition's disciplinary conceptions of the course syllabus, from its often-relegated position as textual object to a more interactive and complex subject of our discipline. The course syllabus is an example of an occluded genre, operating behind the scenes while serving commitments and obligations of a dominant ideology. This position as an occluded genre offers opportunities for composition instructors to thoroughly examine what our syllabi are really doing. By further exploring how we think about course syllabi, we can contribute to the development of our own teaching, as well as the teaching styles and practices of new teachers of composition. This dissertation draws on theories of power, authority, genre, and discourse community construction in composition scholarship, as well as a study component, in which I have collected course syllabi from graduate student teachers. These individuals, graduate student teachers, hold multiple stakeholder positions in the university, and operate as teacher and student simultaneously. This dissertation argues that syllabi allow us to further understand the praxis of composition, providing foundations by which new individuals entering the field frame their pedagogical goals and initial representations of themselves as teachers. 
This dissertation is divided into five chapters. Chapter One reviews published scholarship that often frames the course syllabus as an inert object, a transparently instrumental genre. This chapter also furthers the understanding of the syllabus as a material and ideological subject of composition, an inherently narrative subject in interpretations of its construction and dissemination, and a subject bound up in the embeddedness of multiple audiences. Chapter Two examines developments of theories of power, authority, and genre, and explores the extent to which the course syllabus serves professional academic discourse. Chapter Three analyzes implications of the data collection processes, specifically the reluctance of individuals to participate in this study, reflecting similar departmental and institutional tensions between what is considered publicly available and what is considered more privately guarded. Chapter Four studies sample composition course syllabi collected from graduate students in Rhetoric and Composition programs, using these documents to study how, when, and under what circumstances graduate student instructors make authority, genre, and discourse community formations implicit or explicit in their syllabi. Chapter Five argues that these reexaminations of the course syllabus's place in the discipline of composition can help refashion the graduate student teaching practicum. 


\section{TABLE OF CONTENTS}

PAGE

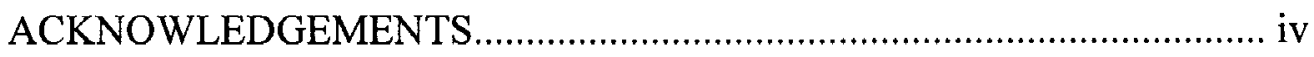

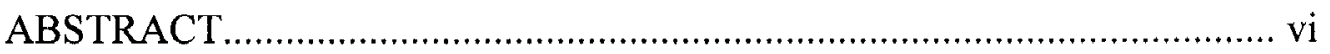

INTRODUCTION

CHAPTER

I. THE COURSE SYLLABUS' ROLES IN THE

CLASSROOM AND IN THE DISCIPLINE.................. 16

II. POWER, AUTHORITY, AND GENRE IN

COMPOSITION STUDIES................................................. 50

III. NARRATIVES OF RESEARCH AND MULTIPLE

STAKEHOLDER POSITIONS - SYLLABUS

COLLECTION AND THEORIES OF DISCOURSE

COMMUNITY CONSTRUCTION........................... 105

IV. THE COMPOSITION COURSE SYLLABUS AS INSTITUTIONAL-PERSONAL REPRESENTATIONS OF TEACHER IDENTITY CONSTRUCTIONS.................... 144

V. THE COURSE SYLLABUS AND THE GRADUATE STUDENT COMPOSITION TEACHING PRACTICUM TOWARDS A METHOD OF UNDERSTANDING

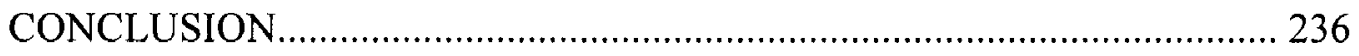

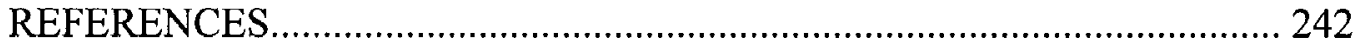

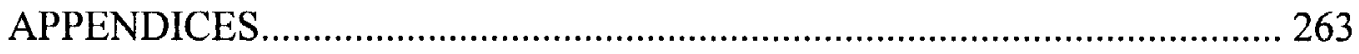

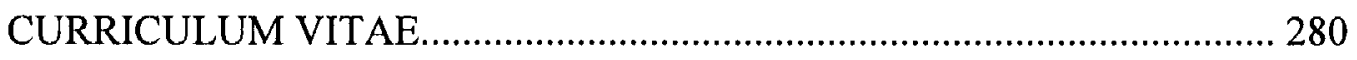




\title{
INTRODUCTION
}

\author{
SURVEYING LOCATION - A WRITING TEACHER \\ WRITING TEACHER-WRITING
}

\begin{abstract}
The syllabus, therefore, is not merely informative; it is also, as all genres are, a site of action that produces subjects who desire to act in certain ideological and discursive ways. It establishes the habitat within which students and teachers rhetorically enact their situated relations, subjectivities, and activities. Both the teacher and the students become habituated by the genre of the syllabus into the abstract nouns that they will eventually perform. Anis Bawarshi, Genre and the Invention of the Writer: Reconsidering the Place of Invention in Composition (125)
\end{abstract}

Both institutional and personal teacher identities are re-created through the course of the semester. Since being a teacher of writing places us in a continual state of reevaluating our chosen profession - in terms of the course, the discipline, the institution, and ourselves - we need to take more opportunities to examine those documents that do not simply act within the boundaries of the classroom, but work upon the conceptual and perceptional frameworks of what it means to be a teacher. The composition course syllabus serves as a partial declaration of how we choose to construct our identities as teachers, an announced, disseminated, and documented record of a version of ourselves. Each academic term, we hand out re-constructions of ourselves in relation to a specific contextual situation. We keep what works; we modify the rest - such a mantra appears applicable not only to individual assignments, but our identities as teachers of writing. In the composition classroom, in the location of composition that traverses personal, disciplinary, and institutional concerns, the syllabus functions as a multivalent discursive 
representation of complications inherent in the presentation of both personal and institutional selves.

On the one hand, composition as an academic discipline is caught in the pretext of offering students what Ira Shor calls "alternative social development, alternative ways of knowing, speaking, relating, and feeling, beyond and against traditional classroom arrangements" (When 62). On the other, composition encounters the realities of the extent to which these desires for alternatives are already repositioned into the background of traditional higher education, institutional frameworks built upon and developed through disciplines in existence much longer than composition, particularly longer than composition recognized as a post-undergraduate specialty, beyond the first-year writing course. Disciplines in this fashion serve to script teachers' and students' performances, especially in relation to one another, and these discursive-performative scripts can never be entirely separated from the locations in which they occur, through which they are continually re-enacted. Who owns these scripts, then, becomes a central ideological sticking point for composition as an academic discipline caught in its own historically founded sense of self-consciousness and inferiority complexes. Ownership arrives at the forefront of composition re-formulating itself as an academic discipline, particularly as entering graduate student teachers of composition face their own conceptions of ownership in their new roles as teachers, ownership of their course syllabi that might very well be subverted by their individual institutions' requirements and obligations.

These scripts - these representations of dual performances, negotiations, types of discursive dances between the teacher of writing and the location that allocates the institutional and disciplinary spatio-temporality necessary to develop his or her authorial 
self, his or her teacherly identity - come to an apex of both initiation and appropriation in the graduate student teacher of composition's course syllabus. Diverse motives and social forces both conflict and interact in this text, this "material artifact of academic composition" (LeCourt 39). Within course syllabi, teachers of writing struggle to represent themselves as teachers, simultaneously maintaining the standardizations often written into these texts, those elements explicitly required by the institution. Particularly to the entering graduate student teacher of composition, struggling with his or her own realities of having to represent him- or herself for the first time in this new role, this new set of discursive performances and options of self-representation, the institutional requirements of course syllabi appear ideologically immoveable. These motivational and social conflicts place the graduate student teacher in a prime position to view the ways in which the institution perpetuates itself by keeping its essential ideological structures hidden from direct view. To understand how texts like course syllabi operate as platforms for teacherly identity development, we must examine how these texts are constructed, disseminated, and discussed within the discipline of composition.

Because of its place (and placement) within the university structure, course syllabi qualify as simultaneously "public" and "private" documents, as subjects of intersection between the apparently public textual representations of competing and potentially contradictory voices, and the apparently private identities of those emerging teachers of composition suddenly responsible for developing these texts. For more than seven decades, prior to the formation of the Conference on College Composition and Communication in 1949, scholars in composition (before there was a formal academic discipline by that name) have been writing about the condition of freshman English 
courses in the university and those often charged with the task of staffing them - graduate students. Part of the reason composition as an academic discipline continues to revisit the definition and status(es) of graduate student teachers lies in Thomas Recchio's summation of the discipline, in his description of the University of Connecticut's graduate student teaching practicum course. Recchio bluntly acknowledges that "composition teaching carries the residue of its de facto lower status based on the marginality of those who teach it" (Bolin and Vandenberg 13). Thus, composition's residual conceptions of its own disciplinary status are inherently connected both to those individuals operating in the lion's share of its courses (variously labeled versions of first-year writing, freshman English, and the like), and to those initial scripts they compose in struggling to represent their own identities and roles as teachers, course syllabi.

In order to embrace this sense of reciprocity, of circularity, then, an examination of arguably one of the most under-theorized yet ubiquitous documents in the field of composition requires a preliminary examination of how this discipline perceives conditions that serve to re-create (or perpetuate) both the course syllabus itself as well as graduate student teachers themselves. To these ends, explorations of the intersections between composition's disciplinary conception and perceptions of power, authority, genre, and discourse community theories offer a lens through which we can more thoroughly investigate the extent to which the course syllabus operates as a method of graduate student teacher identity construction. By extension, this intersection brings together three general threads of composition scholarship often discussed as separate entities, in order to more thoroughly investigate the genre of the syllabus as a representation of negotiations of the institutional authority and power to decontextualize 
and recontextualize conceptions of discourse communities, and ultimately of the composition classroom itself.

Self-reflexivity is by no means a new task for composition as an academic discipline, nor is a desire for introspection, or interrogations of its own disciplinary identifications as a service course. These preoccupations are implicitly tied into ways in which composition talks about power and authority both in and out of the classroom, particularly in terms of how power and authority are often theorized or discussed as "inherited" and "owned" to varying degrees of significance (Adler-Kassner; Bazerman; Dobrin; Halasek; LeCourt; Mortensen and Kirsch; Porter; Sullivan, et al). Graduate student teachers, firmly aware of their own sense of both the inherited nature of and the newness and tenuousness of their classroom authority, build these conceptions of power and authority into their initial representations of themselves as teachers, the course syllabus.

Just as conceptions of power and authority consistently figure into composition's preoccupations with its own perceived sense of disciplinarity, how scholars write about "genre" (in and out of the confines of composition) also shapes and influences the methods of this self-reflexivity. Characterizations of genre as representation of discursive styles, disciplinary methodologies, and social motivations all contribute to extending these discussions as a way to re-theorize the composition course syllabus as an extraordinary genre of academic and professional discourse (Bakhtin; Briggs and Bauman; Carolyn Miller; Swales). Ultimately, these characterizations of the roles of genre both in and out of academic environments lead directly into parallel conceptions of discourse community construction, including the possibility that such a construction does 
not really exist. The social interactivity of genre complements conceptions of discourse communities as working against understandings of communities as unified and static, working to complicate definitions of local and global concerns, and working to demonstrate the complexities inherent in exploring the individual's relationship to society, and the often reductive descriptions of such relationships (Gale; Harris; Killingsworth; Schwartz; Trimbur). These investigations lead to Joseph Harris's development of the "stakeholder," originally framed as "undergraduates, teachers, and administrators" ("Beyond Community" 8). Composition's debates on theoretical and pedagogical implications of defining (academic) discourse communities help demonstrate the opportunity to examine the personal and institutional relationships embedded in the composition course syllabi of graduate student teachers, allowing a restructuring and reexamination of multiple stakeholders in this discipline.

This study examines the various extents to which these threads of composition scholarship - conveniently yet problematically labeled as theories of power and authority, genre, and discourse community construction - factor into analyses of graduate student teachers' course syllabi. Fundamentally, analyses of this often-undertheorized text from an often-marginalized stratum contributes to conversations about how graduate student teachers of composition negotiate their emerging identities as multiple stakeholders and layered participants in the discipline of composition. In this dissertation, I have conducted a study examining composition course syllabi created by graduate students currently enrolled in Masters or PhD programs in Rhetoric and Composition. I choose to focus on this group primarily to explore my own position as a multiple stakeholder in this regard, as well as to demonstrate the extent to which graduate student teachers of composition 
are often discussed in composition scholarship as a relatively homogenized group. In reality (as with all academic discourse communities), they are rarely that cohesively personified. The discovery that I find most interesting from my research relates to what Nina Schwartz, in "Conversations with the Social Text," calls the "what goes without saying" of our enterprise (70). While this dissertation puts forth the idea that the ideological place(ment)s of the course syllabus in various conceptions of "what goes without saying" help redefine and refine conceptions of community in the writing classroom, I was most fascinated by the extent to which graduate student teachers, Rhetoric and Composition program directors, and (in broader terms) threads of composition scholarship in general treated the course syllabus not only as that which "goes without saying," but should probably remain that way.

Currently, within the discipline of composition, there are no studies of the course syllabus that examine these texts through theoretical and pedagogical intersections of power, authority, genre, and discourse community construction, through the perceptual filter of the graduate student teacher. Most recently, Elena Afros and Catherine Schryer's "The Genre of the Syllabus in Higher Education," published in the Journal of English for Academic Purposes in 2009, focuses on the ways in which the syllabus as a genre "offers instructors a constellation of rhetorical strategies to describe the course, its goals and objectives, its structure and its correlation with other courses within the program, classroom and institutional policies as well as general logistical and procedural information" (2). While this piece certainly represents the latest move towards reconsidering the course syllabus as more than a purely functional text in academics, Afros and Schryer's explorations of "the contractual nature of the syllabus" as a method 
of understanding the connections between genre and discourse community are ultimately influenced by the fact that these three key points of reference - contract, genre, discourse community - are accepted as commonly understood.

Other characterizations of the syllabus tend to fall into singular classifications, as they are perceived in the classroom, among teachers of composition, or among administrators or those in other broader official university capacities - and I stress "or" in this case, referring to the syllabus as operational often within only one framework at a time. A proportion of existing research on the syllabus treats this text in a similar unified (or unifiable) fashion, perpetuating (irrespective of intention) the notion of the syllabus as created exclusively for and by one single author, the teacher of the particular course for which this text is intended to be "used" (Danielewicz; Dorwick; Foster; Hamilton; Scudder; Shor; Singh; Sutherland; Townsend). ${ }^{.}$Others have served to complicate this notion of a single author, especially in terms of texts produced in an environment especially conscious of the theoretical and pedagogical implications of constructions of academic discourse communities (Bawarshi; Devitt; Gale; Greer; Ede and Lunsford; Halasek; Hardin; Harris; Horner; Hyland; Johns; Kirsch; LeFevre; Allan Luke; Mauk; Roberts-Miller; Trimbur; Wallace and Ewald). While my intention is not to claim multiplicity over singularity in this regard, I do instead bring these threads together to more fully investigate the extent to which residual conceptions of both affect perceptions of the graduate student teacher's composition course syllabus. ${ }^{2}$ I argue that conceptions of multiple authorship as well as conceptions of the singular author struggle together within identities of graduate student teachers of composition, and that threads of composition 
scholarship that accept and complicate understandings of a single author reveal themselves in the ways we view texts like the composition course syllabus.

In order to have a sound historical, pedagogical, and theoretical framework from which to argue for a re-invigoration of disciplinary interest in the course syllabus as an essential component of identity transmission, Chapter One reviews published scholarship that frames the course syllabus as an inert object of composition - a guide, a map, a contract, which, if constructed properly and under optimum conditions, could yield a successful, or at least more successful, classroom experience for both teacher and student. In the last two decades of composition scholarship, the syllabus is often treated as a textual deflection of authority, particularly in the ways in which syllabus construction is discussed. In order to interrogate these deflections, I first argue that we in composition ought to envision the syllabus as a hybridization of self-presentation(s), and as an instructional narrative responsive to multiple layers of audiences. Next, I explore how the composition course syllabus as an expressly narrative document helps combat traditional presumptions of both the syllabus and narrative as transparently instrumental genres. Using these conceptions of the syllabus as narrative, I then demonstrate how, why, and to what ends the course syllabus can also be employed to shed new light on multiple conceptions of audience in composition. These arguments help demonstrate the importance of understanding the syllabus as a material and ideological subject of composition, especially in terms of the teacher's dual role of conservation and transformation of dominant ideologies.

Chapter Two analyzes the relational nexus between power, authority, and genre, helping to establish that the syllabus ought to be read less in terms of how it seeks merely 
to describe the course of events in a given semester, and more for how it seeks to construct teachers' identities in relationship with, and in contrast to, their institutions'. In order to focus on the extent to which those defined as emerging and sustained stakeholders in composition construct, generate, and enforce various subject positions, this chapter examines the ways in which instructors tend to both reveal and conceal their own conceptions of authority and power through the academic textual genre of the course syllabus. These explorations of how we in composition talk about power and authority on both pedagogical and theoretical levels lead to uncovering ways instructors operate within (and conceive of) discourse community structures, as elements of both the specific classroom environment and of larger conceptions of composition as a discipline within the entity of academia. In tracing certain historical and disciplinary developments in the ways we in composition talk about authority and theories of genre, this chapter offers ways of demonstrating how the course syllabus serves as both an operator and delineator of professional academic discourse.

Chapter Three reflexively examines my own research and data collection processes as I contacted Rhetoric and Composition program directors for permission to obtain the composition course syllabi of their graduate student teachers, as a component of the study for my dissertation. Certain institutions I contacted in the data collection process had their own separate committees on approving requests to allow individual syllabi to be sent to me in the first place, and many composition program directors (as well as individual graduate students) were reluctant to participate in this study, citing the use of a model syllabus as not necessarily productive to my research. These narratives argue that the tensions between what syllabi should do and what they actually do reflect 
similar departmental and institutional tensions between what is assumed to be publicly available and what is considered more privately guarded. These tensions reveal themselves in the implicit understanding of these institutions themselves - that the individual course syllabus reflects an individual identity worthy of protection, while, for example, the widely accessible general course description remains curiously disconnected from specific iterations of that very course. The use of a model syllabus further complicates conceptions of authority, genre, and discourse community constructions as represented in the individual documents themselves. This chapter disrupts common understandings of the syllabus as a publicly available document.

In Chapter Four, I analyze the syllabi I received from participating graduate student instructors of composition at various institutions across the country as the study component of this dissertation. I examine these course syllabi through four rhetorical and textual clues. First, I explore how residual conceptions of power-as-property reveal themselves through the relationships that entering graduate student teachers of composition maintain with their own understandings of authority in the classroom. Second, I reveal the extent to which graduate student teachers tend to employ what I call a rhetorical vocabulary of conditionality in their course syllabi, most often through phrases suggesting sets of consequences for composition students in their classes not following mandates for the course. This language of conditionality, focusing primarily on "may" and "might" clauses, suggests a specific rhetorical move in the genre of the course syllabus in negotiations with constructions of newly-emerging teacher identities. Third, I explore how these course syllabi submitted as part of this dissertation study include various gestures towards the establishment of a sense of community, often through the 
inclusion of the pronoun "we," as a version of "you." This indicates a particularly relevant overlap between perceptions of the communal and those of the directive. Finally, I analyze the ways in which these composition course syllabi encounter, quote, and negotiate multiple versions of broader institutional and more course-specific rules and regulations, resulting in what I refer to as a kind of "deferment" of authority. These sets of rhetorical moves, brought to light through analyzing the course syllabi of graduate student teachers of composition, reveal how these texts tell stories of graduate student teachers' struggles to form and maintain their identities. These texts reveal the embeddedness of ideological structures of power, authority, and multifaceted understandings of the conditions of the course syllabus as a genre of academic writing. These texts offer a way for graduate student teachers to begin to formulate themselves as teachers, while they simultaneously struggle to respond to antecedent versions of this academic textual genre, assumptions of what a course syllabus - and by extension, a teacher - should look like. Through this study presented in this chapter, we can begin to see how the multiplicity of the genre of the course syllabus within the realm of academic writing both acknowledges and threatens to subvert the multiple stakeholder positions occupied by graduate student instructors of composition.

Chapter Five explores ways these re-examinations of the course syllabus's place in the discipline of composition can help refashion the graduate student teaching practicum. Rather than intending to serve as a prescriptive recommendation for how to run a graduate practicum course, this chapter argues for a more invested focus on the course syllabus beyond its traditional place as a purely functional academic genre, using both observations concerning my follow-up survey of graduate student teachers 
participants, as well as recent narrative-based research on the composition practicum. Depictions of a stripped-down "how-to" course, forced to make the choice between the pedagogical and theoretical, leading to (in some descriptions) elements of the ideologically coercive, tend to dominate narratives of the composition teaching practicum (Bolin and Vandenberg; Dobrin; Guerra and Bawarshi; Irmscher; kyburz; Smit; Sternberg and Lee; Sullivan). In contrast, this chapter explains how an invested focus on the course syllabus allows us in composition to use this text as an opportunity to examine and explore conceptions and depictions of the syllabus as a representative institutional, personal, and pedagogical document, offering new opportunities for the composition teaching practicum course.

In the conclusion, I reiterate how conceptions of power, authority, genre, and discourse community construction influence the development of the composition course syllabus. I also offer alternative means of exploration for the syllabus as a subject of composition as an academic discipline, including examining syllabi between related disciplines in the humanities, as well as examining online syllabi. Since course syllabi function as representatives of one's teacherly identity most explicitly, perhaps, as one enters the academic job market, sample course syllabi often offered as part of one's representative "job documents," this marks another transition, from graduate student to emerging professional. This transitional identity is perhaps most in conflict with the syllabus, which appears as a temporary, or "stabilized-for-now" substitutional identity. This substitutional condition demonstrates the extent to which both entering instructors as well as entering students of college composition courses can benefit from examining the syllabi to which they are both inherently held responsible in a relational context, 
including elements of physical design as well as theoretical implications of this reduced self-representation.

This dissertation does not attempt to position the composition course syllabus as a problem to be solved, nor does it serve as an evaluative critique of graduate student teachers' constructions of their individual course syllabi. My focus on the extent to which the syllabus operates as a representation of emerging, developing, and evolving teacherly identities in the composition classroom demonstrates the need to focus on those texts we have come to accept as purely functional, operational only to the degree that it "works" for the class, in a specific spatio-temporal environment. The syllabus is often relegated to the status of textually plain or ordinary, and it is this very status itself that begs further examination. Course syllabi do not spring out fully formed from the teacher's mind, completely original and unique to the individual course at the individual institution; rather, perceptions of authority, academic generic expectations, and disciplinary and institutional perceptions of community co-create an environment, a location for the syllabus. What follows is not a prescription for writing the proper composition course syllabus. What follows is only part of the syllabus's narrative. 
Notes

${ }^{1}$ I realize that including Ira Shor - known for his discourses of empowerment and negotiation his When Students Have Power and Empowering Education - in a list of citations on the reduction of the author of the syllabus to a singular entity might be considered argumentative at best, and perhaps simply incorrect at worst, given his propensity towards discussions of negotiations and building his course syllabus with his students. I stand by this inclusion, however, as I more fully interrogate the problematic nature of "negotiations" as they relate to conceptions of power and authority in composition in Chapter Two of this dissertation.

${ }^{2}$ I operate similarly through my discussions of both genre and discourse community constructions in my second and third chapters, offering the notion that we cannot entertain current iterations of these concepts - particularly as they pertain to pedagogical textual construction - without exploring degrees of influence residual understandings of these same concepts have on current performances. 


\section{CHAPTER I}

\section{THE COURSE SYLLABUS' ROLES IN THE CLASSROOM}

\section{AND IN THE DISCIPLINE}

To identify something assumes a paradigm with a limited set of choices. Stephen Owen, "Genres in Motion" (1390)

Course syllabi, including individualized course descriptions, institutionallymandated disciplinary statements (concerning plagiarism and accommodations for disabilities), and calendars of events, are often under-theorized in composition scholarship.' The syllabus functions as a representation both of the instructor and of the institution that serves as a space in which to create the instructor as such. Owing much to the position of the course syllabus as an occluded genre, operating behind the scenes while serving commitments and obligations of a dominant ideology, this simultaneous insider and outsider status offers opportunities for composition instructors to more thoroughly examine what our syllabi are really doing. To this end, this chapter explores different ways in which composition studies has examined the individual teacher's role in the classroom dynamic as representative of larger goals and implications of the field, specifically through the course syllabus. This chapter serves as an introduction to the argument that the text of the course syllabus and the academic discipline of composition operate in a reciprocal relationship.

I plan to make three arguments. First, through a brief overview of composition scholarship in which discussions of the syllabus play a more prominent role, including 
works from Ira Shor, Lisa Ede, Anis Bawarshi, and Amy Devitt, I argue that the course syllabus is in itself an often under-theorized point of textual self-reference. This undertheorization applies specifically to the ways such a document has been portrayed as an object rather than as a subject of the discipline. The syllabus's presence as an "ordinary" text performing "ordinary" work demonstrates the need to reinvigorate a disciplinary interest in the course syllabus as an essential component of identity transmission, which would in turn allow us to see how these documents help expand, rather than suppress, teacher identity constructions. Raymond Williams reminds us that "[c]ulture is ordinary: that is the first fact. Every human society has its own shape, its own purposes, its own meanings. Every human society expresses these, in institutions, and in arts and learning. [...] Culture is ordinary, in every society and in every mind" (32). It is through the "ordinary" work of the course syllabus that performances of composition as an academic discipline begin to shape themselves.

Second, drawing on Jerome Bruner's use of folk psychology in establishing the grammatical components of narrative as an organizing principle of social interaction, I argue that envisioning the composition course syllabus as a narrative document helps combat traditional presumptions both of the syllabus and of narrative as transparently instrumental genres. Third, I demonstrate how, why, and to what ends the course syllabus can be employed to shed new light on traditional understandings of audience in composition studies, particularly in terms of how the syllabus complicates Ede and Lunsford's conceptions of "audience invoked" and "audience addressed." Together, these arguments enable me in my next chapter to advance conceptions of power, authority, and genre as a particular theoretical intersection, which I will use to examine course syllabi 
produced by graduate teaching assistants in various Rhetoric and Composition programs across the country.

\section{The Syllabus as Object / Subject of Composition}

In this section, I argue for a more explicit and deliberate shift in composition's understanding of the course syllabus, from its often-relegated position as merely informative textual object to a more interactive and complex subject of our discipline. As I have suggested above, a brief overview of composition scholarship reveals that, until quite recently, the syllabus has been thought of strictly as an object of the classroom - a guide, a map, a contract. The syllabus has often been treated as a textual deflection of authority, particularly in the ways in which syllabus construction is discussed. In "Pedagogy of the Distressed," Jane Tompkins places the course syllabus in terms of a spectrum of method, noting how "the students are responsible for presenting the material to the class for most of the semester. I make up the syllabus in advance, explain it in detail at the beginning of the course, and try to give most of my major ideas away" (656). Further, she explains the rush of putting together a syllabus "by hook or by crook" before the beginning of the term, in order to "distribute responsibility" for the class (658). While student participation and presentation of materials in the composition classroom surely ought to be encouraged, her descriptions of the course syllabus in spatiotemporal relation to herself as a teacher warrant further exploration. Tompkins reveals a way of talking about authority in how she talks about her processes of syllabus construction and dissemination. As the individual who makes decisions of material inclusion, conceptual explanation, and the distribution of responsibility, Tompkins places herself in the position 
to "relinquish" her authority in the classroom while in reality presenting herself as the sole author of this document.

This pattern of constructing course syllabi prior to the first class meeting in conjunction with a thorough and early explanation of key elements (including assignments, due dates, requirements of attendance and participation, as well as a host of more deliberately institutionally-specific rules and regulations) becomes a factor in what Nina Schwartz, in "Conversations with the Social Text," calls "the 'what-goes-withoutsaying' of our own enterprise" (70). We as composition instructors assume this pattern is beneficial both to ourselves and our students, especially as it relates to both the specific composition course as well as departmental concerns of indemnification. Indicative of these conceptions of the course syllabus as an informative and individually-constructed text are various guides and handbooks, including Bette Erickson and Diane Strommer's 1991 book, Teaching College Freshmen, in which they describe the syllabus as a document designed to reduce student anxiety through the providing of structure and direction, provided the syllabus is not "poorly written [...] full of misspellings and punctuation errors," since Erickson and Strommer suggest that this undermines teacher credibility (81-85). Most revealing are the ways Erickson and Strommer deal with issues of complacency in the college classroom. Acknowledging that while "it seems worth the trouble to include a few words about why required texts were chosen, how they will relate to class activities, and what students might expect to get from reading them" (82), their attitudes towards these requirements appear rather dismissive as they note how "a sentence or two explaining why such policies have been adopted makes them seem less harsh and arbitrary" (85, my emphasis). Erickson and Strommer define the syllabus in 
terms of (mutual) anxiety-reduction, which in turn, I argue, develops into a conception of syllabus-as-question-reduction. Explanations of certain decisions already made are offered not to develop or encourage student participation in processes of classroom cocreation, but to anticipate and prevent any insecurities asking such questions might elicit. They implicitly acknowledge that policies adopted in the classroom are in fact "harsh and arbitrary," and that all we as instructors can do is make them appear less so. While Erickson and Strommer argue that the syllabus participates in "reflecting the instructor's teaching style" (86), the tone these conceptions of the syllabus establish here appear more of suppression than expansion.

In order to better qualify this tension between modes of suppression and expansion, I point to an earlier course syllabus of my own, from the fall 2003 semester at a private university in Birmingham, Alabama, composed of approximately 1500 students, in which the more typical two-stage introduction to composition course sequence has been compressed into one semester (see Appendix 1). First, let me address the construction and reception of the course description. While I will explore disconnects between perception and reception later on in this chapter - particularly my desire to fit the course description and the calendar of events onto one page each, out of what I assumed was a desire for conciseness and convenience - I wish first to engage in a bit of self-deprecation. With the inevitable benefit of hindsight, I can examine ways in which this syllabus struggles to present a sense of community in the classroom while simultaneously injecting arbitrary policies with little to no explanation of their individual importance to the construction and maintenance of this very community. 
For the most part, this syllabus, constructed early in my post-Masters teaching career, appears fairly straightforward. At this stage in my dissertation, however, following complexities between conceptions of anxiety-reduction and question-reduction, I feel it necessary to point to some specific gestures. While I plan to revisit this particular syllabus again in my dissertation, both on its own and in conjunction with a more recent example of my own syllabi, I want to point out the extent to which I sought to reduce student anxiety while at the same time, through its overarching directive and seemingly arbitrary policy-filled approach, I ended up encouraging student non-participation, both in the co-construction of the course syllabus (and class) and in individual instances of class participation.

Before the fairly typical pronoun shifts largely indicative of composition course syllabi - movements from "we will learn" to "you will produce" to "we will be focusing" - the listing of the office contact information constitutes a moment in which something seemingly ordinary and insignificant functions on a number of different levels. In the first place, I admitted in print that I was new enough at this particular institution that I could not remember my own office phone number, which appears to be nothing more than a gesture towards democratization, an acknowledgement of my own shortcomings as a new teacher to this place of composition and to the discipline in general. At the same time, however, the simple gesture of "I'll tell you Thursday" signals an inherent assumption that the students treat me as a sole source of knowledge, or they should, even if this particular piece of knowledge is otherwise readily available on the college's website or at the English department's office. Following the course description and the table of grade determinations, I declare, "I don't round up grades; this means that if your average comes 
to a 79.9, it's still a C+, and so on." Although I acknowledge that (with the definite benefit of hindsight) this policy is ineffective, incredibly inefficient, and ultimately draconian in its conception, I can also admit that at the time I felt such directness would benefit both myself and the individual students by reducing possibilities of confusion when it came to their grade in the course.

My initial goal of confusion (and thus anxiety) reduction again appears in my policy on excused absences, or at least my deliberate attempts to eliminate them from existence. I attempted to balance a rigid policy with a bit of levity, as I comment on possible excuses: "Frat party, hangover, broken leg, court date, dead computer, dead grandmother - I don't care. Unless you're dead; then, we can talk," referring to losing points on one's average due to excessive absences as "stupid" and "ridiculous." Again, in the present moment of this course, early in my post-Masters teaching career, I saw this as a gesture as an opportunity both to solidify my authority in the classroom as well as to present the personality of a humorous, easy-going individual. The essentiality of this particular syllabus as a solely-beneficial object vis-à-vis my own identity constructions as a writing instructor can perhaps best be summed up in my final words in the course description, emblazoned at the bottom of the text in all capital letters, "ask questions." Positing inquisitiveness as "the only way to learn anything" after I had plied students in this course with rigid polices represents a duality of desire in the maintenance of classroom authority - I wanted students to perceive me as someone they could come and talk to about problems with their writing, with the course, with college experiences in general, while I was simultaneously dismantling any opportunities for them to do so. 
Ultimately, the syllabus succeeded in "neutralizing" (or essentializing) this particular course.

In Empowering Education, Ira Shor comments on the problems associated with treating the syllabus as an objectified "neutral or apolitical" document. Shor's censures of course syllabi are quite similar to Erickson and Strommer's, observing that "a syllabus without critical questions [...] supports the status quo by not questioning it" (41). While arguments depicting freshman composition in opposition to more specific "subjectmatter" academic disciplines have been proffered as early as Fred Dudley's 1939 piece, "The Success of Freshman English," and Harold Scudder's 1940 essay, "A Functional English Course," Shor appears to take deliberate advantage of this conceived position, of composition as more fluidly defined in terms of subject matter, turning key critical questions over to his students. He explains that while "in traditional classrooms, teachers routinely begin by defining the subject matter and the proper feeling to have about the material" (29), composition's placement in academia allows opportunities for students to "ask why the official textbook and syllabus are organized the way they are and how this knowledge relates to their community cultures and to conditions in society [, and] why the books and readings in the syllabus were chosen and what readings are left out of the official texts" (35-36). Empowering Education, as well as his later When Students Have Power: Negotiating Authority in a Critical Pedagogy, both suggest a shift in the way composition teachers can and should view the course syllabus as opportunities of codevelopment, beyond comfortable conceptions of the syllabus as an individually constructed, individually delivered, wholly beneficial (or benign) textual document. 
Reviewing the syllabus in ways that purposefully disrupt and disorient composition's enactment of day-to-day activities directly affects some of composition's (and by extension, academia's) more cherished ideological enterprises. In the spirit of Shor, composition as a discipline becomes more concerned with imagining the syllabus as a document engaged with and invested in these very enterprises, and no longer existing in a vacuum. Course syllabi become platforms of theoretical and pedagogical selfexamination, as Keith Dorwick reflects on his own syllabus to explore its "teachercentered" nature, and "the choice of texts" becomes a primary focal point of the power struggles between student, teacher, and institution. In "Uncovering the Rhetoric of the Syllabus: The Case of the Missing 'I'," Diann Baecker analyzes a collection of composition syllabi from her colleagues at the University of North Carolina at Greensboro, and her analyses of pronoun usage and the operations of multiple "we"s in these texts sets the stage for examinations from Anis Bawarshi, who explores the syllabus as a generating and enforcing text in both "The Genre Function" and Genre and the Invention of the Writer, all of which I will explore in further detail in the next chapter.

Enacting a shift in composition's understanding of the course syllabus from an object to a subject of our discipline also requires a shift from composition asking "what should an effective syllabus look like" to "what do our syllabi do." Such a change in perspective helps to invigorate discussions of a common metaphor for the course syllabus: the contract. Although Shor attempts to qualify and modify this commonplace classification of the syllabus in terms of a "negotiated contract" in modes of exchange between proposition and disposition (When 76-77), others like Stephen Fishman and Lucille McCarthy observe that conceptions of syllabi as "legally enforceable contracts" 
(660) are indicative of transactional models of community, models that "promote professional relationships, the separation of public and private" $(652){ }^{2}$ Fishman and McCarthy's comments on these transactional models of community suggest more about the nature of the metaphor of the contract, as that which forges community through separation, through divisions of "us" and "them" - the party of the first part, and the party of the second part, so to speak.

Baecker explains that, particularly "in this litigious age, perhaps it is not surprising that the importance of constructing this 'contract' so that it is binding on both parties is emphasized" (59). Indeed, as I re-examine the evolutions of my own syllabi over the last decade of teaching at community colleges, state universities, and private colleges, I can see a definite shift from even my own conception of the syllabus as a merely informative calendar of events, assignments, and due dates, to an extension of the university's own mandates, often expressed verbatim in the document itself. The very fact that syllabus-as-contract has become so commonplace in our discipline explicitly connects the syllabus to conceptions of both authority and genre in the theory and practice of composition. These contractual metaphors yield potentially contradictory observations, specifically the mutually binding assumption of a traditional contract in conjunction with instructors reserving the right to make changes to the syllabus as they see fit, or as the class warrants.

Although I find the metaphor of the contract highly problematic and ultimately ineffective in describing the multiple discursive acts of a text like the composition course syllabus, Baecker's suggestion of "this litigious age" reminds me of the transformations in my own syllabus constructions in deference to the institution in which these constructions 
take place. As the first example syllabus of mine from 2003 demonstrates, brevity was the order of the day. I sought to compress all policies, events, schedules of readings, and more into a document no longer than two pages, on the assumption that the more compressed the document (physically and ideologically), the more likely students would refer to it throughout the course, not taking into account more practical concerns, the least of which included the fact that a smaller font with less use of white space is simply more difficult to read. Beyond this, however, and by comparing the structure of the syllabus from 2003 to this spring semester of 2009, I realize how, why, and to what extent the metaphor of the syllabus as contract appears both attractive and problematic. While the 2003 course syllabus provided never really goes outside of policy declaration and enforcement for that particular section of the course (except perhaps the $+/$-grading system established through the college), the example from 2009 demonstrates a sense of movement or oscillation between the individual course section and its placement within the larger structure of the university. I point to the ways in which this example syllabus moves from the basics of course identification and instructor contact information directly into the general course goals as stated in the university's handbook, and from these generally applicable and directly quoted phrases into this specific course description, texts, and assignments, "framed" at the end by a series of directly quoted phrases required by the university, including grievance procedures and a statement concerning the university's definition of plagiarism. These layers of movement between the individual course and the university demonstrate the incompleteness of the contractual metaphor, particularly when expressed as "binding on both parties," as this implies that the entity of the student and that of the instructor are the only parties in play in this regard. 
Furthermore, the metaphor of the contract removes the syllabus from a space of individually authored discursive innocence. In exploring the impact of the metaphor of the contract on the development and reception of texts like course syllabi, I borrow from Min-Zhan Lu's critique of the "politics of linguistic innocence," which she defines as "a politics which preempts teachers' attention from the political dimensions of the linguistic choices students make in their writing" (26). The no-less-troubling concept of "discursive innocence," I argue, is that this preemption becomes internalized and thus more normalized than the linguistic innocence to which Lu refers. The phrase "discursive innocence" suggests the dangers of instructors producing syllabi that are presumably devoid of confrontation, or completely benign in nature - in a sense, enacting the ideology of being "non-ideological." Baecker demonstrates part of the appeal of this "discursive innocence" in terms of a syllabus's "balance," remarking, "One of the most balanced syllabi I looked at is also one of the simplest - only one page. Everything is laid out, including the relative weight each assignment will have toward the final grade. Very little of the instructor's personality comes though, and the syllabus could almost be one for any course" ("Uncovering" 60). Not unlike the metaphor of the contract, this supposed "discursive innocence" reveals hidden ideological assumptions through positive democratic associations like a contract, or a sense of balance.

This sense of "innocence dispersed" becomes complicated in recent compositionists' tendencies to reexamine their own syllabi as part of pedagogical reflection. Notably, Lisa Ede takes the opportunity to delve into her own syllabus archives in Situating Composition - Composition Studies and the Politics of Location, in which she explores her own past composition course syllabi at Oregon State University 
from 1982 to 1995 . Ede comments on the extent to which these syllabi are structured "with a clear attention to - and intervention in - students' composing processes," as indicated by listing due dates "not only for original drafts but also for revisions, and they feature required in-class peer responses" (90). She observes that the enactment of a sequence is certainly not identical from course to course, reflecting that each composition class she has taught at Oregon State University reveals a sequence of presenting the assignment, discussion, invention, responding to drafts, peer review, discussion of revision, and responding to revisions (97). While discrepancies between the plan of a particular composition course as indicated in a syllabus and the reality of day-to-day classroom activities are of course ordinary, and are not the focus of my dissertation, I find more intriguing tendencies to re-examine past course syllabi in an effort to create a stable (not to be confused with static) version of oneself. Ede's reflective engagement with her own syllabi demonstrates part of the complex nature of the relationship between composition theory and practice and constructions of course syllabi. While I argue more for a movement towards a polyvocal, intertextual conception of the syllabus, ${ }^{3}$ beyond the singularity of authorship, Ede's comments about how "a number of activities [...] reflect my engagement with the rhetorical tradition," and how "several days devoted to grammar and sentence structure [on the syllabus] indicate that I had hardly abandoned a concern for 'the fundamentals of expository prose'" (90), reveal an inclination to de-other the syllabus, to fold it back on itself through reflection as a textual representation of an assumed uniform author.

Before I discuss conditions and implications of the syllabus as a narrative text, and how an examination of this document as a narrative contributes to a shift in our 
understanding of both syllabi and narrative beyond conceptions as static genres, I want to briefly explore how the "I" of the syllabus is inescapable, and yet it functions as another element of a complex, multifaceted contribution to understandings of composition theory and practice. During the last decade, conceptions of the syllabus have heavily focused on the implications of pronoun usage and intersections of the "I," "we," and "you" in syllabus construction, from Baecker, to Bawarshi, to Amy Devitt's Writing Genres, in which she explores genres in processes both of being named and being used, observing simply, "Concerned citizens write letters to their editors, students write essay examinations, teachers write syllabi, and doctors write prescriptions" (8). Devitt expands our understanding of composition as a discipline by depicting the syllabus as an operationalizing genre of academic discourse and identity construction that (in part) reveals the choices already open to teachers through their position within the institution.

These choices, Devitt argues, are revealed through sets of particular "expected language, tone, and content" demonstrating "the ideology underlying the syllabus" (Writing Genres 200). In "Style in the Diaspora of Composition Studies," Paul Butler explains that the composition syllabus is "at heart exophoric because of the constant juxtaposition of you and we (and by extension $I$ ) [...] and their reference to an external reality," but at the same time, the syllabus may become "anaphoric, particularly when those pronouns refer to an institutional rule or policy that the instructor is quoting" (10). Pronoun usage as an entry point of examining the syllabus as a particularly "extraordinarily ordinary" genre of academic discourse allows further exploration of multiple and potentially conflicting conceptions of authority and discourse community construction. Tensions between exophoric and anaphoric, as extended linguistic 
conceptions of insider/outsider statuses, further demonstrate movements beyond the course syllabus as a textual document contained in a presumed acontextual vacuum.

\section{Syllabus as Discursive, Disciplinary, and Narrative Space}

Other recent explorations of the composition teacher's identity structures as established and negotiated within the textual boundaries of the course syllabus span the spectrum from the conceptual to the material, suggesting that the syllabus itself offers a lens from which to view the discipline of composition (or any academic discipline for that matter) as a process of juxtaposition, or more precisely an integration of theory and practice. Anis Bawarshi's explorations of the syllabus tend towards the abstract in his efforts to establish the teacher's maintenance of the balance between explicit fulfillments of course requirements and establishing a sense of community through mutual responsibility (122). Others like Frances Singh, in "'Teacher, You've Got a Problem', or Recuperating Humpty-Dumpty," have used explorations of the syllabus as an institutional document to comment on its impact in a more personal, immediate sense. Singh delineates her own experiences as her students force her to encounter not only her course syllabus but also her previously un-problematized views of such a text, as she admits, "I never thought of the syllabi I produced as anything other than compliance with a university obligation to provide students with a map directing them to the end of the course" (21-22). Singh's "tables-turning" moment, one in which she realizes how she had not to that point thought of the syllabus as "an outline of knowledge acquisition and production and as a personally revelatory construct" (22), came after several of her students pointed out that her particular choice of material (including Hawthorne's "Young 
Goodman Brown," and Robert Frost's "The Road Not Taken" and "Stopping By Woods on a Snowy Evening") seemed centered around "enclosed or (en)trapped people" (20). The implications of this moment point to the syllabus as a document that does, quite simply, more than we might think it does during the day-to-day business of the class, complicating the nature of "compliance with a university obligation." Rather than defining the syllabus through the discursive and physical environments it creates in the classroom, Singh refers to her course syllabus specifically and deliberately in personal terms, as a "textualised self-presentation" (22), a hybridization of her experiences (24), and an "instructional narrative" (30).

In this section, I argue that we in composition ought to envision the syllabus precisely as a hybridization of self-presentation(s), and as an "instructional narrative." This re-visioning requires a re-examination of the form of the course syllabus as an inherently narrative structure. In Acts of Meaning, Jerome Bruner argues that "narrative structure is even inherent in the praxis of social interaction before it achieves linguistic expression," and that narrative requires "four crucial grammatical constituents if it is to be effectively carried out" (77). In order to recognize the syllabus as a representation and extension of this fundamental "pre-linguistic" narrative reliance on human interaction, it may be helpful to examine each of Bruner's specific elements individually to further delineate the syllabus as a narrative structure. ${ }^{4}$ Bruner lists "agentivity" as the first and presumably central component, claiming that narrative requires "a means for emphasizing human action or 'agentivity' - action directed toward goals controlled by agents" (77). His careful phrasing here reveals a perspective of narrative as a delivery device - the subtle distinction between narrative requiring "a means for emphasizing" agency and requiring 
agency itself signals an understanding of narrative as a method of human interaction as acted out amongst participants, those willing to claim agency if offered. In this sense, in examining Bruner's choice of words here, narrative seems to occupy the space of potentiality, only "effectively carried out" by those actively willing to participate inside this space.

The inherent potentiality of "agentivity" ties directly to Bruner's second grammatical requirement of narrative, "that a sequential order be established and maintained - that events and states be 'linearized' in a standard way," both of which overlap into the next essential component of narrative (according to Bruner): "a sensitivity to what is canonical and what violates canonicality in human interaction" (77). If narrative requires a set of actions directed towards a certain set of goals, and those actions and goals are framed in a sequential order that must make sense to a particular audience, must be recognized as a sequential order, then both of these requirements together seem to fall under the broader heading of "agentivity," or more generally, control. Imagine the first day of a college composition classroom, in which the instructor hands out a syllabus to his or her students, and reviews class procedures, policies, requirements, and the like. The potentially agentive space of the classroom is (only partially) determined by the instructor, who apparently establishes individual "actions" or assignments the class is to complete, or at least participate in, in order to reach the institutionally pre-determined, already agreed upon goal, the end of the semester, quarter, or term.

The syllabus provides a narrative means for "emphasizing human action," which in turn offers a modicum of control, if illusory or mutually-dependent, for both teacher 
and student. As a document, it offers a path of directionality with a number of possible outcomes, choices, and decisions along the way. As for the establishment of a sequential order, narrative analysis of the syllabus yields somewhat obvious results, essentially linked to what Bruner labels canonical sensitivity. The inherent chronological order offered by the syllabus acknowledges the standard linearization of events predetermined by the already agreed upon calendar - certainly, no student or teacher would expect to receive or produce a syllabus for the fall semester which began in October, moved to September, then to December, only to end in August. Such an order would naturally violate both the narrator's and the audience's most basic sense of expectations of what Bruner earlier refers to as narrative's "inherent sequentiality" (43). For the syllabus, this sequentiality represents the canonicality of its form. In order to better understand what I would argue as inherent interconnections between conceptions of chronology, emphasis, control, and sequentiality, I make the claim that the course syllabus operates as an essential initial reading assignment in any college student's academic career. Its surface establishment is predetermined by a culturally inherited calendar system and replicated without question by individual instructors of all disciplines and levels of experience. Sequentiality represents a central component to these usage conventions that we have come to expect as readers and interpreters of narrative events. Expectations of the order of presentation appear to supersede any presuppositions about narrative content. If the organization of events is unrecognizable, or excessively violates the canonical expectations of form, the content of any particular "story" becomes irrelevant.

The acknowledgment and replication of the essential sequentiality of narrative form take on a particular importance in the consideration of interpreting narrative events. 
In "Storytelling in Criminal Trials: a Model of Social Judgment," Lance Bennett recognizes that "[t]he linear development of action simplifies information organization and aids the identification of a central action and critical junctures in its development" (82). While I argue that the syllabus is much more than a mere organization and presentation of information, its linearization is the first step toward making sense, toward interpreting the story. Acknowledging the interpretive duality of this particular narrative element (sequentiality), Bruner hints at the fundamentally dialectical nature of narrative response as he notes, "the interpreter has to grasp the narrative's configuring plot in order to make sense of its constituents, which he must relate to that plot. But the plot configuration must itself be extracted from the succession of events" (43-44). Essentially, the parts must be derived from the whole, but the whole cannot be made sense of until all of the parts are understood. Narrative represents more than the sum of its parts, and the interpretive moment, the necessary encounter with narrative, requires a dual interpretation of both layers. $^{5}$

In terms of concretizing the retroactive nature of narrative, allow me to describe a situation from my own teaching experiences. For a final exam I administered during the fall of 1999, the inaugural semester of my teaching career, I asked my students to write an essay about one of the last four stories we had read. They were to choose one they would leave off the syllabus for the next semester, and construct an argument in defense of their position. One student wrote a rather scathing essay about Graham Greene's story "The Destructors," recommending I remove it from the course syllabus in the future, because we had already read other stories from Jean Shepherd, Sherwood Anderson, and Jack London. She rightly felt all of the male-composed, male-centered, and male 
character-driven stories left her out of the possibilities of representation. Singh recalls a desire to perform "her pedagogic duty to teach texts taken from the required anthology" (21), and, having also to teach from a departmentally required reader, I felt I had created a syllabus which included stories I deemed exciting, usually with a "twist" ending of some kind. These were intended to teach both dynamic and static characters - those who learned some lesson through the course of the story, and those who learned absolutely nothing. All of this was in an effort to represent what I felt was closer to "real life," an effort to represent the reality that not every experience in life necessarily involves a lesson. This student, however, made me realize that the "real life" I was attempting to recreate through the narrative continuity of the syllabus left her with a profound sense of discontinuity and disconnection through the course of class discussions and readings. Arguably, it was this moment in my teaching career that started my thinking about what our syllabi are really saying about ourselves as teachers.

Bruner's recognition of narrative's crucial "sensitivity to what is canonical and what violates canonicality in human interaction" translates easily into the content of a course syllabus, which is much more than the chronological representation of events, assignments, readings, and discussions. While the overarching sequentiality of the syllabus is determined by a calendar beyond the individual instructor's control, the instructor is in a position to influence and manipulate the individual "events" of the "story" of the syllabus, to varying degrees. Further commenting on the dual-interpretive nature of narrative, Elinor Ochs and Lisa Capps explain that the "chronological dimension offers narrators a vehicle for imposing order on otherwise disconnected experiences. That is, chronology provides a coherence that is reassuring" (24). It is 
essential, however, to recognize that chronology as a narrative device is simultaneously and inescapably imposed and imposing, both consciously applied and simply accepted. This simultaneity between application and acceptance suggests a parallel to Bawarshi's comments about how the syllabus serves to generate and enforce "the subsequent relations, subject positions, and practices teacher and students will perform during the course" (Genre 119). While the instructor may seek to pair certain texts thematically, for example, in order to further his or her own agenda, or at bare minimum to elicit directed comparative readings from students, these same students might (and often do) draw different conclusions about the reasons and motivations for such a pattern.

In the summer of 2005 , shortly before being admitted to the University of Louisville's Rhetoric and Composition doctoral program (thus re-instating my status as a graduate student teaching assistant), I taught what was called a "Mini-May Term" American Literature survey course at Jefferson State Community College in Birmingham, Alabama - an entire semester compressed into one week, meeting from $8 \mathrm{am}$ to $4 \mathrm{pm}$, Monday through Saturday. As an instructor, I was bound to the general terms of when the semester precisely began and ended, but the "middle" (as brief and rushed as it was) involved more personal choice. Throughout this class, I was struck by the ways in which the order of presentation played an essential role in the narrative interpretation of the course, since, through the very nature of reading, we do not read each letter of each word separately, in isolation, but look for those connections which will make the most sense compared to what we've already encountered in our pasts, or our expectations of those encounters. Simply put, under such compressed circumstances imposed by the institution's term chronology, I began considering how students/readers 
made fundamentally different connections reading Whitman's "Song of Myself" followed by the next class session's reading of Allen Ginsberg's "Howl," than they would have had these two texts been separated by a few months' worth of other readings. In short, the teacher may seek to partially construct his or her students through the narrative sequentiality of the syllabus (to varying degrees), but students also seek to create the instructor through answering one of the most basic questions of narrative: why these particular events, in this particular order?

Ochs and Capps, citing Kenneth Burke's $A$ Grammar of Motives, recognize that "[n]arrative activity attempts to resolve the discrepancy between what is expected and what has transpired" (27), yet these discrepancies, particularly in the composition classroom, have the potential to widen in the very process of their supposed resolution. The inherent polyvocality of the course syllabus reveals itself through the relationship between what Ochs and Capps call the fundamentalistic and relativistic tendencies of narrative in general. They point out that while the relativistic tendency "offers a potentially infinite range of interpretive frames for organizing experience and promotes alterity and relative openness to new ideas," this cultivation of dialogue carries with it the risk of "a paralyzing sense of indeterminacy" (32). Comparatively, the consistency and expediency associated with the fundamentalistic tendency of narrative, adhering to a "dominant narrative" which functions as "community-building in that it presumes that each member ascribes to a common story," carries its own risks of "oversimplification, stasis, and irreconcilable discrepancies between the story one has inculcated and one's encounters in the world" (32). 
I argue that the composition course syllabus serves as the middle ground between fundamentalistic and relativistic narrative tendencies. In developing the "dominant narrative" of the syllabus, leaning more toward the fundamentalistic side of narration, the instructor seeks to (re)create a microcosmic community, a written declaration of congruity, an announcement that, whatever their individual backgrounds, educational and social levels, interest and attention in the class, we all apparently agree to participate in the narrative events of the classroom, to follow along with the same story, to contribute to the "community-building" of the dominant narrative. Too strict an adherence to the narrative sequentiality of the syllabus may indeed lead to oversimplification, particularly in an instructor's efforts to reduce potentially complex ideas or concepts to a few phrases, so as to not "lose track" or "fall behind." When I first began teaching in 1999, I had a notepad delineating each moment of class time in five and ten minute increments: from 88:05am, I would take attendance; from 8:05-8:15am we would discuss the first poem assigned for that day; from 8:15-8:25am, we would discuss the second; and so on. A strict adherence to the narrative of the class day - defined almost exclusively as a function of temporality - led almost immediately to perceived disruptions in this carefully plotted continuum, which inevitably led to further frustration and a desire on my part to not "fall behind."

In the context of the syllabus as narrative, "stasis" is always perceived as a threat to the limited and imposed temporality of the individual class session, and the longer duration of the semester, terrn, or quarter. Simultaneously, the composition course syllabus expresses and encourages a "range of interpretive frames for organizing experience," associating the relativistic narrative tendencies with a "cultivation of 
dialogue" that seems central toward the development of critical thinking, a term often employed in both individual instructors' syllabi and in departmental course descriptions for introductory, freshman composition. The risk of "a paralyzing sense of indeterminacy" signals that an over-reliance on the promotion of alterity and "openness to

new ideas" comes only through the sacrifice of coherence, unity, the one "correct solution to the problem." Certainly more complex than the oppositions between an "only this goes" and an "anything goes" perspective, the juxtaposition of fundamentalistic and relativistic narrative tendencies, and indeterminacy subsequently placed in opposition to coherence and unity, lay the groundwork for the syllabus as a narrative space of the composition classroom.

\section{From Addressed and Invoked to "Protopublic" and Embedded}

In the previous section, I have made the case that, through a closer examination of the presentation and implications of components and expectations of the course syllabus, we in composition should see this narrative text as more than transparently instrumental, more than a collection of information, policies, assignments, dates, and calendars. For the syllabus, form and function are not mutually exclusive. I argue that making the case for reading the course syllabus in between fundamentalistic and relativistic narrative tendencies demonstrates an inherent tension at work within the text itself, a tension on par with Butler's conceptions of the syllabus's exophoric and anaphoric susceptibilities. Since I maintain that both of these frameworks operate under broad conceptions of internal conflicts between actuality and potentiality, the position of the course syllabus as an object and a subject of the discipline of composition, coupled with its dualistic 
narrative nature, reveal a need to explore the syllabus in terms of audience. While an intensive review of audience theory in composition studies falls beyond the scope of my study, responses to conceptions of "audience addressed" and "audience invoked" offer opportunities for those in composition to examine how, why, and under what conditions their syllabi are both composed by and directed towards multiple audiences, on multiple discursive levels.

In their canonical essay, "Audience Addressed / Audience Invoked: The Role of Audience in Composition Theory and Pedagogy," Lisa Ede and Andrea Lunsford interrogate previous classifications of audience to demonstrate observed levels of imbalance in these two seemingly disparate conceptions of audience. Ede and Lunsford explain how the differences between the "audience addressed" and the "audience invoked" framework revolve around the concretization or constructedness of a writer's audience (156-60). ${ }^{6}$ Ultimately, Ede and Lunsford stress the plurality and intersecting modes of audience absent from each of these individual notions, explaining how each taken separately fails to balance anticipation of expectations and response. Suggestions concerning the ways in which explorations of the composition course syllabus contribute to understanding of audience perception, addressing and invoking, surface in a brief example they offer in order to question, in terms of an "audience invoked" framework, how often writers' audiences in fact yield circumstances of dialogue, of a conversation of ideas (161). They offer an example of a student operating under constrictions divergent from her professor, explaining, "When this student enters her history class to write an examination she faces a different set of constraints. Unlike the historian who does indeed have a broad range of options in establishing the reader's role, our student has much less 
freedom. This is because her reader's role has already been established and formalized in a series of related academic conventions" (163). Although I could argue that, in the above example, the student is no more or less constrained than the historian, what particularly complicates the syllabus as an operator of multiple audience perceptions in deference to this example is its denial of, or resistance to, this proposed expert/novice relationship. While the student in Ede and Lunsford's example might have to engage in a different perception of establishing the reader's role in composing her examination as a function of this relationship, the syllabus in terms of audience conception is not so cut-and-dry.

Examining the course syllabus in terms of audience (pre)conceptions and (pre)constructions prompts the inevitable and deceptively simple question: who is the audience of the syllabus? Or is this even a fair question phrased in the singular? We construct our syllabi with our students in mind, prior to the beginning of class, where the best indication we have of the makeup of any individual composition course we teach is a list of student names registered for the class, where the only indication we might receive of our "real" audience is how many males and how many females are currently registered for our courses, perhaps their majors and year in their individual undergraduate program. For the remainder of the composition process, we rely on past expectations of students' needs, desires, and what we understand of their own expectations by invoking a particular (perhaps singular) audience of the syllabus. If we are teaching for the first time, we perhaps revert to our own expectations by invoking versions of ourselves as students, suggesting the interconnections between conditions of reception and production operating in any textual genre. What makes the syllabus worthy of further analysis in terms of audience and composition theories and practice is that the temporal space between 
audience-invoked and audience-addressed shrinks in a short period of time, as one transforms into the other, not entirely unlike the synthesis Ede and Lunsford themselves call for. To borrow from Ong, writers of syllabi are placed in a position to conceive of audience as a limited, temporary fiction. Once we hand out a composed version of the syllabus, our audience moves from imagined to real (though both of these conceptions remain mediated from one interpretation to another), and we are now in a position to deal directly with conflict, contradiction, agreement, and acquiescence between our constructions of readers' expectations and their actual expectations as a real audience in the classroom. Through analyses of the course syllabus in composition, we are able to more carefully bridge the gap between audience invoked and audience addressed as one becomes the other through the space and time of the class. We need not limit ourselves only to acknowledging reader's own experiences, expectations, and beliefs, to approximating audience constructions.

Of course, in the construction and dissemination of course syllabi, students are not our only audience. While we naturally write for ourselves as a participant, a "reader" in and of the classroom, more tangible are the institutional and departmental audiences for whom we write, and for whom the syllabus represents a more two-dimensional, stable representative record of the class. In "Representing Audience: 'Successful' Discourse and Disciplinary Critique," Lunsford and Ede revisit their critiques of binary oppositions located within constructions of both invoked and addressed theories of audience, acknowledging that they still "resist efforts to characterize audience as solely textual (invoked) or material (addressed)" (170). ${ }^{7}$ Their return to their earlier work signals an opportunity for critical self-reflection, as they point out how their own positions within 
what they call "schooling" were masked, downplayed, and unquestioningly embraced in their 1984 essay (172-175). Echoing James Berlin's "Rhetoric and Ideology in the Writing Class," Lunsford and Ede refocus conceptions of audience onto themselves as they observe how "representation, of ourselves as well as of those audiences that we both invoke and address, can never be innocent - whether that representation involves writing an essay (such as the one you are now reading) or teaching a class" (176). "Audiences" here, by extension, includes others in a position to determine and define "invoked" and "addressed" in the first place. This unquestioning "embrace" of schooling partially reveals itself through what Butler calls the anaphoric tendencies of course syllabi, defined as pronoun reference through "an institutional rule or policy that the instructor is quoting" ("Style" 10). Beyond these specific instances of policy-quoting anaphorisms, which I will explore later in my dissertation, Lunsford and Ede's return to their own writerly positions as located in "Audience Addressed/Audience Invoked" helps us in composition further concretize the writer-audience relationship (and thus constructions and addresses of audiences) as more complex than these unidirectional modalities might suggest.

These writer-audience relationships help expand notions of teacher identity constructions through the duality of the "public" and the "private," a duality which might qualify the syllabus as a "public" and "private" document in both form and function, to an extent that offers a re-examination of the usefulness of these very qualifiers, not unlike addressed and invoked, especially in terms of negotiating audience. Ede and Lunsford's observations and criticisms in "Audience Addressed / Audience Invoked" recognize that although the addressed audience exists "outside of the text," it is also "only through the text" that writers can conceive of their audiences in the first place (167). More recently, 
in "From Writers, Audiences, and Communities to Publics: Writing Classrooms as Protopublic Spaces," Rosa Eberly suggests a further de-naturing of the term "audience" itself, observing how the very notion of audience "can lead students to think in general terms" (167). Eberly also stresses the need to understand the plural of "public" not in oppositional stance towards "private," but in terms against "ideal, prefabricated, homological audiences" (175), so that students might better understand their own positions as "actors in different and overlapping publics" (167). Observing public space as processes of formation and disintegration, Eberly's reconception of audience helps us reconsider the potential stagnancy and unified conceptions of both audience as invoked and as addressed, further allowing students to experience writing as, in Eberly's terms, "wholly processual" (175).

Multiplicities of audience, specifically as revealed through the composition course syllabus, suggest various levels of embeddedness. ${ }^{8}$ Employing specific examples of IRS tax forms and jury instructions, Amy Devitt explores this concept of embeddedness through (non)specialist sets of relationships. Recognizing that many genres such as tax forms "are designed within one specialist community for functions to be filled by nonmembers of that community" ("Materiality and Genre" 543), she also points out, in reference to the genre of jury instructions, the degree to which "the embeddedness of the genre in its community make it impossible for nonspecialists to understand fully as a specialist would, no matter how well-written, detailed, or rhetorically sophisticated" (547-48). Arguing that these particular genres do not simply cross community boundaries, Devitt's focus on tax forms and jury instructions reveals the "conflicting consequences" of any genre serving multiple groups simultaneously (549). Devitt's 
claims of embeddedness help contribute to an understanding of any genre participating in levels of construction and of use, and how perceptions of usefulness of a given genre depend largely on one's position in a community in relation to that genre. The embeddedness of the course syllabus within the discipline of composition, as well as within the academic institution, adds not only to understandings of this text as an intertextual genre of academic discourse (which will be explored further in the next chapter) but also as a document directed toward different conceptions of invoked and addressed audiences.

Although Devitt's examples indicate a more deliberate rhetorical distancing between the specialist and the nonspecialist, the concept of genre embeddedness helps invigorate the syllabus itself as a genre particularly incapable of crossing community boundaries intact. To the department, the syllabus represents a record of assignments, events, policy statements, textually-based representations of compliance with certain university procedures and guidelines. To the individual instructor, the syllabus represents all of these, as well as opportunities to connect with a particular audience, one shifting from the invoked to the addressed. To the individual student, the syllabus represents a statement of purpose, an expression of mutual responsibilities, an establishment of requirements, a formula for work-and-reward. My central point of analysis here is that the syllabus functions amongst a number of different audiences simultaneously. These audiences overlap amongst themselves, not unlike a Venn diagram - a simultaneity occurring not in parallel but in constellation. When discussing the nature of the syllabus in terms of multiple audiences, classifications such as "the institution," "the teacher," and "the students" are convenient, but not entirely accurate. Xin Lu Gale recognizes that 
"[1]ike the institution they belong to, teachers also have a dual role to play: to conserve the dominant culture and to transform it" (Teachers 36), and this duality of conservation and transformation extends to the composition and dissemination of the course syllabus itself, as a document designed to preserve a record of and transformatively participate in the creation of teacher identity in intersecting deference to the institution, the teacher him- or herself, and the students.

As I have demonstrated in this chapter, understanding the syllabus as a material and ideological subject of composition, inherently narrative in interpretations of construction and dissemination, and bound up in the embeddedness of multiple audiences together reveal this ubiquitous yet often under-theorized academic document as a textual representation of competing voices, in terms of Gale's references to the teacher's "dual role" of conservation and transformation. In my next chapter, I argue that the place, the "material-discursive where" (Mauk 379) of the syllabus in composition as an academic discipline is one of productive ambiguity and contradiction, best expressed and explored through a theoretical nexus of composition's disciplinary discussions of authority and genre construction. My next chapter will demonstrate how these theory networks intersect in the composition course syllabus. I will explore ways in which the place of the course syllabus contributes to composition's disciplinary conceptions of individual and institutional power and authority, in conjunction with conceptions of genre as systems of classification as well as intertextual modes of social interaction. A higher level of selfreflexivity concerning the course syllabus through observations of the intersections between authority, genre, and discourse community offers alternatives for teachers new 
to the discipline, as well as conceptions of how teachers' roles are "read" within personal and institutional frameworks. 
${ }^{1}$ In order to better distinguish between documents like course syllabi, as developed and disseminated by individual composition instructors, and the more general (perhaps idealized?) course descriptions as developed for departmental websites and university handbooks, I argue that the latter describes what this English/writing course should do, while the former explores more specifically what this specific section of English/writing course will do. These disparities are not really my focus here, on parallel to the disparities between what an instructor says will happen on day X of the class in the syllabus and what actually occurs. This is an inevitable, commonly understood position; what we plan and what happens are not often the same, whether in the classroom or as a general axiom of life. Instead, I argue that we ought to stress the idea that tensions between these two (the "should" and the "will") reveals intriguing conditions of what is publicly available and more privately guarded. These tensions reveal themselves most explicitly in the implicit understanding of these institutions themselves that the individual course syllabus reflects an individual identity worthy of protection, while the more widely accessible general course description remains curiously disconnected from specific iterations of that very course. I will revisit this issue in the research narrative section of my dissertation, in which I will discuss how certain institutions I contacted in the data collection process had their own separate committees on approving requests to allow individual syllabi to be sent to me in the first place.

${ }^{2}$ On the necessity of moving beyond encapsulating terms like "public" and "private," see also Rosa Eberly's "From Writers, Audiences, and Communities to Publics: Writing Classrooms as Protopublic Spaces," and my explorations of the syllabus and conceptions of multiple audiences later in this chapter.

${ }^{3}$ I interrogate definitions and functions of the term "intertextual," and conditions of intertextuality, at greater length in the second section of my next chapter. At this stage of my dissertation, I point to Kristeva's denotation of intertextuality as a "transposition" of sign-systems ("Revolution" 111), as well as Charles Briggs and Richard Bauman's postulation that intertextuality is responsible for the construction of the relationship between a text and a genre (163), both of which suggest how intertextual texts (such as the course syllabus) ought to be considered less as objects and more as subjects.

${ }^{4}$ I rely heavily on Bruner throughout this section for two reasons. First, I argue that his explanation of individual grammatical components of narrative suggest both the inherent complexities and interpretive "lure" of narrative as a mode of learning and social interaction. Second, I feel these grammatical components help add to our understanding of narrative as, in Walter Fisher's terms, "a conceptual frame that would account for the 'stories' we tell each other - whether such stories are in the form of argumentation, narration, exposition, or esthetic writings and performance" (313). In "Rhetorical Community: The Cultural Basis of Genre," Carolyn Miller reads narrative as that which "imposes intelligibility on past events" (75), and in the case of the course syllabus, these 
"events" are simultaneously past, present, and future, making a narrative "imposition" most intriguing.

${ }^{5}$ For a further parallel in terms of how syllabi assume a narrative framework, Elizabeth Rankin's "From Simple to Complex: Ideas of Order in Assignment Sequences" elaborates on both hierarchical and non-hierarchical assignment sequences in conjunction with cognitive psychologists like Jean Piaget and Jerome Bruner. Rankin claims that "[t]he notion of a sequence, like our various notions of simple and complex, is itself a social construct. It is a way of asserting order in the midst of chaos, a means by which we assure ourselves and our students that we are making 'progress.' To put it simply, an assignment sequence is a necessary fiction" (134). In this sense, the "necessary fiction" of an assignment sequence parallels the often-fictionalized sequential narrative professed in the course syllabus - the progression of events, the plot, towards a logical and inevitable conclusion.

${ }^{6}$ As perhaps does not need review, Ede and Lunsford focus particularly Walter Ong's "The Writer's Audience Is Always a Fiction" (1975), their main point of contention being that "the writer who does not consider the needs and interests of his audience risks losing that audience" (165). While I recognize the "novice" move I myself am making in this dissertation in directly quoting from what many in composition would consider one of the most well-known and oft-cited texts, right up there with David Bartholomae's "Inventing the University," I maintain this example is worth citing specifically because of the way Ede and Lunsford completely remove the student from the processes of reader-role formulation in their efforts to stress this expert/novice relationship. As I explain later in this section, the genre of the syllabus complicates reader and audience roles, especially in Ede and Lunsford's terms of "options" and "freedom" (or lack thereof), since "readers" of the syllabus are more varied than other texts typically produced in and for academic environments.

${ }^{7}$ I choose to preserve what they call "their practice of alternating the order of their names as one small way of resisting the academy's privileging of first authorship and as a way of acknowledging their deeply interconnected ways of thinking and writing" ("Representing" 167).

${ }^{8}$ David Russell, in Writing in the Academic Disciplines: A Curricular History, observes that "[...] the naïve, mechanical conception of writing which specialization fostered contradicted the actual practice of academics, for whom writing was a very human thing, a complex social activity involving a whole range of rhetorical choices, intellectual, professional, and political, as recent research into the social basis of writing has shown. As a social activity, writing is inevitably embedded in and conditioned by a community. By its very nature it is local, context specific, dependent on a community for its existence and its meaning" (12). 


\section{CHAPTER II}

\section{POWER, AUTHORITY, AND GENRE IN COMPOSITION STUDIES}

Composition's theories of identity and language attempt to negate the more material affects of identity politics and institutional power in which our pedagogies are located. In sum, our own history reveals a similar attempt to disassociate the discursive from the material, the rhetorical from the real, and, most significantly, the institution from power relations. Donna LeCourt, Identity Matters: Schooling the Student Body in Academic Discourse (25)

In my last chapter, I explored ways in which we can view the course syllabus as a productive site for theoretical and pedagogical interrogation. Re-theorizing the syllabus as a subject of composition (in part as a narrative text) refigures some of composition's more long-standing conceptions of audience construction. Such re-theorization of the course syllabus functions as part of a larger project - to explore how, why, and to what ends this seemingly transparent, purely functional document operates in expanding our understandings of teacher identity constructions. In order to establish the theoretical framework for this larger project, this chapter reviews composition's disciplinary conceptions of institutional and individual power and authority, as well as conceptions of genre both as systems of classification as well as intertextual modes of social interaction. These re-theorizations introduce a higher level of self-reflexivity concerning the course syllabus, providing not only notions of what alternatives exist for teachers new to the discipline, but also understandings of how teachers' roles are "read" within personal and institutional frameworks, thus resisting the idea of monolithic representations. By further exploring how we think about, construct, deliver, and explain course syllabi, we can 
understand how to develop the teaching styles and practices of new teachers of composition, as well as our own teaching. In short, a further understanding of what our syllabus does will help us better understand not only what we do in the classroom, but what we do in the discipline of composition as a whole.

\section{Part One - The Course Syllabus and \\ Theories of Authority in Composition Studies}

Composition's incongruous disciplinary status requires more careful considerations of how and to what degrees evolving elements of authority serve to transform our conceptions of what we perceive we do in the writing classroom. ${ }^{1}$ To this end, in this chapter, I will review scholarship from the theoretical nexus forming the basis of my analyses of the course syllabus in composition. I begin my review with examinations of various notions of authority, and how these affect our understanding of the course syllabus. In this section, I first interrogate relationships between conceptions of "power" and those of "authority" in terms of both location and practice, in order to establish composition's general inclination towards an understanding of power as individually-owned property, despite recent theoretical examinations to the contrary. In "Interpretation and Betrayal: Talking with Authority," Dennis Foster's observations regarding a "troubling paradox for most students" might easily be paralleled to the condition of composition instructors, as he notes how students "must at once respect and resist authority, be 'good students' and independent thinkers, imitators and originals" (35). This position, Foster explains, places students "between the wall of authority, of a doxa that leaves them with nothing to say, and the seas of indeterminacy where 'everything is subjective'" (45). Foster's use "doxa" in the 
sense echoes Bourdieu in his 1972 treatise, Outline on Theory and Practice, denoting what is taken as self-evident in society.

Parallel to this idea of doxa, Peter Mortensen and Gesa Kirsch explain how "contemporary myths of authority are so prevalent that authority remains for many a simple matter of common sense" (556). While they side with Henry Giroux in their contention that authority develops from competing sets of values (557), they also acknowledge that "authority functions to conceal the wide dispersion of power in society, leaving the potentially false impression that authority, and the power behind it, can be located in a particular position or person" (560). In this section, I argue that the placement of power-asproperty within discussions of classroom and disciplinary authority functions as an element of this doxa. Anis Bawarshi focuses on the creation of insider/outsider statuses in terms of the syllabus's "use of pronouns, future tense verbs, and abstract nominalizations" (Genre 121). He recognizes the duality of the syllabus as both a personal and institutional document, explaining that the syllabus "is not merely informative; it is also, as all genres are, a site of action that produces subjects who desire to act in certain ideological and discursive ways. It establishes the habitat within which students and teachers rhetorically enact their situated relations, subjectivities, and activities" (125). The course syllabus can be more accurately and emphatically referred to as a site of action because this text produces not only "subjects who desire to act in certain ideological and discursive ways," but also a sanctioned space for that desire to occur. 


\section{Power and Authority, Authority and Power (as Property)}

In order to better explore the landscape of power and authority in and out of composition studies, I would like to begin this section with an exploration of how these two terms both conflict and coexist. Jennifer Clough's entry for "authority" in Heilker and Vandenberg's Keywords in Composition Studies notes that the term "finds mention in virtually every segment of composition studies," and that "the issue of power is often embedded in such discussions" (22). Heavily citing Mortensen and Kirsch's "On Authority in the Study of Writing," as well as Kenneth Bruffee's "The Way Out: A Critical Survey of Innovations in College Teaching" and Ira Shor's Critical Teaching and Everyday Life, Clough's overview suggests that power represents an element of authority, that which becomes embedded. Indeed, Mortensen and Kirsch themselves call for compositionists to map "the manifold ways in which authority defines people and relations of power" (569), indicating that authority itself operates as the principle that defines how we perceive power. In her discussions about "the authority of expertise" as an assumed guarantor of a teacher's authority, Xin Lu Gale notes that the assumption of this brand of authority as a universal good "ignore[s] the teacher's relation to the academic institution and to the job of teaching, [and] also suppresses the power relations implicated in the authority of expertise" (Teachers 47$).{ }^{2}$ This notion of "implication" suggests that the practice of authority (specifically in this case, the authority of expertise) has command over the suppression of perceptions of power relations, once more designating the presence of authority as a derivative of shifts in perceived balances of power. 
In her explorations of feminist pedagogy's collective difficulties in demystifying "the politics of knowledge production," Carmen Luke admits, "in the end I still have to exert intellectual authority and institutional power to judge student work, assign grades, rank student grant and scholarship applications, and mediate the 'hierarchy of oppressions' that so easily creep into identity-based classroom debate" (294, my emphasis). I am particularly drawn to Luke's distinctions between "intellectual authority" and "institutional power," especially the extent to which such descriptors comment on composition's relational constructions of these two terms. While Luke locates the exertion of both authority and power within herself as the individual teacher, her subsequent location of authority as "intellectual" and power as "institutional" signals an intriguing hierarchical relationship in play, even if subconsciously. Authority at work here appears in terms of a specific discipline, while power appears more as a condition of a broader notion, structures of higher education.

Such hierarchy becomes visible in our understandings of the course syllabus operating within both of these frameworks simultaneously. The "intellectual" authority surfaces in the (usually) pre-selected sets of readings and assignments for a given course, while the "institutional" authority surfaces more in references to plagiarism statements, excused absence policies, et cetera. While this distinction appears clear, taken in conjunction with observations from those like Mortensen and Kirsch, Gale, and even in synopses like Keywords, relationships between power and authority in composition appear more complex than an analogy between a university's college (say, Arts and Sciences) and a particular department (say, English). Further, the inevitability of authority seems clear. Patricia Bizzell acknowledges that, despite the observation that it 
"seems to be crucially important to our sense of ourselves as professionals that we do not exercise power oppressively in the classroom" ("Power" 55), the inescapability of authority surfaces through the fact that it "is still the teacher with the teacher's gradegiving power" (63). Gale also recognizes this inevitability, this sense of inescapability, as she explains that "the teacher's authority, no matter whether it appears in the form of the authority of expertise or personal authority, contains some potential danger of oppression, as does institutional authority" (53-54). Power represents broader sets of socially defined, constructed but not determined relationships in which authority is created, generated, exercised, transmitted, or required. Such relationships, located within the presence of authority, supposedly allow for the possibility of its relinquishment, abandonment, dispersal, and negotiation.

Although Nicholas Burbules recognizes the distinction that "[q]uestioning authority does not mean rejecting authority: it means scrutinizing who is an authority, why they merit such a position, and what are the limits of that authority" (107), as delineated in Rhetoric and Composition scholarship, authority is often represented as that which can be relinquished, abandoned, dispersed, or negotiated. This representation takes Burbules's conception of he or she "who is an authority" and transpositions it into he or she "who owns authority," and is thus in a position to relinquish, abandon, disperse, or negotiate it. Although Burbules refutes traditional theories of power that assume "power is a property of individual persons, wielded instrumentally as a means to particular intended outcomes" (96, original emphasis), he notes that power relations specifically arising from the condition of "conflicting interests" exist "where there is a zero-sum game in which gaining or maintaining an advantage for one person or group necessarily entails 
disadvantaging others" (97-98). Similar to the first law of thermodynamics, Burbules' explanations of power as sets of relations among groups of people, rather than as a structure of individual possession, represents an often-unbalanced tension "of resistance and compliance" (97), in which "A has power over B, but [...] in most cases B empowers A" (103). Jennifer Gore specifically objects to the idea of a "zero-sum game" as a common trope of power-as-property, explaining how this conception "is often, but not necessarily, connected with a 'zero-sum' understanding of power which suggests that there is only so much power and that if teachers 'give' some of it to students, they must 'give up' some of their own power" (58). Although Burbules' discussions of power as sets of relations appear to move away from individual ownership, his use of the "zero-sum" in explaining initial conflicts of interest, which generate these power relations, inadvertently returns the subject of power to the individual through explicitly propertied discourse.

I feel it necessary to comment on the implications of the term "empowerment" in relation to composition's disciplinary responses to conceptions of authority and power. In their discussions of in loco parentis in the composition classroom, defined in part as a "parental posture," JoAnne and Leonard Podis distinguish between a parental stance that "seeks not to control students, but rather to inspire and empower them" (137). Even in casual use, the term "empower" rings positive in composition studies, maintaining elements of Shor's depiction of an empowering pedagogy that helps "relate personal growth to public life, by developing strong skills, academic knowledge, habits of inquiry, and critical curiosity about society, power, inequality, and change" (Empowering 15). However, I argue that positioning "empowerment" as a universal good in composition studies belies the fact that empowerment, as Gore suggests, "has no particular meaning 
prior to its construction within specific discourses" (56). Lest this quote imply I am arguing for a neutrality of empowerment, I also point to Sidney Dobrin, who, in critiquing Shor, points out how the latter "does not afford students the opportunity to make actual critical and evaluative decisions and judgments about how and what they learn; rather, he determines what he sees as relevant to students' lives and imposes those values on his students [...]" (140). Such criticism recapitulates my earlier point about how only those in a position of authority can elect to relinquish, abandon, disperse, or negotiate it in the first place, signaling that the very structures of dis/empowerment are still located and promoted from within structures of academia. ${ }^{3}$

Essential to the ways in which composition views conceptions of power within its own discipline, and its position within institutional structures of education, Gore argues that more attention to institutional and pedagogical exigencies of teaching "would help shift the problem of empowerment from dualisms of power/powerlessness, and dominant/subordinate, that is, from purely oppositional stances, to a problem of multiplicity and contradiction" (61). Movement away from these oppositions indicates to what extent the problem of authority becomes a subject of conversation for composition, and under what conditions these multiplicities and contradictions associated with authority reveal themselves, offering further problematization of "power as property." Dissolution of these dominant/subordinate structures lies in making the syllabus an explicit component of discussions of authority in the composition teaching practicum and in the first-year-writing classroom. Elaborating on Gore's initial claims, I argue that positioning the syllabus as a subject of the discipline, as an "institutional and pedagogical exigency," would help make conversations concerning hierarchies of power and authority 
more precisely a "problem of multiplicity and contradiction," particularly as we in composition draw explicit attention to the multiple audiences and levels of accountability associated with this seemingly straightforward text.

Further relating tendencies of conceiving power as property to constructions and disseminations of the course syllabus, I point to Keith Dorwick's interpretations of relinquishment in his "The Last Bastion: Student Self-Determination and the Making of a Syllabus," a CCCC presentation in March of 1995. Dorwick invokes a binary as he discusses the open/closed nature of his syllabus from the previous year. Reflecting on what he believed at the time to be a more progressive, "open" approach to composition, he recalls, "Look at all the authority I did not relinquish - I determined the number of assignments, the length of the assignments, the date they were due [...], the penalties for a late paper being turned in, the penalties for tardiness, the penalties for absences, even penalties for not speaking in class" (3). These observations tend to reveal the reflective nature of any progressive composition classroom, as well as the teacher-centered nature of documents such as course syllabi. Burbules' elaborations on conditions of "compliance" prove helpful in broadening our understandings about the extent to which authority gets discussed in terms of relinquishment.

Recognizing that compliance can be achieved through both action and inaction, Burbules notes that "in some cases, compliance is a result of agreement with the purpose behind the request $[\ldots]$. In other cases, compliance is a response to [an] explicit or implicit threat $[\ldots]$. In still other cases, compliance is secured by an exchange relation, either one of economic incentive or one of social compromise" (100). Rather than examining texts like the course syllabus on the basis of their perceived open or closed 
nature, conditions of compliance as explored by Burbules not only help complicate this binary but also provide a more nuanced vocabulary for discussing the terms of authority relinquishment. Interpreting Dorwick's register of unrelinquished authorities under the framework of sets of compliances yields strikingly different results than an either-or understanding might yield. In this instance, Dorwick's declaration might be transformed from "Look at all the authority I did not relinquish" to "Look at the different modes of compliance with which I was engaged" - compliance with departmental mandates regarding the number and length of individual assignments, as well as compliance in terms of a form of "exchange relation" in doling out penalties for tardiness and not participating in class. "Compliance" thus complicates the assumption of authority relinquishment through demonstrations of accountability and response, both externally and internally imposed.

In order to concretize these multiple layers of accountability and response, I offer one of my own course syllabi from my first semester teaching here at the University of Louisville (see Appendix 3). I point specifically to an "I-you" shift following the establishment of basic instructor contact information. As I explain the best times students can email me and expect a reasonably prompt response, I engage in a rather tenuous balancing act between layers of authority I choose to relinquish and those I am deliberately determined to maintain. While I strive to present myself as open to student communication (as I of course feel all instructors of composition should), I also note that "I am not a slave to my computer," and that "I will not check my email on Saturdays or Sundays, so if you have an email which needs attention before Monday morning's class, be sure to send it by Friday afternoon." Although my initial goal with this declaration was 
to help encourage students into being more prepared for individual assignments due at the beginning of the week, the follow-through, as I warn them not to "email me Wednesday at 430am and expect a response before Wednesday morning's class," can easily be interpreted as a desire not to be emailed at all. Indeed, with the benefit of hindsight, I admit that such a statement of pre-emptive admonishment yielded anything but positive results, as the electronic communications with my English 101 students that particular semester were quite minimal - rightfully so, perhaps, considering I presented to my students what I can only describe as a kind of veiled or "closed" openness.

The more problematic shift occurs after this ill-phrased warning, offered simply as "a piece of advice." I explain, "This is your class. If something I'm doing isn't working for you, let me know as soon as possible [...] Remember, you're all in the same boat, and you should come to rely on each other (and yourselves) as much as, or more than, me." In a sense, this piece of advice acknowledges the pedagogical exigency of the situation. The class needs to function as a class for it to succeed, although in this case, the caveat "you're all in the same boat" appears to exclude myself as the teacher in this process, a key distinction between "your class" and something along the lines of "our class." Through an attempt to relinquish a degree of authority in an effort to suggest the class begin to see themselves as groups of writers encountering some of the same problems and issues with writing, the placement of this advice directly following the warning against emailing me at certain times and on certain days of the week only succeeds in revealing the need to establish myself as the center of authority in the classroom.

Dorwick's catalog of safeguarded authorities also reveals an intriguing conception of authority often used in composition - talking about authority in terms of that which 
can be relinquished. His rhetoric corresponds to an essential contradiction on par with Gore's observations, one that in turn reinvigorates problematic associations with a zerosum imagining of power-as-property: authority as either retained or relinquished. Gale questions this possibility of relinquishment, admonishing compositionists as a collective as she notes, "They do not want to admit that the institutional authority cannot be thrown away at the will of the progressive teacher, not only because the existence of the academic institution makes its authority inevitable but also because the possibility of education ultimately relies upon it" (Teachers 37$)$. Gale's juxtaposition of inevitability and reliance redistributes Buburles' suggestion of an asymmetrical tension between "resistance and compliance" (97), further problematizing this conception of an $\mathrm{A} / \mathrm{B}$ relationship of power, particularly when this very relationship becomes internalized through the material and social conditions of the composition instructor him- or herself. Perhaps the most hegemonically-operative demonstration of understanding power as property in relation to the course syllabus lies in the ease with which so many of us in composition, regardless of our proclivities towards progressivism, casually refer to this text as "my syllabus."

\section{Authority and Composition's Conceptions of Negotiation}

In the previous section, I have argued that conceptions of authority in the scholarship of composition have been, and continue to be, influenced by understanding power as property, leading to constructions of authority as that which can be possessed, and thus transferred, or that which can somehow be relinquished. I have also addressed how implications of power-as-property continue to problematize even the most radically 
self-defined critical pedagogue's relationship to the course syllabus. Investigating the impact of authority on my examinations of course syllabus at this stage in my dissertation requires a reexamination of composition's conception of authority not necessarily as possessed or able to be relinquished, but as negotiated. Conceptions of authority become most relevant to my dissertation in terms of Shor's discussions of the course syllabus, in which he explores the values of his power-sharing project, including modes of what he calls "democratizing discourse" (When 29). In his criticisms of unilateral authority, understood primarily as the presentation of the teacher not only as the sole bearer of knowledge and authority in the classroom but also as the only one with the right to express it (30-32), Shor explains how he resists the urge to simply present the syllabus to the class on the first day, in favor of engaging in processes of negotiating it (30-41). Such negotiations supposedly help call into question academic discourse constructions and the complicity in those constructions of students as entirely authority-dependent.

Though Shor acknowledges that inviting students to participate in co-authorship of the syllabus in what he calls shared authority offers "alternative ways of knowing, speaking, relating, and feeling, beyond and against traditional classroom arrangements" (62), I argue that composition as a discipline has already begun to question how often such opportunities for "alternative ways of knowing" are already repositioned into the background. Dobrin comments on how "Shor does not afford students the opportunity to make actual critical and evaluative decisions and judgments about how and what they learn; rather, he determines what he sees as relevant to students' lives and imposes those values on his students" (Constructing Knowledges 140). In Dobrin's estimation, Shor's experiment in shared authority represents yet another level of value-substitution on the 
part of the instructor, a re-directed, reconditioned variation of Shor's own negative conception of unilateral authority. Linda Adler-Kassner notes how "the notion that students should have ownership of their writing (in some form or another) has virtually become a tenet of composition" ("Ownership Revisited" 208), yet she also recognizes that "for many students the possibility of ownership might be erased even before pen hits paper (or fingers hit keyboard)" (230). Such a comment on the realities of ownership in the composition classroom equally applies to instructors as well, whose conceptions of ownership of their course syllabi might very well be subverted by their individual institutions' requirements and obligations. Compliance functions on both sides of the desk. $^{4}$

Similarly, Gale explains how, "like the institution they belong to, teachers also have a dual role to play: to conserve the dominant culture and to transform it" (Teachers 36). ${ }^{5}$ In the composition classroom, the syllabus functions as a representation of complications inherent in the presentation of both personal and institutional selves. For Gale, the institution's de facto ascription of the teacher's knowledge as legitimate through disciplinary space becomes an inescapable reality, regardless of the degree of radical pedagogy being performed in the classroom. Although authority in the classroom always runs the risk of becoming oppressive and exclusive, it appears that even the most radical and revolutionary of pedagogies encounters this same threat, simply by being a pedagogy that an instructor must perform within the political, social, and ideological confines of an institution. In "Ideology and Freshman Textbook Production: The Place of Theory in Writing Pedagogy," Kathleen Welch signals a version of this same threat. She notes how the study of the three composition categories of invention, arrangement, and style, 
"surgically sliced" (273) from traditional modes of discourse, "is regarded as 'normal,' and attempts to change it are regarded as unhealthy or even dangerous. As in any ideology, the world of the natural order of things in textbooks is obvious and appears not to be examined. Justification is not necessary because it is self-evident" (271). This situation, this place of composition, not only in a physical but also in an ideological sense, presents further points of analysis between composition instructors' perceptions of authority and their institutional positions as colloidally presented in the course syllabus.

At the same time, perhaps "colloidally" does not describe the proper mode of dispersal of selves in the instructor's relationship with the course syllabus, particularly in deference to composition's discussions of authority as processes of negotiation. Robert Yagelski points to an essential counterbalance in composition's conceptions of negotiation, the writing teacher, suggesting that teacher identity itself forms the most significant hindrance to liberatory pedagogical agendas. This identity is the subject of these very institutional positions, and thus epistemological implications, that authorize our power and authority in the composition classroom (41-45). Recognizing an essential imbalance associated with processes of negotiation, Bruce McComiskey notes how "negotiation requires that students learn active reading strategies that most are simply unfamiliar with when they enter college" ("Composing Postmodern" 356), thus inescapably recapitulating the "I know/you don't know" game Dobrin appears to admonish in his Constructing Knowledges (141). Together, these observations signal the fly in the ointment of power-as-negotiation, particularly in terms of the construction and dissemination of the course syllabus. Although we recognize that we have a "dual role to play," our commitment to preserve and change the dominant culture of higher education 
is indeed in a state of imbalance, based inherently on our already-established position within it. Thus, our institutional and personal positions within an academic discipline are not as dispersed as the suggestion and the possibility of negotiation might suggest.

Diann Baecker discusses the position of the composition instructor between spaces of solidarity and the struggle to demarcate authority. She echoes Gale's observations on the impossibility of relinquishing authority, offering a nod towards Shor's power-sharing experiment as well, as she claims, "Certainly I do not wish to imply that we give up our authority - as if that were even possible - or that we negotiate attendance or grading policies with our students. My point is that we need to be up-front and clear about our possession of authority" ("Uncovering" 61). Such an admission of her own institutional positionality comes full-circle in the acceptance of authority, avoiding an oversimplified dismissal of that which can be rejected entirely. At the same time, Baecker's appeal for directness once more realigns with conceptions of power as property, a possession to be doled out as the composition instructor warrants. David Wallace and Helen Rothschild Ewald argue for a more careful consideration of "teacherdominated discourse" in composition, noting that such discourse might help "set up the kinds of activities that will engage students more actively in knowledge making" (40). Simultaneously, Wallace and Ewald warn that "to maintain that the authority to make knowledge in the classroom rests solely on disciplinary knowledge (or the lack thereof) means that the roles open to teachers and students are limited to teachers being subjects and students, objects" (100). Thus their conceptions of "mutuality" as a sharing of potential rather than of power help reposition authority outside the realm of property, and help reestablish negotiation as a transformational rather than transferred concept. 
Similarly, Cheryl Giuliano offers a sense of directness distinct from Baecker's suggestions of being "up-front and clear." Giuliano deliberately poses integrating composition theory and composition practice as subjects of conversation, explaining, "I have found that when students read the theory I practice, they understand my motivations, my in-class demeanor - my pedagogy - better, and therefore they understand the course itself better. I no longer 'keep secret' the theory underwriting my practice. To do so would only perpetuate teacher-student inequality and the institutional authority I work to disperse" (396). ${ }^{6}$ Comparable to Baecker's claims, Giuliano appears to be in the process of negotiating authority (in terms of reducing, removing, or at least making a subject for discussion perceptions of student/teacher inequalities in the composition classroom) through the rhizome-like implications of the term "disperse." Dispersal of authority coupled with Giuliano's descriptions of demystification offer an intriguing point of analysis for the negotiation of authority in composition as a discipline. At the same time, however, it cannot be ignored how teacher-centered Giuliano's claims appear to be, through comparisons of students' understanding of the instructor's motivations to an understanding "the course itself," as well as the specific root of the rhizomatic dispersal. Although dispersal of authority through concepts of negotiation appears laudable, it cannot be ignored that the teacher herself remains the focal point, the source of that dispersal. This sense of teacher-centered dispersal comes to a physical forefront through the simple act of passing out a course syllabus at the beginning of the academic term.

Conceptions of authority negotiation in composition following Shor and Friere more often than not lead to a re-invigoration of power as teacher-centered property. 
Reflecting on power and "parental authority" in the writing classroom, JoAnne and Leonard Podis implicitly connect the disciplinary placement of composition with conceptions of acknowledging the existence and multiple perceptions of institutional authority. They claim that, "by virtue of entering our writing classrooms (rooms assigned by the registrar) at set times (likewise specified by the registrar) and anticipating receipt of syllabi we have prepared, from the start, students expect and acknowledge the authority that the institution provides us" (125). Podis and Podis reveal the reciprocal nature of expectations, inadvertently touching on the course syllabus as a frame of reference for studying negotiations of authority in composition.

We are, of course, institutionally bound by the sequentiality of the term, to calendars with which we must comply, and institutional requirements to which we must submit in order to be identified and accepted as institutional representatives. Both instructor and students appear in rooms and at times not of their own design, yet students accept syllabi "prepared by us," even if they aren't in fact wholly done so. Such acknowledgement of institutional authority reveals the initial script of a dual performance within these modes of appropriation, the course syllabus, which represents what Donna LeCourt calls a "material artifact of academic composition," a textual document whose "linguistic interaction can never be separated from its institutional location" (39-40, original emphasis). LeCourt claims that academic discourse seeks to exclude the possibility of itself as a discursively constructed identity, in order to eliminate potential threats to its own epistemological frameworks. Both Dobrin and LeCourt recognize this "inherited" nature of power and authority, and this inherited nature is perhaps best 
demonstrated through the nature of the course syllabus as an institutional document of record.

\section{Part Two - The Course Syllabus and Theories of Genre in Composition Studies}

In terms of explicating authority through positioning versions of one's institutional selfhood, I argue that the course syllabus functions as an "extraordinarily ordinary" genre of academic and professional discourse. Competitions and convergences of motives and social forces are read into standardizations contained within course syllabi (those elements explicitly required by the institution). ${ }^{7}$ While some of these are not necessarily set in stone, they often appear that way, particularly to the entering graduate student teacher, because the institution perpetuates itself by keeping its most essential ideological structures hidden from direct view. The essentiality of ideological masking further demonstrates the limitations of terms like "public" and "private," particularly as these terms are used to describe (and qualify) the nature of academic texts like the course syllabus. In this section, I make three arguments, so that we in composition might view "genre" in and out of our discipline as a series of transformations. These transformations move conceptions of genre from merely efficient models of literary (and non-literary) categorizations, to constricting and controlling forms of textual (re)production, to intertextual mediations and exchanges, to modes of social-rhetorical intercourse, balancing expectations of inclusion and exclusion. In this section, I also explore how these developments of the ways we understand genre affect interpretations of the course syllabus as a distinctive genre of academic discourse. 
Rather than beginning with more recent conceptions of genre as modes of social interaction, reviewing earlier structures of genre allows us to see to what extent these classifications still residually factor into a more rhetorical understanding of genre. The rationale for this exercise in miniature historical overview is not merely so that we can better understand how we got here, particularly in terms of conceiving of genre as socially (re)constitutive, but to more thoroughly recognize the implications these residual receptions of genre have on both the complication and reinforcement of more recent definitions of genre in action. First, I interrogate conceptions of genre defined and practiced as a mode of classification (including works from Roland Barthes, Jacques Derrida, and more recent contributions from Kathleen Welch and David Fishelov). I argue that what I call the "threat" of genre (as a boxed-in form of classification) operates as a both a reductive and potentially productive lens through which to view the course syllabus: a personal and institutional document, designed to create boundaries of a specific course section while simultaneously preserving institutionally sanctioned, wider community boundaries of the general course.

Second, I explore the relationships between conceptions of genre and conceptions of "intertextuality," from Julia Kristeva's use of the term as borrowed from Bakhtin, to more compositionally-centered texts such as Amy Devitt's 2004 project Writing Genres. I argue that the subject of the course syllabus as an inherently intertextual document ought to be made more explicit, making the development of authorization of institutionally sanctioned texts (like the syllabus) a deliberate point of discussion in both composition practica and in the classroom. Making the intertextuality of the syllabus more explicit not only aids in both teachers' and students' understandings of the complexities inhabited by 
any genre, but also helps make conversations of authority and authorization a focal point of analysis on both sides of the desk.

Finally, I investigate more recent conceptions of genre following Carolyn Miller's canonical 1984 essay, "Genre as Social Action" (including works from Catherine Schryer, Anne Freadman, Francis Christie, Amy Devitt, and Anis Bawarshi), in order to examine the composition course syllabus as a socially re-constitutive text. I argue that the "operationalizing" conditions of the genre of the course syllabus demonstrate how this document functions in reference to past and present incarnations of itself, particularly in the ways the specific genre of the course syllabus and the broader theoretical concept of genre itself operate in a reciprocal relationship of social reconstitution. In other words, given the specific natures and functions of the course syllabus as an operationalizing disciplinary text, examinations of genre theories can contribute to our understanding of the course syllabus just as examinations of the course syllabus can expand and complicate our understanding of genre.

\section{The "Threat" of Genre}

The course syllabus represents a particular genre of academic text. This appears to be an accepted, ordinary, non-combative statement. At the same time, however, in the act of writing down these words, "the course syllabus represents a particular genre of academic text," I am unavoidably speaking of our expectations about how this document is supposed to be both constructed and received. Whether a composition program chooses to provide a "model syllabus" to graduate student teaching assistants, allows these composition instructors to create syllabi for their courses entirely on their own (or with 
minimal requirements), or locates the creation of the course syllabus somewhere else along this spectrum, we inherently operate on what a syllabus should look like. Thus, we also operate on an understanding of genre as a sort(ing) of texts. The threat of genre makes its presence known through limited conceptions of genre solely as a classificatory gesture. In this section, I interrogate earlier responses to the idea of genre-asclassification, including transitional structuralist and deconstructionist warnings concerning the logical ends of perceiving genre in this fashion.

Roland Barthes's "Writers, Intellectuals, Teachers" and Jacques Derrida's "The Law of Genre" together offer insight into conceptions of genre as a privileging of form, a constriction of possibilities, and a threat to the speech act and its pedagogical implications, through Barthes's and Derrida's application of "law." Barthes presents a rather bleak double-edged sword for the pedagogue, declaring, "The choice is gloomy: conscientious functionary or free artist, the teacher escapes neither the theatre of speech nor the Law played out on its stage: the Law appears not in what is said but in the very fact of speech. [...] Nothing to be done: language is always a matter of force, to speak is to exercise a will for power; in the realm of speech there is no innocence, no safety" (192, original emphasis). In Barthes's estimation, the conditions that reveal this fatalistic conception of the teacher's function within the nature of the speech act make up what he calls "the mise en scene imposed by the use of speech under the simple effect of a natural determination" (191). In other words, the classification of speech as such forces these determinations regardless of the content of that speech.

Though Barthes does not focus explicitly on genre as a subject of interrogation in and of itself, he does define "teacher" in ways that appear to establish a genre of 
discourse through form rather than function. He paints the scene: "Imagine that I am a teacher: I speak, endlessly, in front of and for someone who remains silent, I am the person who says $I[\ldots]$, I am the person who, under cover of setting out a body of knowledge, puts out a discourse, never knowing how that discourse is being received" (194, original emphasis). Barthes further conceptualizes this act of "putting out a discourse" in what he calls "readerly texts" in $S / Z$, those "controlled by the principle of non-contradiction" (156), those that avoid disrupting or disturbing the doxa of a surrounding community, and those that work "like a cupboard where meanings are shelved, stacked, safeguarded" (200). The putting out of a particular discourse without recourse to its reception, thus transferring any potential or inherent transactional qualities, serves as a reminder of genre's perception as a type, a form, something that merely is, in terms of the Law, the very (f)act. This conception of depositing a discourse further recalls Shor's negative depiction of composition teachers who merely read their course syllabus in front of their students on the first day, what he refers to as "the preemptive didactic presentation" (When 30). Reading Shor's warnings in light of Barthes's depiction of the teacher, we can begin to see how the composition course syllabus as a genre of academic text encounters this threat, this conception of genre as a closed, defined system of classification.

Somewhat anticipating Carolyn Miller's "Genre as Social Action," Derrida positions the subject of genre, what he later calls "the genre 'genre'" (58), more in terms of participation than mere acceptance. His claims that the very existence of genre as a mode of classification constitutes a threat to interminable interpretations cannot be ignored. These claims affect composition's understanding of genre. Derrida explains, "as 
soon as genre announces itself, one must respect a norm, one must not cross a line of demarcation, one must not risk impurity, anomaly, or monstrosity" (57). Thus, "the genre," as that which marks "the identifiable recurrence of a common trait by which one recognizes, or should recognize, a membership in a class" (63), functions as a limit, a law of order which cannot itself become classifiable. Responding to Derrida's claims, Anis Bawarshi observes that "while Derrida does not reject genre, he nonetheless subordinates it to an ad hoc status" ("Genre Function" 344). Such relegation is best revealed as Derrida explains that genre has always "been able to play the role of order's principle:

resemblance, analogy, identity and difference, taxonomic classification, organization and genealogical tree [...]" (81). The very roles genre allows itself to play in "order's principle" establish, and allow Derrida's deflation of, genre's constricting and controlling nature.

David Duff positions Derrida's essay as the pinnacle of a generational "suspicion" towards genre "as a repressive mechanism by which cultural institutions sought to classify, commodify and control artistic production" ("Intertextuality" 56), and it is precisely this conception of commodification that solidifies the threat of genre as limited classification. The composition course syllabus especially succeeds in revealing the dual operations of this commodification, since the construction of the document itself plays the role of "order's principle" by drawing an inherent limit in the feature-based generic classifications of what qualifies as a syllabus and what does not, while individual assignments (particularly in the composition classroom) offer micro-moments of this control of "artistic production," whenever we assign a literacy narrative, a descriptive essay, a proposal argument, et cetera. Referring once more to the example syllabus 
provided in Appendix 3, the drawing of inherent limits is implicit in the identification (and lack of explanation) of the assignment sequence from definition arguments to evaluations to causal analysis to proposal arguments. While I did in fact make each individual major assignment an essential point of discussion in class, as well as the transference from one assignment to the next, the assumptions of value contained within the assignment sequence itself were never really fully interrogated, instead holding the status of that which just "was."

What remains unwritten in this particular syllabus is my own desire to maintain a privileged position in determining what is to be already implicitly valued, both in this specific composition course and in the broader scope of understanding writing practices. Further, this unwritten quality suggests what Allan Luke describes as the tendency for many "educational descriptions of 'how texts work' [...] to separate analytically ideology from function (where they mention ideology at all), and thereby to represent particular genres as principally geared for doing intellectual work, rather than always sites for the contestation of difference" (318, original emphasis). In other words, what I have done in this syllabus (through acts of inclusion and omission) is assume the inherent value of the types of texts produced in the course, and transferred that uninterrupted, intact assumption to my students. This example demonstrates the extent to which conceptions or understandings of genre as form or as a mode of classification function as residual elements of re-enactment, particularly in texts like the course syllabus.

Potential and real threats of genre-as-form appear in Anne Herrington and John Moran's disciplinary-historical summary of composition's characterizations of genre theory vis-à-vis reactions and responses to traditional modes of discourse. ${ }^{8}$ Ultimately, 
Herrington and Moran employ their conceptions of composition's formulaic relegation of genre in order to critique what they call the "freeze-drying" of genres in typical composition textbooks as rigid and decontextualized (15). Such commentary points to the essentially reciprocal nature of genre as form, function, and subject in composition theory and pedagogy. Herrington and Moran's discussions of "freeze-drying" point out that the "threat" of genre as limited to classificatory gestures, what Tzvetan Todorov calls "nothing other than the codification of discursive properties" (17-18), often reveals itself in composition studies through examinations of textbook production. ${ }^{9}$ The ways in which genre is conceived directly affect conceptions and limitations of academic writing, and the fact that genres (pedagogically speaking) are so often artificially determined as "stable entities that can so easily be classified, defined, and taught" (Herrington and Moran 11) recapitulates genre itself as a deliberately decontextualized privileging of form. Genre as an announcernent of normality replicates conceptions of genre as a limit, a line of demarcation, exemplified in the warning, "when a limit is established, norms and interdictions are not far behind: 'Do,' 'Do not' says 'genre,' the word 'genre,' the figure, the voice, or the law of genre" (Derrida 56). The residual threat of genre lies in its ability to mask itself within ideological constructions of the normal, the application of a classificatory system upon that which is already considered simply "to be." Genre as categorical limitation functions and is perceived as a threat in recent incarnations of composition studies precisely because of its appearance as the natural order of the world.

Although Charles Briggs and Richard Bauman recognize that genre "strikes some practitioners as too global and fuzzy a concept to be of much use to detailed and formal and functional analysis," and that "all of us know intuitively that generic classifications 
never quite work," and that "an empirical residue that does not fit any clearly defined category - or even worse, that falls into too many - is always left over" (132), such "fuzziness" does not prevent attempts to define genre in deference to this empirical remainder. David Fishelov establishes an early working definition for genre as " $a$ combination of prototypical, representative members, and a flexible set of constitutive rules that apply to some levels of literary texts, to some individual writers, usually to more than one literary period, and to more than one language and culture" $(8$, original emphasis). Designed to expand more traditional, limitation-oriented understandings of genre's function, Fishelov hopes such a definition succeeds in "crossing the boundaries of literary periods" (8). Most significantly, Fishelov's more expansive definition hopes to usher in new conceptions of how we speak of genre, and thus of how genre works. Explaining how, "by speaking of rules (or norms) rather than of traits or characteristics, I seek to depict genre as a kind of 'mediator' between author and reader" (14), these norms place genre once again in the path of Derrida's warning, a conception of genre as a line of constricting normality. Although Fishelov's explorations concerning genre theory's use of analogies helps to mediate that line, substituting notions of traits and characteristics with notions of rules or norms only further aids in establishing the threat of genre's ideological self-masking. I argue that conceptions of "embeddedness" surface once more in conceiving of the course syllabus not only as responsive to multiple audiences but also in the ways in which it operates to mask its depictions of authority and genre, in the composition classroom and in broader disciplinary structures.

Most significant to understanding conceptions of genre as they work within and upon composition as an academic discipline is the idea that the threat of genre, conceived 
as cataloging gestures, still looms large. In a recent review essay for College English, Peter Vandenberg declares, "To classify is to make order - to make doing, in a linear sense, possible. We live to sort, sort to live" (532), suggesting that the classificatory impulse associated with more traditional understandings of genre is more hardwired into our collective unconscious. Vandenberg points to an essential roadblock accompanying categorical notions of genre when he asserts, "Dependent as categorization is on observing commonalities for the purpose of declaring differences, to classify a text is to agree to see it as a bounded, static object" (533). Though he is quick to point out that genre theory "is itself an ideological product" (540), this textual objectification-throughclassification is precisely what is both so attractive and repulsive about genre theory visà-vis composition studies. Regardless (or perhaps even more so, because) of wellestablished conceptions of writing-as-process, we tend to overlook the product inherent in both acts of writing and acts of teaching writing. While I certainly do not intend to argue that we forget about the process of teaching in the writing classroom, I argue we should also not forget about a representative "product" of that teaching, the course syllabus maintained in physical and online departmental files and databases. Todorov recognizes that "'genre' as such has not disappeared; the genres of the past have simply been replaced by others. We no longer speak of poetry and prose, of documentary and fiction, but of novel and narrative, of narrative mode and discursive mode, of dialogue and journal" (14), indicating that the static nature of text itself has not been erased, only transformed. It is precisely this transformation within the static nature of text we need to respond to in composition as an academic discipline, through a revision of the ways we encounter, interpret, and analyze our course syllabi. We in composition implicitly or 
explicitly agree to see a text as a "bounded" object, whenever we assign a literacy narrative, a descriptive essay, a proposal argument, and when we in turn judge whether a student's completed assignment has or has not "fit" that category. We name; we categorize; we bind and constrict the nature of text and textual (re)production, perhaps no more so than at the beginning of the composition class, with the initial delivery of the course syllabus. Such a performance of the course syllabus - in the act of its presentation - demonstrates, in part, a tacit understanding of this particular academic genre as limited, structuralizing, classificatory textual de/re-contextualization. Composition instructors, at the dual behest of chronological limitations inherent in academic calendars, as well as antecedent generic expectations of what a syllabus should look like, run the risk of reinforcing the constricting potential of genre. Although I have already discussed chronology as an expected element of the narrative structure of the course syllabus, I maintain, similar to generic-feature expectations, we cannot read these chronologies to the point where they become purely instrumental. The construction and dissemination of the course syllabus in the composition classroom - particularly the ways in which newer instructors often direct students to refer to the syllabus for further clarification on points of course goals, requirements, or penalties - often recapitulate notions of genre (and by extension, the course itself, the discipline, the nature of knowledge) as repository, static, contained and containable.

These directive moments are not limited to new teachers of composition. I have been teaching composition and literature courses since 1999, and I still find myself, usually towards the end of the semester, sending students emails peppered with the phrase "as per the syllabus," or an equivalent phrase. Early in my teaching career, I might 
have been able to rationalize such gestures as efforts to make me feel teacherly, a concept I will explore later in this dissertation. Now, I find the authoritative deflections towards the syllabus indicative of something far more ordinary, and far more dangerous - simple fatigue through the course of a semester. Rather than recapitulating the syllabus's policies and rules of engagement in what Butler might call anaphoric fashion, simply being tired and overworked (especially in my adjunct days, teaching six or seven classes in a semester, with well over 120 students) led to more encapsulated moments of the syllabusas-directive. The more tired I was, the more likely I was to not even quote the syllabus, but simply re-orient the students in the direction of this text, tacitly acknowledging that it somehow spoke for itself. The "threat" of genre is not something we can or should ignore in the academic discipline of composition, not the least of which because teaching from a "genre-free" position (just as a "power-free" position) is both impossible and undesirable, because such positions would inherently neglect both genre and power as enabling forces. Limitations of genre, when conceived solely as modes of classification, help us more productively see the dimensions of the course syllabus as a simultaneously personal and institutional document, concurrently creating and preserving boundaries, productively juxtaposing roles shaped through institutional placement and the constructions and expectations of textual forms.

\section{Genre, Intertextuality, and the In-Between}

Thus far, I have examined both the risks and potential benefits of associating genre with classification in broader theoretical constructs and in relation to the composition course syllabus as a particular genre of academic text. While we cannot 
abandon the conception of genre-as-form, nor should we, we must interrogate the means by which genre becomes something else - form plus. Recognizing genre as "an abstraction or generality once removed from the concrete or particular," Devitt acknowledges that genres emerge, transform, and respond to individual input, and that "even the most rigid genre requires some choices, and the more common genres contain substantial flexibility within their bounds" ("Generalizing" 580). The ways in which "form" traces (while not constituting) genre, coupled with the potentially paradoxical notion of containing flexibility, reveal one of the more complex developments in understanding genre in recent years. This falls appropriately between more traditional constrictive definitions of genre as classificatory system, and more modern variations of genre, defined through operations of rhetorical communities. I am speaking of genre's relationship(s) with conceptions of "intertextuality."

Julia Kristeva's 1974 essay, "Revolution in Poetic Language," initiates conceptions of intertextuality in genre studies, as the author elaborates on the semiotic significance of what she calls "the transposition from one signifying system to another," a movement that "demands a new articulation of the thetic - of enunciative and denotative positionality" (111). Playing on Greek roots of "thetic," that which is arbitrarily or dogmatically placed, Kristeva explains: "If one grants that every signifying practice is a field of transpositions of various signifying systems (an intertextuality), one then understands that its 'place' of enunciation and its denoted 'object' are never single, complete and identical to themselves, but always plural, shattered, capable of being tabulated" (111). Kristeva incorporates Bakhtin's contention that, "prior to the moment of appropriation, words do not exist in a neutral and impersonal language, but in other 
people's mouths, in other people's contexts" ("Discourse" 283), as well as his notion that an utterance "is never just a reflection or an expression of something already existing and outside it that is given and final" but rather "always creates something that never existed before, something absolutely new and unrepeatable" (Speech 119). In essence, Kristeva borrows both from Bakhtin and from Saussure's semiotics in order to recast the very notion of the "thetic," the arbitrary, as always already borrowed, stressing the mediation of meaning over its point-by-point transference, what Kristeva calls "an altering of the thetic position, the destruction of the old position and the formation of a new one" (111, original emphasis). Such conditions of borrowing, exchanging, mediating, and altering contribute to later evolutions of genre as sites of socio-rhetorical enactment, which I will explore further in the next section of this chapter.

Kristeva's proposition of intertextuality succeeds in re-appropriating tensions within perceived relationships between intertextuality and genre, and in turn adds significant depth to my analysis of reading the course syllabus as a particular genre. Briggs and Bauman recognize that "one of the most central and persistent approaches to genre is from the vantage point of classification," and that "in its most basic terms, genre serves as a way of making categorical discriminations among discursive forms, which may be conceived of in textual terms, as verbal products, or in practice-based terms, as ways of speaking (and writing)" (143). Recalling Kristeva's use of intertextuality as contributing to the dilution of this limited "vantage point" (categorization), Briggs and Bauman claim that Kristeva's contributions to conceptions of intertextuality remind us how "structure, form, function, and meaning are not seen as immanent features of discourse but as products of an ongoing process of producing and receiving discourse" 
(146). Suggestions of mediation and exchange allow the idea of intertextuality enough room to play within traditional functional formations of genre, so that we might place the teacher in more of a participatory role, rather than one who merely "puts out a discourse."

Although teachers of composition implicitly recognize the exchange value of the syllabus, even in the more literal sense that it requires students for its enactment, mediation and exchange as they relate to intertextuality help demonstrate the internalization of these concepts. In this sense, incorporating intertextuality into discussions of the genre of the course syllabus modifies "form" from something that "is" to something that "is becoming." Briggs and Bauman draw distinctions between the placement of generic categories onto texts and the "practices used in creating intertextual relations with other bodies of discourse," a set of practices which "naturally selects and abstracts generic features" (163), transpositioning genre itself from a condition of property to a condition of interrelationship. Such interrelationship demonstrates how the course syllabus operates both in the classroom and in departmental records, as embodiments of practice. Envisioning the course syllabus as an "embodiment of practice," however, runs the risk of "freeze-drying" the genre, to recapitulate Herrington and Moran's critique. This is partially my point, since the existence of the course syllabus is not limited to its enactment and fluidity as expressed in classroom practices; the syllabus also shares its existence as a representative of form, an expression of classificatory response, and a record operating as, indeed, a frozen moment. Devitt's assertion, that "if we are to understand writing as a unified act, as a complex whole, we must find ways to overcome these dichotomies [of and related to form and content]" ("Generalizing" 573), appears to come more to fruition through the idea of intertextuality. 
Such a shift also indicates the extent to which conceptions of authority, in terms of my earlier explorations of power-as-property, are inextricably linked to conceptions of genre.

Of course, it is not enough simply to state intertextuality's contributive transformation of genre. I argue that we cannot merely claim that a text like the composition course syllabus operates "intertextually" without first examining the complex sets of relationships between intertextuality and genre, and the middle ground the syllabus appears to occupy. The employment of the term "intertextuality," appropriated and transformed through various disciplinary frameworks, seems to suggest that genre's hold on the binary structure of form/content contradicts potentially expansive and more malleable conceptions initiated through the concept of intertextuality itself. Duff recognizes how, since the appearance of Kristeva's term more than thirty years ago, "the term intertextuality $[\ldots]$ has come to serve as an umbrella word for any critical procedure or creative practice involving a relation between two or more texts" (54). In efforts to explain the attraction of intertextuality to genre theorists, Duff explains how the former "appeared to offer a solution to the problem of genre, or at least a way of circumventing it. Reconceived in terms of 'intertextuality,' genre could shed its authoritarian connotations, remove the taint of prescriptiveness, and rid itself of its traditional role as arbiter or policeman of the writing and reading process" (57). In other words, intertextuality's appearance on the critical scene of genre theory helped remove, or at least deflect, constricting and controlling ideations traditionally associated with genre.

An essential point of contention with these methods of deflection is that genre in these terms is often relegated to "simply one aspect of the larger phenomenon of intertextuality" (Duff 54). Commenting on Kristeva's reactions to Bakhtin's concepts of 
dialogism (in her 1967 essay, "Word, Dialogue, and Novel"), Duff explains, "The concept of intertextuality completes this transformation [from diachronic to synchronic] by treating the whole of literary history, and history itself, as a text or system in which every part has a potentially infinite number of relations with other parts. The individual text becomes a 'space' in which other texts intersect, and the axis of time tends to disappear altogether" (63). Although Kristeva's intertextuality does much to explain how and under what conditions texts absorb and transform other texts (see also Séméotiké: Recherches Pour une Sémanalyse), Vandenberg reminds us that genre theory itself is inescapably an ideological product, and so by extension this transposition of intertextuality remains inherently subject to conditions of ideological/disciplinary filtration and dissemination.

Embracing and seeking to encapsulate this sense of deflection, John Swales explores the idea of the "genre network," making specific references to intertextuality as located in professional research discourse activities, focusing specifically on genres such as the review article and the plenary conference lecture. He defines genre networks as "the totality of genres available for a particular sector (such as the research world) as seen from any chosen synchronic moment - even though in reality there is little stability since much is in flux, especially as generic changes along the lines indicated above by [Tzvetan] Todorov and [Clifford] Geertz are taking place all the time" (Research Genres 22). While hinting at genre as a "stabilized for now" concept, which I will explore in the next section of this chapter, Swales constructs a "third term" realm for genre, genre networks that "operate at an intermediate level between the structural properties of institutions [...] and the communicative activities of single individuals" (23). I argue that 
it is through this intermediate level that the course syllabus occupies its rhetorical space in academic discourse, requiring both "structural properties of institutions," including the sanctioning and authorization associated with its presence within these institutions, as well as "communicative activities" of individual teachers and students. Viewing the course syllabus an inherently intertextual document helps reveal the extent to which conceptions of genre-as-form can simultaneously constrict and expand our conceptions of how such a text operates.

As a postscript to this section on genre and intertextuality, I point out that although traditional conceptions of genre as classificatory and limiting in nature appear too strict, intertextuality, employed as umbrella term or specific radical textual application, might at first appear too broad in scope as something to be employed, particularly in the context of a document so apparently functional and well-defined as the course syllabus. Indeed, the scope of intertextuality helps explain why a concept like genre has been relegated to one aspect, but the textually liberatory potential of intertextuality is explicitly dependent upon limiting views of genre to a "coercive, restrictive force" (Duff 57). Other recent interpretations and employments of intertextuality suggest not that genre functions as a mere factor in the larger scheme of intertextual relationships, but rather that intertextuality operates within and through genre. Linguist Norman Fairclough distinguishes between "manifest intertextuality" and "constitutive intertextuality" (117). The former identifies intertextual elements including "presupposition, negation, metadiscourse and irony" (119), while the latter, which Fairclough also calls "interdiscursivity," the relationships between discursive features in a particular text, includes "genre" as a category in and of itself, defining it as that which 
sets the rules for styles (125). What is perhaps most intriguing and problematic in considering tensions between conceptions of intertextuality and genre, intertextuality by definition (and, subsequently, by later expansion and restriction of definition) places itself in a pluralized state in deference to a presupposed singularity of genre. When Briggs and Bauman claim that "when discourse is linked to a particular genre, the process by which it is produced and received is mediated through its relationship with prior discourse" (147), the assumption that "prior discourse" constitutes a necessarily plural field while the discourse itself is linked only to a "particular genre" cannot be ignored.

I argue that such intermediacy (a concept I will revisit in Chapter Four) allows for a preservation of plurality within both intertextuality and genre, and by extension, within conceptions of "the social" and "the individual," particularly as Swales's conceptions of "genre networks" help us realize "our attempts to characterize genres as being essentially a metaphorical endeavor, so that the various metaphors that can be invoked shed, in varying proportions according to circumstances, their own light on our understandings" (61). Metaphorical characterizations allow plurality within the discursive limitations of individually conceived and categorized genres, subsequently within the larger scope of intertextuality. Stressing what Devitt refers to as "genre's ability to capture both form and situation, both constraint and choice" ("Generalizing" 584), the notion of genre networks allows for a further recasting of traditional categorizing definitions of genre in efforts to recast the entire relationship between intertextuality and genre as mutually pluralistic.

Complex and overlapping relationships between genre and intertextuality reveal this encapsulation both of genre-as-constricting, or genre-as-categorizing, and genre-asnetwork. Bawarshi refers to genres as "rhetorical ecosystems" (Genre 8), acknowledging 
that genre acts (or allows writers to act) more as a "double agent, one who is both an agent for his or her desires and actions and an agent on behalf of already existing desires and actions" (50). Specifically concerning the syllabus in terms of what closer examinations of this document can bring to conversations surrounding genre and intertextuality, Bawarshi details an essential "desire" of this double-agent position, explaining how "[i]t is perhaps this desire to mask power as solidarity that most characterizes the syllabus, a desire that teachers, as the writers of the syllabus, acquire, negotiate, and articulate. Positioned within this desire, the teacher tries to maintain the contractual nature of the syllabus while also invoking a sense of community" (122). As considerations of intertextuality enter discussions of both limitations and possibilities of genre, Bawarshi's placement of the composition teacher within the "desire to mask power as solidarity" echoes David Duff's claim of how, through processes of intertextuality, "the individual text becomes a 'space' in which other texts intersect, and the axis of time tends to disappear altogether" (63). Extending Kristeva's explanation of the thetic, the composition teacher, as positioned in this transposition of power, reveals the literal text of the course syllabus (as well as the figurative text of the composition instructor him- or herself) in this space of intertextual intersection.

The course syllabus and the composition instructor represent the quasi-diachronic nature of this sense of community, juxtaposed with the equally quasi-synchronic nature of the specific composition classroom. Ultimately, relationships between intertextuality and genre can best be expressed as intersections between that which is perceived as fixed or frozen and that which is perceived as perpetually in flux. The focus of my research study in and of itself operates within this particular intersection, since I am collecting 
course syllabi, fixed representative versions of composition courses which in actuality operate in a state of fluctuation.

Bawarshi's conceptions of the inventive reciprocity of genre, coupled with Devitt's analysis of antecedent genres and the historical difficulties in tracing them, help make the subject of syllabus construction valuable for explicit discussion with our composition students. If we were to make explicit to our students various iterations or drafts of our own syllabi for different courses throughout our teaching career, or, if graduate teaching assistants are just beginning, if they showed students syllabi from past classes they themselves had attended, or those they found from the institution's archives to use as deliberate models, these gestures would assist in both de-simplifying and demystifying the authority of the composition teacher. In this sense, we could make developments of authorization of written institutionally sanctioned texts an overt point of discussion, rather than positioning authorization as that which simply "is" or "is not," while at the same time revealing interactions of the instructor and these institutional authorizations. Spaces of intertextuality would become more explicit within the development and acceptance of the syllabus as an academic(ally required) text.

\section{Genre and the Exigence of Social Action}

Having already explored how we might re-visualize the course syllabus as an extraordinarily ordinary genre of academic text in terms of its duality of commodification, and in terms of its construction and development as an intertextual moment for composition, I now turn my explorations to more recent conceptions of genre as modes of social interaction. Beginning with Carolyn Miller's seminal 1984 essay, 
"Genre as Social Action," and following scholarly paths initiated and explored by Amy Devitt and Anis Bawarshi, I argue that recent discussions of genre as social action help further illuminate the position of the syllabus as a genre of academic writing within the discipline of composition. While Swales recognizes how genre shapes "the schematic structure of the discourse and influences and constrains choice of content and style" (Genre Analysis 58), other studies following Miller help demonstrate genre as intently and thoroughly ideologically-bound. Along these lines, in this section, I argue that conceptions of genre as social action - including elements of exigence, textual contextualization and de-contextualization, temporary stability, and genre knowledge's relationships to disciplinary knowledge - together contribute to our understanding of the course syllabus as an operationalizing text, both enabled by and enabling rhetorical situations.

In "Genre as Social Action," Miller argues that "a rhetorically sound definition of genre must be centered not on the substance or the form of discourse but on the action it is used to accomplish" (151). Drawing heavily from Kenneth Burke's Permanence and Change and A Grammar of Motives, she points out that this accomplished action "must involve situation and motive" (151). Motive in this sense offers a direct connection between conceptions of genre and conceptions of community within the framework of the composition classroom, particularly as she revisits these issues ten years later in "Rhetorical Community: The Cultural Basis of Genre," under the framework of Bakhtinian conceptions of centrifugal and centripetal forces (74). Miller expands composition's understandings of genre by defining them through recurrence of social situations and actions; refocusing the impact of genre on the rhetorical, she asserts that 
the recurrence of social actions maintains "not a material situation (a real, objective, factual event) but our construal of a type" (157). Stressing the fluidity of genres, particularly as non-idiosyncratic and non-archetypal (162), her use of exigence allows genre to sidestep traditional classificatory, material, surface conceptions.

Miller first defines exigence as "social motive," that which supersedes both the individual speaker's intention and the cause of action. She stresses the need "to base a classification of discourse upon recurrent situation or, more specifically, upon exigence understood as social motive," thus basing the classifications of said discourse "upon the typical joint rhetorical actions available at a given point in history and culture" (158). Employing such a definition of exigence allows a redistribution of motive itself. The social context of a speech or writing act constructs the event of genre, more so than the speaker's original intentions for speaking or writing. Though such distinctions are necessarily problematic, particularly in the ways in which concepts of the individual and of society have the potential to become disparate, Miller's addition to genre theory incorporates intertextual shifts from diachronic to synchronic modes of analysis, while maintaining substantive formal similarities as participatory elements of what she calls the "pragmatic component" of this understanding of genre (164). Exploring motive at the level of genre as "a conventional social purpose, or exigence, within the recurrent situation" (162), conceptions of exigence relegate motive beyond the individual and beyond the arbitrary, so that perceptions of genre might move beyond that which is merely imposed, a further variation of Kristeva's intertextual transpositioning of the thetic. 
Reevaluating her earlier conceptions of genre, Miller draws tacit connections between the exigence of social motive in genre construction and conditions of power. Exploring ways in which "genre becomes a determinant of rhetorical kairos - a means by which we define a situation in space-time and understand the opportunities it holds," Miller positions genre as "a specific, and important, constituent of society, a major aspect of its communicative structure, one of the structures of power that institutions wield" ("Rhetorical Community" 71, original emphasis). The simultaneously constituent and transformative nature of genre appears through "the rules and resources of a genre," which "provide reproducible speaker and addressee roles, social typifications of recurrent social needs or exigencies, topical structures (or 'moves' and 'steps'), and ways of indexing an event to material conditions, turning them into constraints or resources" (71). These "ways of indexing" immediately recall conceptions of genre as classificatory, but at the same time, genre itself is not inherently constraining or limiting; rather, genres contribute to the reproducibility of social roles necessitating the indexing of events genre as both representative and intervening, both containing and moving beyond earlier conceptions of genre as a mode of classification or categorization. Briggs and Bauman explain that genre "pertains crucially to negotiations of identity and power," and that "by invoking a particular genre, producers of discourse assert (tacitly or explicitly) that they possess the institutional authority needed to decontextualize discourse that bears these historical and social connections and to recontextualize it in the current discursive setting" (148). While not focusing on motive as such, Briggs and Bauman further complicate the operations of genre by determining them as processes of de- and re- 
contextualization, performed at the behest of those institutionally-granted the authority to perform these very acts of de/re-contextualization.

Composition instructors serve as operators of de-contextualization, for example, whenever we assign a particular series of readings on our syllabi, transforming the very order and receptions of such texts. We also employ the syllabus as an opportunity for recontextualization, as the course (or "my course") represented and encapsulated by the syllabus gets deciphered through the institutional authority of the instructor, he or she who brings these assigned readings to bear in the first place. Conversations about social motive demonstrate a key juncture in my decision to intersect theories of power, authority, and genre as modes of analyses for the composition course syllabus. The genre of the course syllabus succeeds in providing reproducible social roles, in the sense that the syllabus functions as both an initial college reading assignment as well as a kind of academic dramatis personae, establishing at least tenuous roles of teacher and student in terms of pronoun differentiation. The very nature of the form and structure of the syllabus contributes to its processes of textual de- and re-contextualization. As suggested by Briggs and Bauman's use of the term "invoke," the course syllabus represents a document confronting us in composition with the inextricability of authority and genre theories.

In order to better explain these conceptions of de- and re-contextualization in play in the construction, dissemination, and performance of the composition course syllabus, a point to which I have hinted earlier in Chapter One regarding expected narrative sequentiality, I offer an example of my own, from an English 102 class I taught during the spring semester of 2009 at the University of Louisville (see Appendix 4). A research writing-centered class, I situated the two main readings for the semester (Abbie 
Hoffman's Steal This Book and Saul Alinsky's Rules for Radicals) amidst three assignments - writing a research proposal, an annotated bibliography, and a draft of a formal MLA-cited research paper - so that students might better understand the sociohistorical and deeply contextual nature of research writing. As evident in this example, I assigned readings from the first twelve chapters of Hoffman's text in sequential order before shifting into the introductory prologue from Alinsky's text together with a handout on the origins of the Burkean Parlor, from which we moved decidedly more selectively through Alinsky's text, and then back into later selections from Hoffman.

Similar to my earlier concerns in the first chapter regarding the description of the mini-May term I taught (in which we were forced by the compression of the calendar to breeze through a summary of more recent American literature), this example demonstrates the extent to which any syllabus in composition, offering reading assignments in conjunction with writing assignments, inherently engages in layers of textual de-contextualization and re-contextualization, as a matter of institutional authority granted by and expressed through the formal generic expectations of the text itself. Assignments from week eight of this term, for instance, offer the de-contextualization of both the chapter from Rules for Radicals entitled "Communication" and the first chapter from the section of Steal This Book entitled "Fight!", while simultaneously offering a recontextualizing of these two readings when repositioned in a new sequential order unintended in the texts themselves. Although the two readings in the above example both comment on the nature of getting one's message across, I chose to de/re-contextualize these readings together so that the class might better understand the nature of how audience reception, ethos construction, and conceptions of "the generation gap" (Alinsky 
writing in his late $60 \mathrm{~s}$, Hoffman in his late $20 \mathrm{~s}$ ) play out in constructions and perceptions of research-based writing. Thus, for this course, the social role of the instructor (as an authority of de/re-contextualization), through the genre of the course syllabus, shifts into the authority of student writers themselves engaging in their own layers of de/recontextualization through the genre of the research paper.

Although Bawarshi analyzes genre in terms of function over form, describing genre as that which "can account not only for how certain 'privileged' discourses function, but also for how all discourses function, an overarching concept that can explain the social roles we assign to various discourses and those who enact and are enacted by them" ("Genre Function" 338), I argue that this inextricability signals an implicit overlap of form and function as they pertain to conceptions of genre. Relationships between authority and genre also call into question the perceived relative stability of the latter, particularly in the sense that constitutive social roles created by and initiated through genres are constantly evolving and adapting. The rhetorically continuous processes of recreating situation/actor roles within genre recalls Catherine Schryer's conception of genre, in "The Lab vs. The Clinic: Sites of Competing Genres," as that which can only be classified as "stabilized-for-now" (107). In "Integrating Rhetorical and Literary Theories of Genre," Devitt acknowledges "how genres enable choice as well as constraint" (711), taking issue with Schryer's "stabilized-for-now" theory of genre, and arguing instead that genres are never really stable, that "if each text always participates in multiple genres, then even in that text a genre is moving, shifting, and becoming destabilized. Even temporary stability is an illusion of genre theory rather than a reality of genre-in-action" (713). ${ }^{10}$ Such stability, even if only provisional, belies the fact that genre requires "both 
conformity with and variation from expectations," and remains "always unstable, always multiple, and always emerging" (715). In and of themselves, debates over genre as either "stabilized-for-now" or as perpetually changing, immersed in intertextual diachronic transpositioning, propel the concept of genre beyond static categorizations and surface textual features and more into the realm of the socially (re)constitutive.

Revisiting these constitutive and regulatory functions in Genre and the Invention of the Writer, Bawarshi's focus on genre's potential reveals the extent to which genre functions as an "account" of privileged discourses, an explanation of social roles, while also operating in response to the "recurring rhetorical situations" of both privileged discourses and social roles in general. In "Materiality and Genre in the Study of Discourse Communities," Devitt, Bawarshi, and Mary Jo Reiff collaborate to explore the nature of genre as representative of communities, and how a text is received in terms of generic expectations. These receptions of expectations take an interesting turn in the metaphor of "the invitation." From William Coles' attention to the material conditions of writing in higher education and students' perceptions of chronology of experiences, to Ira Shor's arguments for the participatory classroom and general notions of offering options, to Irene Clark's analogies of "stage directions" to explain how students are being asked to perform specific roles within the contexts of writing assignments, composition scholars often discuss the classroom environment and the notion of assignments as "invitations." This particular metaphor demonstrates another moment the course syllabus links conceptions of authority (in this case, the "invitation" that is not quite what we expect) and generic expectations of reception. Devitt's assertions that genres strive to create (and recreate) specialized discourses in order to preserve and exclude community boundaries 
help characterize genre as that which strives to protect itself, that which strives to preserve "the common order of things" while responding to necessary social, historical, and communal changes in these orders.

Taken together, concepts of temporary stability and insular self-protection characterize the socially re-constitutive framework of the genre of the course syllabus. Particularly in composition, we recognize and in fact count on altering perceptions of rhetoric and writing, as well as the changing sociological makeup of our students. We respond to certain inherent instabilities in the genre of the syllabus by altering these texts to more carefully and accurately respond to both changing conceptions of our discipline as well as developments in institutional regulations. Of course, while the syllabus responds to shifts in social realities, it also seeks to preserve at least the temporary "common order of things," particularly in the sense that (regardless of degrees of negotiation) some representative of "the way things work" in a particular composition classroom is distributed early in the term, most likely on the first day of class. The genre of the course syllabus and the concept of genre itself operate in a reciprocally contributory relationship. While understanding genre itself beyond modes of categorization contributes to the complexity of that which was formerly defined as functionary, the syllabus helps solidify an example of an academic textual genre that comprises elements of classification, preservation, and regulation, together with responses to shifts in social roles and motivations.

Drawing heavily on Carolyn Miller, Devitt explains genre's transformation, noting how, of late, "genre has been redefined, then, from a classification created by critics to a classification that people make as they use symbols to get along in the world" (Writing 
Genres 8), stressing the continuous nature of genre (re)creation. Most significantly, she notes how "a genre reflects, constructs, and reinforces the values, epistemology, and power relationships of the group from which it developed and for which it functions" (6364). Emphasizing the extent to which genre "must be flexible synchronically and changeable diachronically" (89), Devitt recognizes that long-standing genres are so due to a "balance between stability and flexibility" (116-17). Thus, an essential function of genre is to change, to continually reshape itself as a reflection of rhetorical situation. Employing conceptions of genre as more relational than representational, together with the idea that genres must be simultaneously flexible and stable, Melanie Kill argues that a more careful consideration of genre's multiple functions can help further clarify the extent to which resistance "works to maintain stability, not necessarily because that stability serves either individual or community interests, but simply because it is familiar and therefore comfortable" (216). Notions of "comfort" signal another level of genre's potential threat, in the case of self-definition and performance, against individual-toindividual relationships in the creation and dissemination of these performances. Kill draws a direct connection between "generic actions and interactions that are valued in particular communities" and the performance and development of identities "appropriate to the places and spaces we want to occupy" (217). The occupation of rhetorical space relies more on knowing a genre, more than some sort of communal desire to fit in, and ultimately it is genre's position as "an already established series of signs" that determines whether we are successful in our "performances of self" (222). Through these analyses, we can begin to see genre itself (as well as the specific genre of the course syllabus) both 
ensuring and risking comfort, further revealing ways of talking about genre that move beyond oppositions of limitation and variation.

Most recently, rhetorical/situational conceptions of genre have moved into constructions and disseminations of disciplinary knowledge, from Carolyn Miller's development of genre as relationships between materials, individuals, and value systems, to Swales' constructions of genre networks, operating between institutional structures and individual acts of communication. In "Ways of Knowing, Doing, and Writing in the Disciplines," Michael Carter stresses the need for the idea of the "metagenre," as a genre of genres, that which "directs our attention to broader patterns of language as social action, similar kinds of typified responses to related recurrent situations" (393, original emphasis), laying the groundwork for reciprocity between genre knowledge and disciplinary knowledge. Carter incorporates conceptions of genres as artifacts through his development of metagenres in terms of artifact (re)creation. He focuses specifically on the research paper, recognizing how, "as a rule, the goal is not simply to write a research paper for the sake of learning to manage research from sources but to use the process of doing and writing research to shape a disciplinary way of knowing" (407). Thus, the nature of genre as cultural artifact becomes more than just evidence of the ways in which specific social groups use(d) a particular process of written communication - genre becomes the ways in which these processes themselves change, what Carter calls "a shift from knowledge to knowing" (410). Intersections of disciplinary and genre knowledge indicate the extent to which Miller's definition of genre as social exigence remains particularly relevant for composition studies. Citing Linda Brodkey's Writing Permitted in Designated Areas Only, Mary Boland points out how, "for university officials and 
other academics, writing largely represents a static subject - a set of rules and formulas that once internalized may be drawn upon to create the officially sanctioned version of good writing" (43). Such stasis and official sanction applies to composition students' struggles to complete individual assignments within a specific course, as well as to course syllabi constructed and submitted by composition instructors.

Just as Bawarshi conceives of genres as "conceptual realms within which individuals recognize and experience situations at the same time as they are the rhetorical instruments by and through which individuals participate within and enact situations" (Genre 113), I argue that such conceptions move rhetorical genre theory into a manner of intertextual operation, where genre functions as a mode of definition, coordination, or encapsulation, at the same time opening spaces within which participants might interact with a genre, even to the extent that the genre itself will change. This intertextual operation helps further define genre as operationalizing, both enabled and enabling. Such an operationalizing condition reveals itself in the composition course syllabus, functioning as an answer to previous incarnations of a specific academic genre, while relying exclusively on the performances and realization of its activities and assignments in order to be deemed successful. In Bawarshi's estimation, "the syllabus plays a major role in establishing the ideological and discursive environment of the course, generating and enforcing the subsequent relations, subject positions, and practices teacher and students will perform during the course" (119, original emphasis). The suggestion that genre operates both as a generative and enforcing construct refashions Amy Devitt's recent notion that genres strive to both preserve and exclude, and I argue that the course syllabus occupies intermediary space between these modes of generation and 
enforcement, between the desire to preserve and protect and those desires to exclude. From conceptions of genre as modes of classification, to explorations of genre's implicit and explicit relationships with intertextuality, to interpretations of genre as that which responds to and helps regenerate sets of social motivations, this section has offered a more in-depth analysis of the transformations and variations of our understanding of how genre operates in our interpretations of institutionally mandated textual productions like the composition course syllabus. Examining how developments in genre theory reciprocally affect a particularly "ordinary" academic genre like the syllabus demonstrates the extent to which the latter serves as both an operator and delineator of academic professional discourse.

In this chapter, I have argued that the composition course syllabus serves as a partial declaration of how we construct our own authority, and that this text represents an announced, declared, and documented record of such, established through our placement of institutional selfhood and the orders in which we present materials. I have argued that both personal and institutional teacher identities are recreated through the course of the semester, and that we in composition ought to use this text to more fully interrogate relationships of identity constructions through examinations of composition or first-yearwriting course syllabi, to understand more about how such documents do not simply act within the boundaries of the classroom, but how they can and do work upon the conceptual and perceptional frameworks of what it means to be a teacher. Through the relational nexus between power, authority, and genre, I have established that the syllabus ought to be read less in terms of how it seeks merely to describe the course of events in a given semester, and more for how it seeks to construct teachers' identities in relationship 
with, and in contrast to, their institutions'. I have established that the ways in which composition instructors negotiate conceptions of authority and power through the academic textual genre of the course syllabus reveal the ways in which they operate within and conceive of larger conceptions of composition as an academic discipline. 
${ }^{1}$ Though by no means an exhaustive list, for recent self-reflective forays into composition's disciplinary status, see Sidney Dobrin's Constructing Knowledges - The Politics of Theory-Building and Pedagogy in Composition, Sharon Crowley's Composition in the University, and Mary Boland's "The Stakes of Not Staking Our Claim: Academic Freedom and the Subject of Composition." These three authors interrogate composition-as-a-discipline's apparently contradictory trap of fearing identification as a service course (with implications of purpose, use, and function) while also building up necessary and inevitable walls of exclusion academic disciplines are founded upon, and in turn, fearing the implications of this inaccessibility. Although composition's preoccupation with its own disciplinary status is not an explicit focus of my dissertation, I argue that such preoccupations are implicitly tied into ways in which composition talks about power and authority both in and out of the classroom.

${ }^{2}$ In this text, Gale traces discussions of authority within composition through the endeavors of cognitivists (such as Emig, Hartwell, and Witte), expressivists (notably Elbow, Murray, and Macrorie), social constructionists (including Bartholomae, Bruffee, Bizzell, and Berlin), and radical educators (particularly Freire, Shor, Berthoff, and Giroux). Sketching these four canonical encyclopedic periods of composition's disciplinary development, Gale explains that, "implicitly or explicitly, however, all the new schools of thought make claims of authority: the cognitivists' authority, located in the mind and text; the expressivists' authority, focused on the private self, private discourse, and private truth; the social constructionists' authority, found in communal consensus and conventions; and the radical educationists' authority, ensured by utopian goals and personal morals" (33).

${ }^{3}$ Similarly, in "Genres of Power? Literacy Education and the Production of Capital," Allan Luke notes that through the "recycling of the term 'empowerment,' power has become a possession; something that can be transmitted (and therefore bought, owned, rented, leased, and yes, foreclosed), something that is apparently culturally-neutral and political neutral" (322). In this sense, these acts of "recycling" signal the presence of problematic conceptions of power operating in approaches to genre, an issue I will explore further later in this chapter, as implicit connections between what "counts" as a disciplinary text directly relates to one's conception of the power - institutional or otherwise - of what might be called evaluative regulation.

${ }^{4}$ Conceptions of "ownership" in composition have a lengthy and complex history. From a broader cultural perspective, see Schwartz's "Conversations with the Social Text," in which she suggests the distinctly American impulse to label the title of owner as "one to be attained, not questioned," since "ownership is supposed to be the way 'internal' qualities like intelligence, perseverance, willpower, and determination manifest themselves externally" (67). David Jolliffe, in "Discourse, Interdiscursivity, and Composition Instruction," discusses the need for students of composition to feel "a sense of ownership," coupled with the unlikelihood of such a possibility when students are usually asked to "write only to summarize, analyze, or synthesize others' ideas" (202). In 
doing so, Jolliffe connects ownership to the equally monetarily-centered metaphor of investment (202). Divisions between ownership and "others' ideas" lead to Doug Hesse's 2005 CCCC Chair's Address, in which he distinguishes obliged writing as "writing that institutions require and sanction" and self-sponsored writing as that which "people do for reasons of expression or social affiliation" (350).

${ }^{5}$ See also Stanley Aronowitz and Henry Giroux's 1986 collaboration, Education Under Siege: The Conservative, Liberal and Radical Debate Over Schooling, particularly "Teaching and the Role of the Transformative Intellectual" (23-46).

${ }^{6}$ Giuliano's essay is largely a response to Jerome McGann's 2001 article, "'Reading Fiction/Teaching Fiction': A Pedagogical Experiment," in which he comments on the development of his Learner's Classroom, an environment "organized to ensure, as far as possible, that the instructor will leave great latitude for the agenda of topics to be covered in any class and will not select the passages from the assigned readings that are used to focus class discussion" (McGann 147-148). Giuliano explores the retention of power-asproperty in McGann's conceptions of this "Learner's Classroom, as she notes, "Such a teaching scene is meant to empower students and disrupt the master-teacher-subordinatestudent complex. Yet while he stands on the periphery of class discussions, McGann does not give up the authority to design his course and to make unpopular decisions about who teaches when and in what ways" (394).

${ }^{7}$ For more on genre as a containment of convergent social motives, expressed by Aviva Freedman in "The What, Where, When, Why, and How of Classroom Genres" as the "interactive energy" of genre (124), see Bakhtin's "The Problem of Speech Genres" (from Speech Genres and Other Essays) and "Discourse in the Novel" (from The Dialogic Imagination), Anne Freadman's "Anyone for Tennis?," and Carolyn Miller's "Genre as Social Action."

${ }^{8}$ These include, of course, exposition, persuasion, description, and narration. Herrington and Moran point out that "the documents that issued from the 1966 Dartmouth Conference defined the principal aim of instruction in English as personal growth [...] and paid scant attention to the teaching of forms" (5), thus opening the door to the devaluation of transactional writing, and teaching the modes of discourse with a "concomitant understanding of genre as form" (6).

${ }^{9}$ For more on considerations of composition textbooks and modes of genre-asclassification, see Mike Rose's "Speculation on Process Knowledge and the Textbook's Static Page," Kathleen Welch's "Ideology and Freshman Textbook Production," as well as David Bleich's comments on the "declarative and directive [...] discourse of direct instruction" in Frederic and Xin Lu Gale's (Re)Visioning Composition Textbooks: Conflicts of Culture, Ideology, and Pedagogy (16). These arguments and others more than imply that genre itself operates as a threat, as an imposed classificatory closedsystem. 
${ }^{10}$ See also Anne Freadman's "Anyone for Tennis?" and Francis Christie's "Curriculum Macrogenres as Forms of Initiation into a Culture," both of which have contributed to explaining (in)stabilities of genre. Freadman argues that textual classifications associated with traditional conceptions of genre can only be understood through the metaphor of the game, how a text "plays" a genre through series of exchanges. Christie's discussions of how pedagogic discourses operate through processes of "delocating" instructional discourses and relocating them "for the purposes of selective transmission" (157) recapitulate Briggs and Bauman's discussions of de- and re-contextualization. 


\title{
CHAPTER III
}

\section{NARRATIVES OF RESEARCH AND MULTIPLE STAKEHOLDER POSITIONS -}

\author{
SYLLABUS COLLECTION AND THEORIES OF \\ DISCOURSE COMMUNITY CONSTRUCTION
}

The intransitive verb to converse has as its root meaning "to live with, to keep company with, to turn around." This etymology suggests the complexities of "conversation" when it is considered seriously: to live with other people is a difficult enterprise precisely because it requires a willingness to keep "turning" ourselves around, sometimes inside out, sometimes into something we normally are not, in order to accommodate the needs of being together. Nina Schwartz, "Conversations with the Social Text" (64)

In my last chapter, I explored ways in which we in composition can restructure the ubiquitous course syllabus along theoretical frameworks of authority and genre, in order to better conceptualize operations of this particular text amongst those engaged in multiple stakeholder positions. Although I do make the claim that the syllabus ought to be read less in terms of what David Bleich calls the "discourse of direct instruction" (16) and more as a conglomerate of constructions, generations, and enforcements of various subject positions, I have yet to explore my own position as researcher in this dissertation (encompassing both my general insider status towards the discipline of composition, and my outsider status vis-à-vis specific Rhetoric and Composition programs outside of the University of Louisville). In distinguishing between course syllabi and general course descriptions early in Chapter One, I pointed out how both the idealization and realization of a writing course reveal tensions between what might be perceived as publicly available 
and what is in fact often treated as more privately guarded, particularly as these conceptions pertain to these elements of construction, generation, and enforcement of teacher identities.

In this chapter, I would like to revisit these tensions as they reveal themselves through my data collection process, in which I will explore how certain institutions I contacted had their own separate committees on approving requests to allow individual syllabi to be sent to me. While I do not claim that these particular institutions represent the wider response I received through the data collection process, in this chapter, this "research narrative," various Rhetoric and Composition program directors' communications with me do offer a chance to demonstrate how the course syllabus further complicates notions of "public," "private," and conceptions of embeddedness, as conceived both within a specific discipline and amongst perceived academic discourse community structures.

Before I reexamine communications with various Rhetoric and Composition program directors, I feel the need to explore my own multiple stakeholder positions in regards to my identity as researcher, graduate student, and participant in the academic discipline of composition. In "Theorising How Student Teachers Form their Identities in Initial Teacher Education," Dennis Atkinson remarks how, regardless of whether we take the stance of a reflective, reflexive, or critical practitioner, we tend to "assume the notion of a transcendent individual, someone who is able to stand back and occupy a neutral position in order to make a rational analysis of practice, self, others or social processes so as to improve practice, modify attitudes or beliefs or achieve a more emancipated educational system" (381). Atkinson's comments, suggesting that "the belief in being able 
to occupy such a position of transcendence [...] is the ultimate position of ideology" (391), reflect why I need to discuss my own ideological conditions vis-à-vis my multiple disciplinary statuses, and to engage in a self-reflective inquiry into my own structures of ideological masking or interpellation, or the impossibilities of doing so.

While I tend to agree with Phyllis van Slyck's observation about creating better dialogue through "the recognition that neutrality is an illusion, that we all occupy positions, inscribed by cultural codes, but that these positions can be explored and challenged" (168), I keep returning to Atkinson's notion of the transcendent individual, particularly as this position pertains to the construction to my own ideologies of "self-asresearcher" in this dissertation project. As composition instructors, we remain thoroughly ideological beings. Ideology permeates culture. We are inescapably representatives of the educational institution that serves not only to grant us the status (in terms of authorization) to publish, to attend professional development conferences, and to stand in front of the class and teach, but also serves to pay our rent, our utility bills, and (in the case of graduate student teachers, anyway) grants us authorization to take out student loans. For the most part, however, on a day-to-day basis of classroom organization, we cannot see these ideological underpinnings of our positions because we are so heavily invested in them. Ideology, like hegemony in this regard, succeeds through its supposed invisibility.

The early stages of data collection, specifically in developing my formal responses to this university's Human Subjects Protection Program, began to make the ideologically invisible a bit more visible, through formulations of what I came later to see as (at least) a duality of my own self-perception in relation to this dissertation project. 
While clearly announcing myself as a graduate student in a Rhetoric and Composition program (as well as the primary contact for the Institutional Review Board) as part of both the study announcement and the informed consent preamble, this establishment-ofself was coupled with the fact that I was required to list my dissertation director as the researcher of record for the study. Because I did not yet (at the time of this study) hold a terminal degree in my field, I could not be listed as the "primary investigator." Of course, this situation is not unique or indicative of one type of investigation. My own identity as a graduate student became hierarchically reshaped according to what Bawarshi might call the generic "rhetorical ecosystem" of these institutional requirements of response (Genre 8). Borrowing from Bawarshi once more, through these earlier stages of data collection, I came into contact with my own status as "double agent," acting on my own desires to fulfill the necessary bureaucratic requirements to move on to the next stage of the dissertation process, while at the same time those very requirements demonstrated a need to act more as an agent "on behalf of already existing desires and actions" (Genre 50). Because the Institutional Review Board required the primary investigator's current curriculum vitae and other documentation evidencing qualifications, and required no such documentation from me personally (though I was listed as the primary contact for members of the IRB), the construction of "I-as-graduate-student" entered into a fullyestablished, pre-existing hierarchy implicitly linking conceptions of authority and genre.

This hierarchy also demonstrates what James Berlin refers to as the "social endorsement" ideology itself carries, as a method of integrating definition, reinforcement, determination, and interpellation ("Rhetoric and Ideology" 479). From the sense that Berlin refers to ideology as operating in the display of "a given historical moment" (479), 
to Kathleen Welch's arguments that ideological justification becomes unnecessary through appearing to be self-evident (271), this construction of "I-as-graduate-student" entering into the (meta)physical space of others' composition classrooms, others' institutional ideologies already in place, further complicates the notion of "embeddedness" I explored in the first chapter of my dissertation. I have indicated in Chapter One that constructions of embeddedness help us understand how the course syllabus operates as a genre incapable of crossing community boundaries intact, and, in Chapter Two, that the course syllabus simultaneously responds to multiple layers of audiences through its ability to mask its own unfamiliarity. I have yet to explore my own sense of embeddedness (coupled with my identifications with both insider and outsider disciplinary statuses).

An essential element of my next chapter will be an exploration of markers of both personal and institutional disciplinary embeddedness, in which I examine course syllabi submitted from graduate teaching assistants currently enrolled in various Rhetoric and Composition graduate programs across the country. For now, in this chapter, I will first examine my own position in relation to multiple discourse community constructions, as revealed through my processes of data collection. These explorations can, in turn, better structure our understanding of the ways the course syllabus operates in composition, as a participatory genre affecting constructions and perceptions of that discipline. Through tracing developments of the concept of a "discourse community," I propose that lingering binary constructions of "the individual" and "the social" still remain part of composition's disciplinary conversations about discourse community, and that course syllabi produced by entering graduate student instructors of composition operate amongst multiple 
"stakeholder" positions, to borrow from Joseph Harris. This multiplicity, in turn, further demonstrates the embeddedness of the syllabus as an academic genre, which ultimately explains why the syllabus itself ought to be read not as a simple description of course operating procedures, but as an active document participating in the construction of teacher identities in terms of multiple subject and stakeholder positions.

\section{Identification and Discourse Community}

In this section, I begin with a brief suggestion that Kenneth Burke's idea of "identification," which predates the coinage of the term "discourse community," lays the groundwork for later determinations of discourse communities' intermediate space. I make three key arguments concerning relationships between our developing understandings of discourse community construction and the text of the course syllabus. First, I argue that composition as a discipline has succeeded in focusing more on the reflective and productive tensions between personal and institutional identities. The course syllabus, as an initial college reading assignment, functions as a precise focal point of these tensions between exclusionary and constraining tendencies of discourse community construction and the natural intertextual nature of writing assignments. These tensions culminate in the benefits and problems associated with consensus, as well as John Trimbur's use of the term "dissensus," which complicates composition's understandings of itself as a "social" discipline. Second, I argue that part of our disciplinary responses to the concept of the contact zone (in relation to discussions of discourse community construction) result in an unavoidable typification of teacher roles. Such typification can present itself in the text of the composition course syllabus, as the 
instructor struggles between individual self-presentations and a document, by definition, designed to deliver encapsulations of a particular course community. Finally, I argue that my own experiences with processes of data collection demonstrate the extent to which multiple stakeholder positions reveal and conceal themselves, a multiplicity visible in the ways people in the discipline of composition negotiate and respond to the embeddedness of the course syllabus as both an outlier and a representative of a specific department, institution, and discipline.

In order to better engage and synthesize the idea of a discourse community, I argue for a return to Kenneth Burke's $A$ Rhetoric of Motives, published in the earliest stages of composition as an academic discipline. Though Burke never mentions the phrase "discourse community," his explorations of substances and identification offer an intriguing precursor to conceptions of discourse community. Conceptualizing definitions and processes of identification which simultaneously preserve and threaten constructions and assumptions of community, Burke recognizes "an intermediate area of expression that is not wholly deliberate, yet not wholly unconscious," operating "midway between aimless utterance and speech directly purposive," specifically offering the example of "a man who identifies his private ambitions with the good of the community" as both "partly justified, partly unjustified" (521). In other words, within the intermediacy of intention and indifference, determining distinctions between individual and community advantages becomes difficult, if not entirely impossible. The textual artifact of the composition course syllabus finds a place in this Burkean sense of intermediacy, the identification of interests between the composition instructor's desires to fulfill the requirements of the 
department-institution, and his or her desire to offer students a sense of order, goals, clarity, even a sense of belonging to a specific section of a composition course.

Burke explores an essential element of discourse community when he explains the nature and practice of identification, noting:

A is not identical with his colleague, B. But insofar as their interests are joined, A is identified with B. Or he may identify himself with B even when their interests are not joined, if he assumes that they are, or is persuaded to believe so. Here are the ambiguities of substance. In being identified with B, A is "substantially one" with a person other than himself. Yet at the same time he remains unique, an individual locus of motives. Thus he is both joined and separate, at once a distinct substance and consubstantial with another. (544-545)

Burke anticipates distinctions between an individual engaging in identification of his/her own volition through an assumption of common interests (self-identification) and being identified with another's interests. Thus, akin to Bawarshi and Devitt's conceptions of genre, identification operates as a function of generation and enforcement, of selfactualization and imposed categorization. The nature of identification is, in Burke's estimation, "compensatory to division," in the sense that, "if men were not apart from one another, there would be no need for the rhetorician to proclaim their unity" (546). While the juxtaposition of distinction and consubstantiality, perhaps reinterpreted as self and other, proves intriguing and relevant to later instantiations of discourse community theory, Burke's comments about the rhetorician's need to "proclaim their unity" raise more pervasive questions concerning perceptual implications of what would thirty years later be termed "discourse community."

Through my data collection process, I was witness to a particular moment of identification in the Burkean sense, one that demonstrates both a reaffirmation of my own position as graduate student researcher as well as a documentation of my own sense of 
"otherness." After submitting my requests to various Rhetoric and Composition program directors to obtain graduate teaching assistants' course syllabi, I received an email from one institution's director of the "Core Writing Program," informing me that she would need to review my research protocol with their own internal institutional review board. While I will revisit this trend my research later in this chapter (composition program directors noting the need for further internal review), as an element further complicating the course syllabus's status as a strictly public or private document, I wish to focus for a moment on a response I received following the successful approval of my request for course syllabi. In an email sent to teaching assistants at this particular program, which she forwarded to me as well, the director of the Core Writing Program indicates a specific move of identification, as she notes, "Your decision to participate or not is entirely up to you--I won't know or be concerned either way! Please consider this request for assistance, which comes from one of your graduate student peers at another institution."1 While this response represents a common enough gesture - assuring potential participants in the study that they will receive neither reward nor reproof for participating - this email also suggests a set of gestures geared towards a simultaneous joining and disjoining of interests. While this individual recognizes her position of authority as a possible threat to the participation in my study of graduate student teaching assistants placed in her charge, she also recognizes her position as one in which she is able to perform this declaration of indifference in the first place, a condition inherent in acts of safeguarding authority, one which I have discussed in the previous chapter. In this email, the program director succeeds in occupying an intermediate space between indifference and intention. She directly announces the former as a way of producing a sense of 
distance between myself-as-researcher and the discourse community construction already at work in this institution, while suggesting graduate students occupying this discourse community space consider at once my (institutional) otherness as well as identification with one of their "graduate student peers." Such a communication - rather, such a display of communication, since this individual was not expected to forward to me the email she had sent to graduate student teaching assistants in this program - demonstrates a sense of intermediate con/substantiality.

The affirmation of earnestness Burke refers to in gestures of identification exhibits a duality of inclusion essential to discussions of discourse community construction and, for lack of a better term perhaps, maintenance. While patterns of identification constructed as locations of motives suggest that the former "can be critical and transformative rather than merely reproductive despite the fact that experience is always already socially patterned" (Branaman 445), identification vis-à-vis discourse community constructions in the narrative of my data collection also suggests that the line between the transformative and the reproductive becomes quite thin through acts of identification themselves.

\section{Discourse Community Constructions, Model Syllabi, and Impositions of Consensus}

In this section, I explore the extent to which the course syllabus operates as an intersection of personal and institutional identity tensions, and how this common academic text positions the act of writing as a function of displacement. This displacement in turn yields a particular take on Burke's concept of identification, 
especially considering how the opposition of ab/normal discourses, potential differences between knowledge generation and knowledge preservation (or maintenance), separates notions of the "self" and the "other" in ways Burke believes are deliberately and productively ambiguous. Kenneth Bruffee comments on perceived relationships between knowledge generation and knowledge preservation, stressing the understanding that "concepts, ideas, theories, the world, reality, and facts are all language constructs generated by knowledge communities and used by them to maintain community coherence" ("Social Construction" 777). ${ }^{2}$ Although such a claim appears to suggest a union between conceptions of knowledge generation and maintenance, Bruffee's later claims complicate this relationship further as it pertains to ways we in composition talk about discourse community. He notes how "a writer's language originates with the community to which he or she belongs," and that "we use language primarily to join communities we do not yet belong to and to cement our membership in communities we already belong to" (784). Essentially, Bruffee's speculations concerning writtenknowledge-based community construction reveal the self-fulfilling, insulating nature of discourse communities in ways not necessarily conducive with the potentially uniting metaphor of the "conversation." Bruffee's suggestions that language constructs are used by knowledge communities "to maintain community coherence," and that these knowledge communities themselves generate these constructs, both lead inherently to an essential term in the examination of discourse community theory - consensus.

Concepts of and debates over consensus, I argue, lie in the thick of the production, dissemination, and performances of the composition course syllabus. Whether we define consensus simply as an agreement reached by a number of people in a 
specific group, or more as sets of coercive ideological unification strategies, the very presence of the syllabus in the composition classroom, even if negotiated, suggests a certain imposition associated with any proposed act of consensus. This imposition appears through what Greg Myers calls the act of teachers embodying authority in the "more effective guise of class consensus" (442). ${ }^{3}$ Through these (dis)guises enacted in the presentation of the course syllabus, we can begin to see how, in Bawarshi's words, "On the one hand, the teacher has to make explicit what the students will have to do to fulfill the course requirements, including the consequences for not doing so [, while on] the other hand, the teacher also has to create a sense of community with the students so they can feel responsible for the work of learning" (Genre 122). Bawarshi's observations concerning relationships between consequences and community point more explicitly to the realities in which discourse communities participate, both those which they shape, and those they are shaped by.

The syllabus demonstrates an understanding of consensus-as-conflict, not in broad theoretical terms of the idea of consensus arising from the idea of conflict, but rather in specific, socio-historical contexts through which consensus becomes a way for composition as an academic discipline to continue the processes of self-structure in the midst of palpable perceived threats to its apparent and assumed consistency. Intersections of authority and discourse community construction function on more "global" and "local" levels, qualifiers I will discuss at greater length in the next section, as authority helps to shape the semblance of consistency in the discipline and in the classroom. We count on at least some degree of imposed consensus in the act of handing out a course syllabus. For example, a single student choosing to simply ignore or not acknowledge a course- 
established policy on attendance or late paper submissions would, I suspect, result in a dismissal of that individual student's choice more often than such an action would result in an opportunity to discuss these policies as intersections of authority and discourse community construction in the classroom. Closer attention to what our course syllabi are really doing and saying about us, our discipline, and our placement in the academy can reverse these kinds of situations, and transform the tenuous nature of consensus into a subject of conversation for the composition classroom, not some entity we must either embrace or implode.

Issues of consensus enter into the narrative of my data collection when discussing the use of a "model syllabus," particularly in terms of how those in positions of authority perceive the relationships between these model syllabi and the formation, maintenance, and balance of discourse community constructions within individual Rhetoric and Composition programs. Two email communications from two different composition program directors best characterize institutional relationships between modes of consensus and an understanding of the multiple functions and implications of a model syllabus. While my point here is not to denigrate the value of having a model syllabus (particularly in a program in which a large majority of the introductory composition courses are taught by graduate student teaching assistants with a wide range of pedagogical and institutional experiences), the reactions from these two program directors demonstrate the extent to which binaries of positive or negative evaluation are inadequate in engaging the structure of the model syllabus into conversations concerning the syllabus's various personal and institutional implications. Such responses to the 
conditionality of the model syllabus, I argue, further demonstrate variability within conceptions of consensus themselves.

My first response comes from a composition program director more inclined toward, in his words, "the suitability of [their] program" in deference to the goals of my research study. To this end, this director informs me that their program has just "installed a new syllabus and a new course reader," and that since "these materials are new to all of our instructors I suspect they will follow the syllabus template fairly closely for this semester before customizing their sections in subsequent semesters." He then reframes the discussion of his particular program through the filter of my specific research study, questioning whether the use of their syllabus template "might skew any data" I collect from their program. ${ }^{4}$ In effect, this program director manages to project perceptual concerns a community outsider might have towards the presence (or installation) of a model syllabus into his own concerns of the validity and reliability of my study. This exchange reveals the course syllabus as a functional demonstrator of consensus-asconflict, within a precise socio-historical contextual moment. Responding in terms of "suitability," this program director recalls Peter Vandenberg and Colette Morrow's observation that "[e]ntry into a community marked by particular discourse conventions is always entry into an institutional order [, and] following institutional constraints demands some degree of conformity to discursive authority" (21). However, in this particular instance, this program director succeeds in complicating notions of consensus in terms of Vandenberg and Morrow's later evaluation, concerning the extent to which "conformity to a socially constructed reality through an articulation of what is not appropriate or acceptable reflects a value judgment favoring things as they are" (22). The presumed 
conformity accompanying the presence of a model syllabus in a composition program becomes problematized through the relatively new nature of this recently installed syllabus and course reader. Since the materials in question are described as being "new to all of our instructors" (my emphasis), and conformity to the new model-qua-reader operates as a matter of assumption rather than strict obligation, this communication demonstrates how consensus can operate in the institutional frameworks of composition programs as a balance between perceptions of freedom and those of constraint.

This balance between perceptions of freedom and those of restraint as we encounter theories of discourse community construction, however, is always rather tenuous. James Porter discusses discourse communities more in terms of a progression of constraints against the self, writing as "an attempt to exercise the will, to identify the self within the constraints of some discourse community" ("Intertextuality" 41). Porter acknowledges that while we are "constrained insofar as we must inevitably borrow the traces, codes, and signs which we inherit and which our discourse community imposes," we are also "free insofar as we do what we can to encounter and learn new codes, to intertwine codes in new ways, and to expand our semiotic potential - with our goal being to effect change and establish our identities within the discourse communities we choose to enter" (41). Our involvement within and against discourse communities relies on recognizing layers of inevitability and imposition, while we struggle to "do what we can" to establish ourselves. Referring to the "dialectic process within a discourse community" (43), Porter suggests that this form of self-establishment requires transformation, synthesis, and a certain degree of submission as well. Porter's suggestion that there are those discourse communities we choose to enter, and by extension those we deliberately 
choose not to enter, operates on the assumption of the tangibility of an academic discourse community, one into which we might be able to initiate ourselves or our students. ${ }^{5}$ Tensions between constraints of a discourse community and the intertextual nature of writing assignments reveal themselves in the composition course syllabus, particularly when viewing the course syllabus as the first college-level reading assignment, an initial introduction to what can only be loosely called academic discourse.

In this way, the syllabus functions in terms of both form and content, as an introduction to new "traces, codes, and signs," and the practice of these very codes as assumptions embedded within an academic discourse community, an admission of its own unfamiliarity hidden within the ideological structures of its delivery. Using the syllabus as a textual opportunity to engage the power and productivity of these tensions in disciplinary conversations and in the individual composition classroom helps establish a concrete example of the interrelationships between consensus and conflict. Just as Joseph Harris calls for a more polyphonic view of the ways in which we perceive and teach from discourse communities, rather than a "mastery of some particular, welldefined sort of discourse" ("The Idea of Community" 17), stressing the syllabus as a polyphonic, intertextual result of multiple enacted discourse communities would help composition teachers truly teach these convergences of consensus and conflict.

Over the last two decades or so, composition has moved steadily to make reflective the tensions between personal and institutional identities, to make the indirect direct, to make the implicit an explicit subject of conversation. ${ }^{6}$ Ushering in more radical responses like Thomas Kent's "On the Very Idea of a Discourse Community," John Trimbur explores tensions inherent in the very use of the term consensus in his 
"Consensus and Difference in Collaborative Learning." Determining that objections to consensus as a threat to individual student identity are "based on an unhelpful and unnecessary polarization of the individual and society" (603), Trimbur explains how touting the individual as the pedagogical end-all-be-all ignores the value of both "dissensus" and negotiation as embedded in writing. Examining how knowledge should be established through power negotiations, and not merely as a method of comparison and contrast, to see if and when students' discourse will match up with those representatives of the discipline (614), Trimbur's use of the word "dissensus" sets the stage for later discussions of the theory and practice of discourse community structures, as well as what it means for composition to act as a "social" discipline.

My second response from a different composition program director represents a more invasive, "polarizing" side to consensus, one negating Trimbur's suggestions of negotiation and any possibilities of conceiving of consensus as a potential threat to individual graduate teaching assistants' personal, professional, disciplinary, and institutional identities. Once more, in my requests to contact individual graduate teaching assistants, I encountered a director who informed me that their program employs a model syllabus. Her response, however, could not be more different from the one I have previously described, as she states, "I create the syllabus the TAs use for their introductory course, so they are all the same. We are a very large, multi-section program and our novice instructors all receive prepared materials from me to make their transition to teaching easier."

Let me be clear here: neither the narrative of my data collection at this stage of my dissertation nor my research project as a whole is intended to function as a value 
judgment regarding graduate Rhetoric and Composition programs, their directors, their individual graduate teaching assistants, or their course syllabi themselves. This downplaying of value judgments succeeding in eliminating an apprehension I saw numerous times among my colleagues in the earlier stages of soliciting syllabi for my data collection process. At the same time, however, this particular response begs a comparison to the one I received previously, since both these emails and my responses to them came in quick temporal succession, within a twenty-four hour period. Although both of these individual program directors' responses to my request for course syllabi demonstrate their model syllabus's place in their programs in terms of "newness" (either in terms of the materials themselves, as in the previous email communication, or the newness of the instructors, as in this one), their different tones in their responses reflect the complex nature of the model syllabus, especially in terms of institutional identification, modes of consensus, and discourse community construction.

The tone of the above communication in comparison to the one before reflects a distinction of both pronoun usage and audience de-centering. Whereas the first email regarding the program's use of a model syllabus (and its potential implications for my research project) places the collective of the "we" in terms of those responsible for the installation of the new model syllabus ahead of the individual program director's use of the first-person pronoun in reference to his own assumptions regarding its implementation, this communication takes a precisely opposing structure. This particular program director's initial statement, "I create the syllabus the TAs use for their introductory course, so they are all the same," suspends any assumptions of deviation from the model, and thus operates more on what Tom Fox calls "the idea of a closed 
community" (Social Uses 32). In her study of syllabi from the University of North Carolina at Greensboro, Diann Baecker, citing Muhlhausler and Harre's Pronouns and People: The Linguistic Construction of Social and Personal Identity, extends practices of pronoun usage (even in a casual sense, as might be argued in this particular email exchange) to structures of moral responsibility, noting particularly how the academic "we" is "not mainly used to imply teamwork. Rather it is used to draw the listener into complicity, to participate as something more than an audience" (59). While the first program director using a model syllabus frames his communications with me in terms both of my study and the representation of the program (drawing me-as-researcher beyond the position of audience), the second director frames her response first in terms of her own position within the program (and thus by extension my position as outsider or spectator in this regard). What best puts these two different emails into perspective concerning relationships between the employment of model syllabi and impositions of consensus is the operative structure of each individual's response.

The implications between "we installed" and "I create" in this instance demonstrate relationships between notions of consensus and those of customization. The program director who responded by acknowledging her position as the sole creator of the model-syllabus-in-use further insulates conceptions of customization. As I mentioned previously, this email came after the one asking whether the presence of a model syllabus amidst my data collection would skew any results I might produce. This being the case, I sent a response to this second director, noting how model syllabi would most likely factor into my explorations, requesting a copy of said model, and, since she refers explicitly to "novice instructors," asking whether any concessions or exceptions were made for more 
advanced graduate teaching assistants with more experience. To this date, I have not received a response, and while I acknowledge that such a lack of communication might be simply a result of busy schedules, I cannot at the same time ignore the implications such a lack of response has for more insular notions of consensus in discourse community constructions.

\section{Contact Zones and Threats of the Static}

Harris and Trimbur help move conceptions of discourse community beyond notions of stability and into the recognition of the power and productivity of tension and multivocality, which I argue is (by definition) in operation in the production, dissemination, and reception of composition course syllabi. So far, I have explored how the composition course syllabus contributes to conceptions of discourse community's relationships to the idea of consensus, and why we ought to make the more implicit impositions of consensus a more direct subject of our disciplinary and classroom conversations. While the spectrum of positive and negative notions of consensus continues to color theorizations of discourse community constructions in composition, consensus is not the only factor we need to examine further in order to explore how and to what ends our course syllabi operate as creators and commentators of discourse communities. In this section, I argue that our disciplinary responses to the concept of the contact zone has resulted in typifications or generic reductions of composition teacher roles, and that textual demonstrations of these typified teacher roles often appear in the course syllabus. 
In her "Arts of the Contact Zone," Mary Louise Pratt initially defines contact zones as "social spaces where cultures meet, clash, and grapple with each other, often in contexts of highly asymmetrical relations of power, such as colonialism, slavery, or their aftermaths as they are lived out in many parts of the world today" (63). Noting how we move in and out of what she calls "rhetorics of authenticity" (72), Pratt's conceptions of the contact zone offer much in the way of exploring how, why, and to what ends composition scholars and instructors employ the term "community" in the classroom. Although Pratt speaks specifically of "ways for people to engage with suppressed aspects of history (including their own histories)" (71-72), rhetorics of authenticity offer another way to view discourse communities in terms of constitutive and participatory roles (as opposed to that which just "is," or is imposed). In The Social Uses of Writing, Tom Fox's re-depictions of discourse communities in which "understanding, not judgment would be the dominant focus" (115) lie in teachers' "knowledge of institutional history and the social forces that help define it," providing them "with a general interpretive frame from which they can seek to understand the relationship between themselves, their students, and $[\ldots]$ day-to-day classroom practices" $(111){ }^{7}$ Stressing active teaching without the creation of passive students (45), Fox's discussions of academic discourse communities reveal the reality that "students construct their teachers not on the basis of a unique faceto-face interaction, but on the basis of a type whose function it is to transmit knowledge and evaluate students" (43), as well as the subsequent need to subvert the typification of the teacher-role in the composition classroom.

These very typifications unavoidably (perhaps productively) present themselves in the distribution and subsequent filing of the composition course syllabus, as the 
composition teacher presents him- or herself in front of an audience of students, struggling to identify him- or herself as an individual while simultaneously forging these individualistic tendencies within a textual document which, at its most efficient, struggles to encapsulate the course itself. The instructor, engaged in methods of self-identification, operates in this textual space of the course syllabus, as one speaking from a subjectposition. Through her development of what she calls "active interference" (153), Phyllis van Slyck argues that the way to keep "values" from becoming some over-generalized, non-specific, and thus non-spoken topic of conversation in the writing classroom is to explore the real emotional consequences of actively interfering in student writing, and having them actively interfere in the instructor's self-identification (154). Pratt's initiation of the "contact zone," together with its critics and respondents, suggest that it takes more than talking about conflict in the composition classroom in order to not merely tolerate but engage with conflicts already inherent in discourse community systems. Through the course of my data collection process, I came across a more microcosmic version of Pratt's original conception of the "contact zone," simultaneously coupled with tensions from "active interference" against an over-generalization of values.

As I have already mentioned in my last chapter, if we understand the course syllabus as both a material and ideological subject in the discipline of composition, the embeddedness of its structure, authors, and audiences then represents sets of competing voices, once again recalling Xin Lu Gale's descriptions of teachers' dual roles in both conserving and transforming the status quo. Momentarily revisiting distinctions between the two sets of email communications discussed above, the ways in which these two program directors respond to the condition of the "novice instructor" reveal varying 
degrees of this typification in action. While the first maintains merely an assumption that new(er) instructors of composition will tend to follow the model syllabus and course reader provided in order to alleviate the assumed fears and trepidation of being on the other side of the desk for perhaps the first time, the second appears to collectively refer to all graduate teaching assistants as novice instructors in need of a "transition to teaching." It is not difficult to extrapolate implications between assumptions of consensus and the creation of a contact zone in this case. Rather than the responsive case of a more complex "us-us" relationship (multiple perceptions of the program-authority of "we" in both potential conflict and agreement with equally multiple perceptions of graduate teaching assistants), the more deliberate maintenance of an "us-them" relationship (the singularity of the program director in deference to the more artificially unified novice graduate teaching assistants) succeeds in establishing its own need for consensus through the more rigid assumptions of "asymmetrical power relations" (Pratt 63), as played out in traditional depictions of contact zones.

More along the lines of van Slyck's call for a certain level of "active interference," I received only one email communication from a composition program director interested in crossing these insider/outsider boundaries. Rather than being wary of the fact that I might not entirely understand the rationale for a program different than the one in which I am currently involved as a graduate student instructor, following my request for course syllabi, one program director was particularly accommodating. Here, I define accommodation not merely in the immediate sense - through the fact that she agreed to forward my request to individual graduate teaching assistants placed in her charge - but more in terms of the extent to which her communications with me as an individual 
outsider sought to contextualize her program further, and in more detail, than anyone else I encountered through my data collection process. After my initial request, this program director informed me of the fact that "all requests to conduct research or collect materials in our program need to be approved by the First-Year Writing Council," and asked whether waiting for the council's formal meeting would delay my data collection.

In and of itself, these formal "layers" of departmental approval were not uncommon in my data collection process. They were at first more of a surprise to me, in the sense that these individual committee-based approvals inherently complicate notions of these syllabi as public documents (in terms of domain and availability), as well as more stable, monolithic representations of insider/outsider statuses. Beyond this initial declaration, and after my request for course syllabi had been approved by this "First-Year Writing Council," this program director sent me a detailed follow-up email. In addition to describing the consistency of this institution's first-year writing program, including the fact that graduate teaching assistants "represent about $25 \%$ of our teaching faculty in the First-Year Writing Program, teaching approximately $10 \%$ of the courses offered," she also emailed me a link to the online faculty handbook, and included the username and password so I could access descriptions of teaching assistant preparation at this particular program. In other words, once a series of departmental approvals hierarchically "outside" the individual program director herself had been achieved, I was granted a certain degree of access to information that might otherwise have been restricted, information which would allow a more deliberate contextual interpretation of the inner workings of this composition program in terms of teacher training and syllabus development and dissemination. 
This moment in my data collection reveals a significant crux between threats of consensus conceived as static, unified ideological agreements and a point of "active interference." In Pratt's terms, the "asymmetrical power relations" present themselves in multiple instances of contact zones - between the individual graduate student researcher and the individual composition program outside of his immediate experience, as well as broader instantiations of these power relations revealed through supplemental exchanges between layers of authority within the composition program in question. In a sense, my own data collection process seeks these tangible spaces of asymmetrical power relations, to better understand the formal and operational implications of the syllabus in the discipline. This particular composition program's detailed level of response, coupled with an awareness of being in the position to grant access, functions as a complication of Fox's earlier discussions of the construction of teacher roles and identities vis-à-vis academic discourse communities in terms of either "a unique face-to-face interaction" or "on the basis of a type" (Social Uses 43). Recognizing that such interactions are impractical under the given circumstances, the exchanges between the First-Year Writing Council and this program director, as well as subsequent communications on an individual basis, demonstrate both the recognition of teacher role-typification and efforts to circumvent them. Interactions within and responses to contact zones in this respect alter the ways composition interrogates, employs, criticizes, and (d)evolves conceptions of discourse communities.

Thomas Kent, in "On the Very Idea of a Discourse Community," argues that we ought to be able to "relinquish" the term altogether, as he maintains that the concept of a discourse community depends on a constricting externalist understanding of knowledge 
and meaning (431). Arguing for the dismissal of the term "discourse community" as one of convenience, Kent maintains that such a concept limits the hermeneutic possibilities of writing. Ultimately, Kent takes particular issue with Trimbur and his use of "dissensus," which he feels "simply replaces one conceptual scheme with another," where "for Trimbur, struggle becomes the new master-term to which everything - including consensus - is reduced" (439). The charge of being a "master-term" has been levied against composition's discussions of discourse communities for some time, and this point of contention suggests a powerful catch-22 for composition teachers. Although he never mentions this explicitly, Kent's issue with substitutions of master-terms signals a key problematic: when we speak of community, whose version of community are we talking about?

Jimmie Killingsworth raises similar concerns, suggesting that the term "discourse community" itself "can lead the analyst astray by promoting an uncritical acceptance of 'community' as a 'natural' element or transcendental category" (110). Killingsworth reminds us that most people are located between local and global discourse communities. He tangentially defines the former as "groups of readers and writers who habitually work together in companies, colleges, departments, neighborhoods, government agencies, or other groups defined by specific demographic features," while the latter function as "groups of writers and readers defined exclusively by a commitment to particular kinds of discourse practices and preferences, regardless of where and with whom they work" (121). This distinction between local and global further complicates Bruffee's oppositional relation between those communities we do and do not belong to, disrupts the notion of "community coherence" in general, and further clarifies Pratt's notion in the 
ways we move in and out of rhetorics of authenticity. Relationships between local and global discourse communities, particularly as expressed as modes of conflict within a single individual writer/reader, help move discussions of discourse community structures in composition beyond an understanding of the static writer entering into, or participating in, an equally static discourse community. ${ }^{8}$

These persistent threats of a static discourse community reveal themselves in responses to the composition course syllabus, particularly through a return to the threat of conceiving genre as a set of surface textual features. From the different responses I received regarding particular programs' employment of a model syllabus to efforts of active interference designed to complicate notions of consensus, I am reminded of Kay Halasek's discussions of authorization in A Pedagogy of Possibility, particularly as she draws parallels between freshman composition students and non-tenured university faculty. Halasek observes particularly how both "write within and are authorized through a powerful credentialing system," while both "work from an implied relationship to their subject matter," indicative of institutional discoursal expectations (103-104). The course syllabus represents a framework for the written textual documentation of this "powerful credentialing system," while offering challenges to conceptions of authorization. Who writes the syllabus, who participates in the "credentialing" of this text, and to what extent are course syllabi constitutive and reflective of discourse community constructions composition classrooms are attempting to create? This reminder of the constitutive, rather than merely (or only) reflective nature of discourse communities, coupled with Peter Vandenberg and Colette Morrow's responses to the reduction and filtration enacted upon intertextuality within discourse community pedagogy, ${ }^{9}$ in turn reveal intertextual 
relationships between conceptions of academic genre and academic discourse communities. Conflicts between local and global discourse communities, coupled with the threat of generic reduction associated with conceptions of discourse communities as static entities, comment on the complexities of the composition course syllabus as it attempts (and only attempts) to create, temporarily define, or engage in multiple discourse communities.

While we might argue we in composition are especially in tune with the idea that we all operate in a number of different and overlapping discourse communities simultaneously, pronoun usage as an element of the course syllabus helps reveal the extent to which we tend to oversimplify these understandings of local and global discourse communities as inherent multiplicities. The threat of static reduction comes into play every time we refer to "I," the teacher and "you," the students, both of which operate simultaneously in multiple, overlapping, contradictory constructions of local and global discourse communities. Beyond this, composition as an academic discipline has both a theoretical and practical need to refocus discourse community as these conceptions intersect within theories of authority and genres of academic textual production. We composition teachers shape the syllabus, which in turn is shaped within this provided space, time, room, what Lee Ann Carroll calls "a grid of blank squares" ("Pomo Blues" 919). We are also inextricably in a position to shift who "we" is, to "soften" the authority we often accept as a given (Baecker 60), or to maintain our own versions of academic discourse communities. The more aware we become of variations in the creation, construction, and dissemination of the syllabus, the more likely we are to prepare to 
combat threats of static consensus and maintain levels of active interference inherent in productive contact zones within the discipline of composition.

\section{Loca(liza)tion and Stakeholder Positions}

While composition's past interrogations of discourse community structures and relationships have struggled with variations of initiation arguments, insider/outsider statuses, and modes of agreement and conflict as the material and discursive conditions under which these communities are created, enforced, and questioned, conceptions of struggles between "the individual" and "the social" still remain a factor in the ways compositionists talk about discourse communities. While it of course cannot and should not be ignored that tensions, conflicts, disagreements, and differing worldviews keep alive any perception of discourse community, it becomes almost a limitation of composition scholarship itself that these tensions are often reduced, appearing to operate as a function of internalized $\mathrm{A} / \mathrm{B}$ relationships, hearkening back to my earlier discussions of power-as-property in the previous chapter. In this section, I explore how further shifts in disciplinary vocabulary concerning theories of discourse community appear in the ways composition names participants involved in discourse community constructions, in efforts to sidestep more reductive conceptions of individual/social binaries. Ultimately, I argue that these multiple subject positions of teacher identities revealed through these recent discussions of discourse community help further the notion of the composition course syllabus as an embedded genre of academic writing.

Throughout the process of my data collection, I can perhaps best explore my own position as researcher through distinctions made in Robert Cherry's "Ethos Versus 
Persona - Self-Representation in Written Discourse." Distinguishing between the two titular terms, Cherry argues how, "at the ethos end of the continuum, writers garner credibility by identifying themselves as holding a certain position or having particular kinds of knowledge or experience, as well as by demonstrating their 'practical wisdom' and showing a concern for the audience," while "at the persona end of the continuum, writers exercise their ability to portray the elements of the rhetorical situation to their advantage by fulfilling or creating a certain role (or roles) in the discourse community in which they are operating" (265). Revisiting the earlier stages of my data collection where I could not be listed as the primary researcher of record because of my status as a graduate student, while at the same time I needed to combine representations of myself with those of my dissertation director into a collective "we" - and applying Cherry's distinctions, I realize I needed to form an ethos of credibility not necessarily limited to my own knowledge or experience. In contrast, I also needed to form a persona indicative of my "ability to portray the elements of the rhetorical situation" to my own advantage, through direct communications with composition program directors.

Although Roz Ivanic takes issue with Cherry's distinctions between ethos and persona, specifically that he "does not incorporate in [such a distinction] any understanding of the way in which writers' identity is constructed by the norms and conventions of the community within which they are writing" (91), I argue that, in the specific instance of my data collection process, this distinction in and of itself operates in the awareness of the socially constructed nature of these conflicting yet interrelated norms and conventions. While reinforcing my position as graduate student researcher in responses to my university's own institutional review board, I also needed to develop a 
persona "both in the dramaturgical sense and in the broader sense of a social role" beyond my own institutional conventions, in my efforts to introduce myself into the alreadyconstructed composition programs to which I had not previously been granted access (Cherry 256-57). Donna LeCourt recognizes how "identifying within a given subject position requires the creations of borders between the discursive practice of a given enuncative modality and those practices that do not fall within this discourse's parameters," and that these borders create only a "seemingly stable space within which identification can be orchestrated" (146). Through the process of my data collection, the course syllabus itself became an impetus for examining and further interrogating these "seemingly stable" spaces of identification.

Extending discussions of discourse communities, Joseph Harris comments on what he calls "public teaching," a shift in focus from global to local discourse communities ("Beyond Community" 8). Such a shift, he argues, would entail examining the true "stakeholders" in composition as a discipline, including "undergraduates, teachers, and administrators" (8). Harris's use of the term "stakeholders" appears to move beyond conceptions of the individual starkly and deliberately positioned as "versus" the social. Harris claims that, in order "for people to work through their intellectual disagreements in a serious and sustained way, they need to feel at ease with one another not as members of some abstract, organic, disciplinary community, but simply as interlocutors who have agreed to hear each other out at this time and in this place" (4-5). This focus more on the material/physical time and place of composition reveals itself through my data collection process specifically, as the version of myself constructed as 
an outsider (to this time and this place of composition) encountered the realities of negotiating various disciplinary hierarchies and institutional calendars.

In close succession, I received three brief responses to my request for graduate teaching assistants' course syllabi, none of which were especially unusual, yet all three reveal the process of collecting syllabi - as indicative of moving from insider to outsider to insider statuses - as a process of negotiating conflicting temporal-spatial realities. In the first case, I received a prompt response from a particular program director who informed me only, "Let me run this by a few people and I'll get back to you." In the second, the individual I had assumed was the director of the composition program informed me that she had recently "stepped down" from that position, and had forwarded my request on to her successor. Again, in and of themselves, these moments are perfectly ordinary; however, these specific replies do comment on the shifting nature of academic disciplinary stakeholder positions. While an earlier communication with a different composition program director revealed the existence of a "First-Year Writing Council" from which I would need to receive approval before moving further with my study, these communications above demonstrate more of a sense of uncertainty. This uncertainty appears expressed both through an awareness of foresight into potential problems or criticisms in approving my study prematurely, and through the realization of disconnects between information obtained on a departmental website and the updated reality of who now holds this position. A final communication in this regard reveals another common, ordinary aspect of composition as taking place within an institutional, academic spatiotemporal framework. In this case, the composition program director was more than willing to forward my request for course syllabi to his composition teaching assistants, 
but suggested that he wait two weeks before doing so, noting, "Classes start next week and there's a better chance of it getting their full attention after the craziness of the first week subsides." Once more, such a relatively ordinary communication reveals the extent to which discourse community constructions are not merely indicative of practical considerations of time and space - they are in fact responding to these conditions as an element of their maintenance, transformations, and even existence. Harris's use of the term "interlocutors" reinvigorates Bruffee's metaphors of conversation, while at the same time resisting the abstractions of community embedded in the very use of the word. The personal and institutional relationships expressed in the course syllabi of graduate student instructors of composition (in the position of both student and teacher, both nonadministration and seeking advancement within it, occupying multiple spaces in Harris's framework of "stakeholders") offer a lens through which to view these power negotiations. By extension, the processes of collecting these representative personal and institutional texts demonstrate functional levels of conversation in the specific times and place an academic discipline like composition occurs. We are then not simply members of academic discourse communities, but those in positions to maintain, alter, or transform how conceptions of these academic discourse communities are perceived and received. Our course syllabi function, in this way, as both implicit and explicit markers of our own embeddedness.

While I argue that holding multiple subject positions does not expressly reflect a hybridization of stakeholder positions, ${ }^{10}$ it is interesting to observe how composition's interactions with discourse community structures in the last decade can be most readily characterized in terms of a discipline searching for a vocabulary, ways of defining this 
term juxtaposed with questioning the need for this term at all. ${ }^{11}$ While Anis Bawarshi acknowledges that "composition scholarship has become less concerned with inquiring into generalizable cognitive processes and more concerned with inquiring into the localized, textured conditions in which cognition and social activity are organized" (Genre 5), others like Johnathan Mauk questions the ease with which compositionists employ the term "local." Mauk points out that "it is too easy to suggest that the act of writing demands location, and so writers must learn to locate themselves within a particular (academic) place and then generate ideas accordingly," and although composition has made moves toward examining the local more than the global aspects of discourse communities, this very assumption of localization runs the risk of, in Mauk's terms, "evacuat[ing] the complexities of both academic and non-academic life" (379). I have argued for conceiving of the composition course syllabus as an initial reading assignment of any student's college career, and in this case, I claim that such an interpretation specifically allows for a more concrete conception of a material-discursive sense of location that communicates a potential sense of self-contained actuality not germane to the student's individual and collective participation in the course.

Such application of localization signals the embeddedness of the course syllabus as an academic/disciplinary genre. Devitt, Bawarshi, and Reiff observe that "the concept of discourse community as stable and utopian has been, to some, so seductive that it both conceals the language and the social practices that take place within it and distracts researchers from examining how its internal workings may be recognized and studied" ("Materiality" 541). In "Discursive Conflict in Communities and Classrooms," Trish Roberts-Miller acknowledges a similar degree of concealment inherent in the ways we 
talk about discourse communities. Depictions of such as stable entities notwithstanding, she claims, "discourse of community can obscure the discursive inequalities that really exist among members of that community" (539). Such levels of concealment are often at work in the ways those in composition discuss course syllabi, whether as an extension of the depiction of discourse communities as "stable and utopian" (despite theoretical suggestions to the contrary) or, perhaps more significantly, as a function of the universal and supposedly self-contained localization of discourse community the syllabus itself is assumed to carry.

Amy Devitt points out that the concept of discourse community "emphasizes too heavily the role of discourse in constructing groups and not enough the role of groups in constructing discourse" (Writing Genres 39), simultaneously implying the reciprocity and the distinctiveness inherent in social-discursive relationships. I argue that, just as the simultaneity of genre functions as enabled and enabling, the operationalizing conditions of discourse community structures serve to de-contextualize and re-contextualize the ways in which composition seeks to define, amplify, or outright eliminate this term from its rhetorical vocabulary. More complicated and varied than the containments of "individual" and "social," "hybrid," or even "global" and "local" might suggest, less stable and thoroughly organized than even the most detailed course syllabus might provide, contentions of discourse community operate similarly to earlier explorations visà-vis authority. Donna LeCourt observes how composition's own disciplinary history "reveals a similar attempt to disassociate the discursive from the material, the rhetorical from the real, and, most significantly, the institution from power relations" (25). These disassociations ${ }^{12}$ - whether in discussions of authority and power or of discourse 
community construction - reveal themselves as inadequate, as the composition course syllabus demonstrates the indissolubility of the discursive and the material, the rhetorical (genre) and the real, and abstractions of the institution and tangible power relations within these conceptions. 
${ }^{1}$ See Appendix 5 for the complete email communications between me and Rhetoric and Composition program directors, with institutional and personal identifying information removed.

${ }^{2}$ Following Nystrand's formulation of the term, Kenneth Bruffee refashions discourse community in the early-to-mid-1980s, postulating thought as internalized conversation, writing as "a technologically displaced form of conversation" ("Collaborative Learning" 641), and abnormal discourse, that which generates knowledge, as distinct from normal discourse, that which serves to maintain knowledge.

${ }^{3}$ In "Reality, Consensus, and Reform in the Rhetoric of Composition Teaching," Myers particularly focuses on reality as a process in society which in turn structures that society, begging the question of how we define reality in perceptual and generational terms. Myers discusses the cyclical nature of community (re)construction, arguing that while appeals to individualism are common in American rhetoric (450), reformers of any community come from the establishment itself, historically centering his observations on Open Admissions at CUNY, which in his estimation emerged not from "a paradigm shift in the philosophy of education" but rather from "the political conflicts of New York City in the 1960s" (453).

${ }^{4}$ After I informed him that model syllabi would still be a significant factor in my study, and would not skew my data in any way, he readily passed along my request to the graduate teaching assistants in the program.

${ }^{5}$ Joseph Harris discusses the problematic associations of this perceived tangibility in his "The Idea of Community in the Study of Writing." Essentially, Harris's responses to "recent social views of writirg [which] have also often presented university discourse as almost wholly foreign to our students" (12) point to a dual trap involved in the discussion of academic discourse communities - the assumption of an us/them relationship, as well as the assumption of a monolithic, singular term of "academic discourse community" in and of itself. In his reading of Bartholomae's "Inventing the University," the tension Harris alludes to arises from conflicts between the developing discourse of the student and the presumably fixed discourse of "our community" of teachers. Essentially, if we remove the physical aspect of "community" and replace it with the presumption that we "think much like one another," we fall back on "community" as an empty sentimental term at best, or a manifestation of the group-think Trimbur suggests as a reactionary fear of collaborative learning.

${ }^{6}$ See Kenneth Bruffee's explorations of indirect teaching in "Collaborative Learning and the 'Conversation of Mankind."' See also Nina Schwartz's "Conversations with the Social Text," in which she explores students' conceptions of the inevitability of their own worldviews, what she sees as silence elicited from "what goes without saying" (61), 
assumptions that govern students' lives on such an ingrained level that they go unnoticed, unexplored, unrecognized as values, and are instead relegated to that which just "is."

Schwartz's observations on the "space" of composition also echo Harris's call for a "more specific and material view of community [,] like a city" ("The Idea of Community" 20).

${ }^{7}$ In Fox's "Basic Writing as Cultural Conflict," he depicts the initiation argument of academic discourse communities as exaggerating the stability and coherence of academic discourse itself. His critiques of these initiation arguments coupled with his emphasis on a more complete understanding of disciplinary knowledge's relationships to institutional histories help further a more constitutive depiction of these rhetorics of authenticity.

${ }^{8}$ Altering the vocabularies of discourse community theory acknowledges how an understanding of what Gregory Clark calls "community as practice" ("Rescuing" 71) intertwines with Carolyn Miller's depiction of a rhetorical community as requiring both "identification and division (in Burke's terms)" ("Rhetorical Community" 74).

${ }^{9}$ Vandenberg and Morrow reinvigorate the nature of discourse community pedagogy qua pedagogy, as inherently centered on "restriction, limitation, and constraint" (22), in their "Intertextuality or Intratextuality? Rethinking Discourse Community Pedagogy." While Vandenberg and Morrow never mention genre specifically, their critique of how "discourse community pedagogy tacitly supports the preservation of institutional authority by privileging discursive authority, a gesture that renders a community an oligarchy, an exclusive rather than inclusive construct" (22), suggests that the indeterminate nature of "intertextuality," once appropriated through the parameters of the institution, becomes refocused on preserving borders and boundaries rather than crossing them.

${ }^{10}$ Patricia Bizzell revisits her use of the term "hybrid" as a method of interrogating discourse community structures in her introduction to Alt Dis-Alternative Discourses in the Academy. She explains how she "was attracted to the term hybrid because it upsets the dichotomy established in my earlier work between academic discourse and students' home discourses, and thus implies that discursive and cultural boundaries are more blurred and, perhaps because of that blurring, more easily crossed than had been thought in so-called current-traditional, error-hunting writing instruction" (3, original emphasis ). Bizzell's reflections on her relationship of attraction and repulsion towards a descriptor like "hybrid discourse" reveal the inherent dangers of singularizing that which is intended to pluralize notions of discourse community.

${ }^{11}$ Russell maintains that the development of the modern American university in the 1870 s signaled the end of anything remotely resembling a single, unified academic discourse community. He observes that, historically, "the term academic discourse community has powerful spiritual and political connotations, but today academia is a discourse community only in a context so broad as to have little meaning" (21-22, original emphasis), particularly considering developments of "tightly knit, turf-conscious disciplines and departments" (22). Perhaps what continues to pull composition in 
directions of attempting to define a concept like academic discourse community is its own status as a not so tightly knit, not so explicitly turf-conscious discipline.

${ }^{12}$ In terms of finding signs of the local in course descriptions as opposed to individual composition course syllabi, I offer up the current (as of Spring 2010) course description of English 101 as offered in the online course catalog at the University of Louisville: "Prerequisite: Meet admission requirements of the University of Louisville. Students engage in critical thinking and writing by developing their writing processes and producing finished prose. Required writing consists of multiple drafts of 4-6 papers of varying lengths." Such a course description is deliberately designed to reflect both the specificity of the institution, particularly in terms of laying out prerequisites for attending the course, and the imprecision of terms inherently linked to a general idea of a writing course, leaving open to interpretation terms like "critical thinking," "writing processes," and even what constitutes "finished prose." These struggles between specificity and openness parallel LeCourt's observations on disassociations, particularly those between the discursive and the material; in this case, the course description (more specifically, the institution responsible for its generation) inherently struggles to separate the relativity of qualifications from the concrete quantities representative of the course (here, the specific number of papers required, leaving the path toward that requirement open to the individual instructor). 


\title{
CHAPTER IV
}

\section{THE COMPOSITION COURSE SYLLABUS AS INSTITUTIONAL-PERSONAL}

\section{REPRESENTATIONS OF TEACHER IDENTITY CONSTRUCTIONS}

\begin{abstract}
After all, every building covers only a finite amount of space, is created of humble materials, and will eventually fall - facts that we usually pay attention to only during construction, renovation, and natural disaster; the rest of the time our attention is drawn to how to live within these buildings, which are taken for granted. Charles Bazerman, Constructing Experience (158)
\end{abstract}

In my last chapter, I explored ways in which the simultaneity of genre as enabled and enabling play out in the composition course syllabus vis-à-vis institutional structures of various composition programs I encountered in collecting data for my research study. These "research narratives," in which different composition program directors expressed varying degrees of reception of my insider and outsider disciplinary and institutional statuses, reveal the extent to which definitions and contentions of discourse community structures inherently argue for the inseparability of the discursive and the material conditions of the discipline of composition. In short, such analysis sheds light on the ways power and genre reveal their interconnectivity, through the ways in which those operating within the discipline both conceive of and act upon their own notions of discourse communities. Through my own encounters with these developments of "discourse community," I make the claim that, while the binary opposition of "the individual" to "the social" remains inherently problematic, such oppositional recourses remain operative in the ways in which entering graduate student instructors of 
composition - those most at stake in composing themselves into the discipline as teachers - disclose versions of themselves in their course syllabi. Thus, through my interactions with various composition program directors, and through negotiations of my own multiple subject positions, I further argue that such revelations indicate the activity of the course syllabus as a participatory document in the processes of creating teacher identities.

In this chapter, I will explore in detail the syllabi I received from participating graduate student instructors of composition at various institutions across the country, in order to more thoroughly analyze how these texts tell stories of the embeddedness of ideological structures of power, authority, and multifaceted understandings of the operationalizing conditions of the course syllabus as a genre of academic writing. After an overview of the data, in which I explore some of the discursive and material conditions under which I received these syllabi, I characterize four key moves made in these course syllabi. First, I examine the ways residual conceptions of power-as-property (as explored in further detail in my second chapter) reveal themselves through the relationships entering graduate student teachers of composition maintain with their own understandings of authority in the classroom. Second, I explore the frequency with which these graduate student teachers tend to employ what I will later call a rhetorical vocabulary of conditionality, most often through phrases suggesting sets of consequences, implying a specific rhetorical move in the genre of the course syllabus in negotiations with constructions of newly-emerging teacher identities. Thirdly, I discuss various gestures towards the establishment of a sense of community (both broadly and narrowly conceived), through and beyond the inclusion of the pronoun "we" as an oftenthinly-disguised version of "you," indicating the overlap between the communal and the 
directive. Finally, I examine the ways in which multiple versions of broader institutional and more course-specific rules and regulations often result in a kind of "deferment" of authority, rather than a deflection. Through a more careful analysis of how these four specific sets of moves operate within and against each other, we can begin to see how the multiplicity of the genre of the course syllabus both acknowledges and threatens to subvert the multiple stakeholder positions occupied by graduate student instructors of composition.

The syllabi provided for the study in this dissertation will allow me to formulate responses to the following questions: How do instructors' understandings and conceptions of genres (of academic discourse) as sets of forms and structures, and genre as responses to sets of social and rhetorical actions, affect ways in which they compose and conceive of their course syllabi? To what extent are teacher identity representations complicated and revealed through conceptions of community within the institutional space in which they are performed? How, under what circumstances, and to what different degrees does the course syllabus operate writhin and against this institutional space? How do composition instructors use their course syllabi to establish or complicate their conceptions of authority and community? To what degrees do instructors acknowledge, embrace, and attempt to diffuse institutional authority in the establishment of "community" in the classroom, and how is this establishment textually represented through the course syllabus?

In examining syllabi in textually-documented and institutionally-discussed formats, I approach two interrelated methods as parts of a single study, allowing for a broader understanding of composition's interaction with conceptions of the course 
syllabus on several levels, and within multiple discursive frameworks. Through this study for my dissertation, I will further our discipline's understanding of what different types of work the syllabus does in composition, and the kinds of work teachers of composition make the syllabus do. This study explores how respondents think about their course syllabi in deference to conceptions of their authority within their institution, as participants in the discipline, and as a particular genre of academic discourse. The study for this dissertation helps develop and contribute to a more widespread overview of how graduate student composition instructors (of varying levels within the discipline) conceive of their course syllabi in both personal and institutional terms.

\section{General Overview of Data}

The first part of this study consists of results from a request for course syllabi of first-year writing courses from graduate student composition instructors at Rhetoric and Composition programs from a wide range of geographical and institutional perspectives, and from public universities which have at least a Masters degree program in Rhetoric and/or Composition. The range and scope of the first part of this study focuses on analyzing sample syllabi elicited from graduate student teachers of composition. This

element of the study examines the specific interactions of authority, understandings of genre, and conceptions of community, as expressed by graduate teaching assistants.

These points of analysis comment on how those newer to the discipline of composition (and thus newer to constructions of teacher identity) construct and present their syllabi in relation to both their own personal teaching styles and to the institution. This part of the 
study explores textual representations of these teacher identity factors as revealed through rhetorical moves and pragmatics performed in these documents themselves.

Through an analysis of patterns and dissimilarities in these syllabi, this study investigates how graduate student instructors depict their syllabi on both personal and institutional levels. Through this collection of first-year writing/composition course syllabi, my goal has been to gather information pertinent both to the construction of the syllabus and its placement within the discipline and individual institutions of higher education. The study for this dissertation took place from August 2008 to January 2009, and through the course of this study, I received a total of 43 course syllabi from 25 different respondents enrolled in graduate work (at the time of this study) at a total of seven different institutions which offer at least a Masters degree in Rhetoric and/or Composition. Of the 43 total submissions, 40 represent course syllabi from first-year writing courses (variously designated according to institutional protocol), while the three other submissions include the syllabus of an introductory creative writing course, as well as one syllabus constructed for an introductory graduate-level English studies course along with an accompanying critical essay concerning its construction. Of the 25 individual participants in this study, 19 were PhD students at the time of their submission of their course syllabi, and six were Masters students. Their college-level teaching experience ranged from less than three months (the beginning of one's first year of teaching) to more than ten years at various institutions.

This syllabus request (see Appendix 6) has functioned as a dual element of this study. First, asking individual graduate student teaching assistants for course syllabi has granted me the opportunity to cover a wide range of schools with differing composition 
programs and graduate student populations in a relatively short amount of time. Second, I amended this syllabus request with a brief set of follow-up questions (see Appendix 7), which I sent to individual graduate student teaching assistants from each institution, so that they might better characterize their program or institution's theoretical frameworks guiding their understandings of their course syllabi, how they see the syllabus operating within the discipline of composition as well as within their individual institutions. Of the 25 individual study participants who submitted sample course syllabi, only 13 submitted responses to my follow-up questions - 10 graduate teaching assistants in doctoral programs and three in Masters programs.

I will discuss some of my observations regarding the results of this survey in the next chapter, and although the results for this portion of the study are admittedly limited, and include elements I wish to expand for further analysis beyond this dissertation, such a questionnaire does grant me the opportunity to analyze various responses to the institutional guidelines and requirements of the material and ideological conditions of syllabus production and submission, as well as the chance to construct preliminary characterizations of particular boilerplate language (those phrases required to be included by the department or institution) in operation. In turn, since 14 of the 25 individual participants in this study submitted more than one syllabus, these multiple submissions (from different courses taught at the same institution, or from courses taught at different institutions altogether) allow me to explore how this boilerplate language (both institutionally- and self-imposed) affects these instructors' layering of teacherly identities. This data provides a broad level of analysis, allowing me the opportunity to examine and 
explore conceptions and depictions of the syllabus as a representative institutional, personal, and pedagogical document.

\section{Acts of Designation and "Reserving the Right" - Residual Conceptions of Power-as-Property?}

As a method of opening these composition course syllabi towards a more rhetorical-pragmatic conversation, I first wish to explore these texts in terms of the ways residual associations of power appear to function as near-physical transferrable property. In Chapter Two, I discuss how composition's incongruous disciplinary status lends itself to a more thorough exploration of the ways in which conceptions of power and authority affect how we talk about, interrogate, and justify our actions in the writing classroom. Mary Boland discusses the "disciplinary apparatus" of composition "that first defined our work as predisciplinary and therefore the 'property' of everyone else (except, perhaps, those who do the work of teaching writing)" (33). An initial examination of these sample course syllabi reveals the extent to which graduate student teachers of composition arguably on the front lines among those who "do the work of teaching writing" - seem to attempt reclamation of this disciplinary property through their often-projected variations of "power-as-property," seeking to establish a sense of newly-developing teacherly authority. While Jennifer Gore, in "What We Can Do For You! What Can 'We' Do For 'You'? Struggling Over Empowerment in Critical and Feminist Pedagogy," acknowledges that a more careful and deliberate distinction between "power-as-property" and "power as exercised" helps reposition conceptions of power and authority in an immediately contextual and practice-related framework, a significant portion of the syllabi I received 
displayed variations of references to a teacher-centered authority - more specifically, to a desire to establish or maintain the explicit ownership of that authority.

Of the 40 sample syllabi representing those from first-year writing courses, I encountered 24 syllabi that engaged in some variation of an establishment or maintenance of authority as a condition of ownership. One of the essential challenges throughout the course of writing this dissertation has been to clarify my own reactions and judgments, operating to a degree in each reading of each syllabus I received from other graduate student instructors, while simultaneously battling against the substitution of one question ("how would I rework this syllabus if I were the instructor of record?") for the other, more essential inquiry - what are these syllabi doing, or how can I interpret what they are doing in deference to the teacherly identities being portrayed within these texts? So, rather than evaluating each syllabus individually according to what would ultimately amount to a rubric of my own pedagogical styles, preferences, and aggregate experiences (filtered through my experiences with the praxis of composition), I wish instead to examine trends and patterns associated with this sample of course syllabi from relatively inexperienced teachers of composition, new(er) to the discipline. Of course, a presentation of each of these 24 syllabi exhibiting varying degrees of explicit (oftentimes depicted as inherent) claims to authority as a simple exercise in counting the number of occurrences is not my intent. Through an analysis of some of the rhetorical patterns and associations made in these various claims to authority, I hope better to interrogate the composition course syllabus as a "material artifact of academic discourse" (LeCourt 39), particularly in terms of how residual constructions of power-as-property often mask authority's epistemological frameworks. 
As the subtitle of this section suggests, one of the ways conceptions of power-asproperty reveal themselves are through what I determine to be acts of designation, or more specifically, nomination in its more literal interpretation - acts of naming, and the degree to which these syllabi promote these acts of naming as self-evident (again recalling a doxa in the Bourdieuian sense). A particularly noteworthy syllabus stands out among the others in this regard. While making an effort to establish a definition of teacher-student relationship that includes how "[p]art of becoming a good writer is learning to appreciate the ideas and criticisms of others," together with the recognition that "in this course our purpose is to come together as a writing community," the instructor follows up such efforts with a what I would classify as a definitional directive. Among others in a list labeled "Top 10 Teacher Pet Peeves to Avoid," the fourth is "Excuses. About anything. You think it's a reason. I think it's an excuse." In this case, the decision to assemble a series of potential disruptions or interferences appears not in the context of the chance to encounter conceptions of criticism or as obstacles to the formation and maintenance of a writing community, but instead as an opportunity, particularly as displayed in list form, to derive a more us-them relationship between teacher and student. Subsequently, this instructor reflects a sense of ownership of the definition of excuses in this regard, as the instructor's act of naming gets substituted for the students' (or at least the predetermined expectations of the students'). This substitution, in turn, collapses any potential differential discussions about the nature of these terms, and what might qualify as a reason rather than an excuse. In this example, this syllabus demonstrates the potent nature of power-as-property as reflected through the conception of definitional ownership of sorts. In this sense, perceptions of the ownership 
of the definition of "excuse," to the point of announcing a sublimation of a different-butrelated reason, are directly related to the instructor's perceptions of authority's function in the composition classroom.

Other acts of designation in the syllabi I collected for this study are considerably more understated, yet these conceptions of authority in terms of power-as-property often seem at odds with a desire to create a form of community in the classroom, an aspect I will discuss at length later in this chapter. While one instructor begins the syllabus with a rather informal and friendly "Hello class," and proceeds to inform students that they "will have a great deal of intellectual freedom as far as essay topics are concerned," this desire for community creation becomes subverted by a similarly impressed desire to create and maintain (or "own," if you will) an authority in the classroom. Shortly after this declaration concerning the amount of intellectual freedom in this class - following descriptions of course management software protocols, workshops, and a list of major project due throughout the term - the instructor writes: "For the 'open' papers, students will be expected to formulate a research proposal in advance of the project's due date (see semester calendar). These proposals will be shared with the class, discussed and submitted to me for final approval. Any paper written on an unapproved topic will be considered incomplete." Going so far as to place the proverbial quote marks around "open," even the instructor acknowledges that the intellectual freedom referred to earlier in the syllabus represents only a particular version of intellectual freedom, one over which the instructor remains in the position to grant "final approval," to the extent that any topic circumventing this stage in the approval process will subsequently be designated "incomplete." Although the gesture of relinquishing authority through 
concepts of intellectual freedom of course appears laudable, it cannot be ignored that the instructor remains the focal point, the source of that freedom, and the designator of its degree of openness.

Once more, let me take a step back from this analysis to clarify my intentions. I do not in any way mean to irnply that the above instructors are making "mistakes" when it comes to the composition of their course syllabi. In Chapter Two, I make extensive use of my own past course syllabi to interrogate my pedagogical choices in my various identity representations, and I do so not only as a means of self-deprecation. I only intend to demonstrate through the above examples how residual conceptions of power and authority as property, that which can be owned by instructors and thus dispersed to the students, still function in the composition course syllabus despite our best efforts to "disrupt the master-teacher-subordinate-student complex" (Giuliano 394). I mean to suggest as well that these residual implications reveal themselves more readily through the composition course syllabi of graduate teaching assistants, as their multiple stakeholder positions (including but not limited to their simultaneous positions as teachers and as students) can result in a more directive, if not entirely intentional, conception of authority. The point at this stage is to offer the syllabus as an ideologicaltextual springboard so that we in the discipline of composition, as Jane Greer comments in "Refiguring Authorship, Ownership, and Textual Commodities," might "highlight the ways in which writing and reading are activities that give rise to relationships, rather than property rights" (622). The essential problematic is, of course, how often these two pedagogical conceptions of authority coincide. 
Perceptions of authority as a function of ownership often appear in the ways in which some of the graduate student instructors construct their versions of student-teacher relationships. Although only apparent in two of the samples I collected, one of the more interesting constructions is as an employee/employer relationship. In a double-layered act of designation, one instructor writes, "If you absolutely must be absent, I expect the same respect that you provide an employer," following this comparison later in the syllabus by noting, "I have provided you with a Get-out-of-Deadline Free Pass. To redeem this pass, you must contact me before the due date, so we can arrange an appointment to discuss your situation." The dual designations in play in this case both function as operatives of the remainder of authority as a condition of ownership. While I will discuss the prevalence and implications of the employer/employee relationship in a moment, in conjunction with another syllabus I received, I wish to focus for just a minute on the naming of the "Get-out-of-Deadline Free Pass." Most intriguing in this case is the use of this naming to direct the focus of redemption (operating within multiple definitional frameworks here) towards the teacher, particularly the phrase, "I have provided you with," as well as the more formal capitalizations. Of course, I realize the extent to which this naming expresses a degree of humor and lightheartedness in the course syllabus, an aspect of composition which can help put both students and newer instructors of composition at ease, especially when seeking to establish relationships in the first few days of a new term. At the same time, it is difficult to ignore the position it places on, and the weight it seems to give to, teacher-centered authority.

As an extension of these kinds of representations of teacher-centered authority, one instructor in particular elaborates the employer/employee relationship, explaining: 
"Think of college as one of your jobs. Would you like for your cell phone to ring during a board meeting? Would you text message while the boss is talking to employees? Would you want the boss to walk by while you are sleeping in your office? Would it look good if you arrived at work consistently late? You'd be fired, and you wouldn't move up in your career. Consider this for your college courses." Unlike the first example in this case, in which the instructor explicitly identifies with an employer, this instructor seeks to expand this relationship through the broader implications and expectations associated with a more general understanding of the responsibilities of a college education and an individual student's place within this framework. Later in the syllabus, while discussing grading philosophies, the instructor notes, "Please remember that you earn your grade in this class. Your parents' financial contributions to the university, your status as a star athlete, the grades you received in high school, or your desire to make it into law or medical school are not sufficient reasons for me to give you a good grade." While this air of democratization appears to place students' grades firmly under the pretext of their responsibilities and efforts, the word choice here is intriguing, particularly the superimposition of "earn," "receive," and finally "give" in terms of the location of the grades themselves. This statement does more than assure students. It becomes difficult to deny the teacher as the source, in a double play on "establishment," in this case.

Further, while the comparison of teacher-as-employer might seem to resonate more with working-class students, with those students maintaining one (or more than one) job while going to school, it is my estimation that such a comparison reveals residual understandings of power-as-property, in what Anis Bawarshi calls "the habitat within which students and teachers rhetorically enact their situated relations, 
subjectivities, and activities" (Genre 125). I confess that I often use the "college is one of your jobs" description, particularly when I teach introductory freshman composition courses, whether in the syllabus or during the first few days of class; however, I feel the distinction between "college-as-job" and "teacher-as-employer" lies in the ways in which we as instructors of composition are more effectively able to negotiate multiplicities and singularities in relation to identity constructions and performances thereof. Such a distinction (between "college-as-job" and "teacher-as-employer") centers on whether the instructor can use these comparisons as means of directing opportunities to discuss how students and teachers negotiate various facets of their identities in various social and academic environments, or whether these comparisons signal a more rigid adherence to "scripted" performances.

In this specific case, I am further reminded of explorations I made in Chapter One concerning the treatment of the course syllabus as an object rather than as a subject of composition as an academic discipline, particularly as these conceptions of power-asproperty demonstrate a reciprocal relationship between structures of teacher identity and the course syllabi these entering graduate student teachers of composition construct. Further, this relationship suggests ties to my earlier claims regarding the extent to which the embeddedness of a genre can operate in ways that mask its own depictions of authority. Momentarily, allow me the opportunity to revisit Amy Devitt's Writing Genres, and in this opportunity, I hope to further the encounter of the challenge the course syllabus represents to conceptions of both authority and genre. Discussing the multifaceted nature of genre representations through various social environments (both practical and professional academic workplaces among them), Devitt summarizes six 
"principles" of genre, two of which I argue reveal themselves in a state of contradiction in examining these composition course syllabi obtained for my study.

Devitt argues that "genres function for groups, though those functions are typically multiple and ideological as well as situational," observing at the same time that "a genre reflects, constructs, and reinforces the values, epistemology, and power relationships of the group from which it developed and for which it functions" (Writing Genres 63-64). The contradiction of the course syllabus comes into play between the plural and the singular formation of the "group" in Devitt's analysis. On the one hand, these acts of designation delineated above - including the ownership of power and authority in the classroom, naming as an explicit function of control (like a "Get-out-ofDeadline Free Pass), and equations of an employer/employee relationship - suggest Devitt's conception of multiple, ideological, and situational conditions of groups vis-à-vis conceptions of genres. On the other hand, the ownership of power and authority as conceived in terms of property reveals how the reflection, construction, and reinforcement at work appear to be those of a singular group, "from which it [the genre] developed and for which it [the genre] functions." In the case of the course syllabus, the text itself operates in the contradiction between the plural groups (at bare minimum, but not limited to, broader generalizations of teachers and students) and the singular group of teacher-as-sole-author, the owner of authority. This contradiction in the intersections between conceptions of authority and conceptions of genre mirror those between the fundamentalistic and relativistic tendencies of narrative I have explored in Chapter One, particularly in the ways in which struggles between the establishment of both a dominant 
narrative and a framework for developing multiple interpretive organizing experiences emphasize the challenges of composing the text of the course syllabus in the first place.

Finally for this section of my analysis, I wish to interrogate the usage of "reserving the right" in the composition course syllabi collected for this study. This particular phrase appears most often in the samples I have from graduate student instructors at one particular institution, which requires instructors to include in their syllabi the phrase, "The instructor has the right to make changes to the course schedule/syllabus if necessary" (see Appendix 8), although the majority of instructors' syllabi obtained for this study from this institution substitute a version of the phrase "reserves the right" instead. Of the 21 composition course syllabi I received from graduate student instructors at this particular university, only one-third maintain the original phrasing of the required language as listed on the program's website; two-thirds alter the phrase to a variation of "I reserve the right to make changes." Although perhaps a more minor aspect of the construction, dissemination, and delivery of the course syllabus, the distinction between "having a right" and "reserving a right" offers suggestions as to how to read graduate student instructors' ownership of these texts, as well as their placements of authority within them. Momentarily sidestepping the issue of whether the instructor chooses to refer to him- or herself in the third person or to use the first-person singular pronoun (an issue I will discuss to some degree later in this chapter), I claim that while "the instructor has the right" offers a more explicit proposition of ownership, such ownership appears more static than the use of the variation "the instructor reserves the right." While both phrases indicate a certain degree or at least an acknowledgement of self-indemnification for those force majeure (to borrow from the 
contractual) associated with the practice of composition in a real-world classroom and university-sanctioned environment, the former appears more as a statement of fact, independent of any suggestion of usage, while the latter appears more as a statement of potential action, a right to be exercised (or not) at the instructor's discretion.

The conditions of "reserving the right" are most intriguing in the context of exploring how entering graduate student instructors of composition negotiate their own sense of authority in the classroom. These instances reveal themselves more explicitly in those uses of "reserving the right" that fall outside (or at least not entirely inside) variations of the more boilerplate language associated with versions of these "right to make changes" statements. In one instance, an instructor included two versions of this "right to make changes" statement - one referring to "the instructor" and one referring to "I" - one right after the other, perhaps inadvertently commenting on the nature of how the syllabus operates as a pastiche genre of boilerplate, copy-paste, and recycling past versions of these types of texts. Other modifications to this "right to make changes" statement include the instructor who added the condition "to make our lives easier" to the traditional reasons one might have to modify the current form of the syllabus or daily course schedule, indicating both a degree of levity as well as an attempt to suggest the boundaries of a limited community ("our lives") within the confines of a mutual desire for an uncomplicated course. Another instructor modified the "right to make changes" clause with the condition, "so long as it does not conflict with [university] policy," indicating the extent to which policies established by an individual department need to coincide to an extent with those established by the larger structure of the institution. 
Beyond these instances, however, the use of the phrase "reserve the right" most often surfaces in the composition course syllabi collected for this study in the context of potential punitive actions. Specifically, I refer to the syllabus that warns students, "if you answer a phone, text message, or use other media during class, I will mark you as absent for that day and reserve the right to ask you to leave class," as well as a number of different syllabi (from at least three different institutions) that note how, should an instance of plagiarism arise, the instructor "reserves the right to grant you [the student] a failure" for the assignment or course as the situation warrants. Although neither the deeply contextual nature of acts of plagiarism and institutional/departmental responses to it nor an exhaustive case-by-case examination of individual word choices are my intentions in this dissertation, I do argue that the presence of "reserving the right" and its variations functions as another act of designation in the treatment of power and authority in the composition course syllabus. Once more echoing Xin Lu Gale's discussions of the dual nature of the teacher's role in the classroom as an instrument of conservation and transformation of the dominant (institutional) culture (Teachers 36), these acts of designation in these course syllabi demonstrate the extent to which entering graduate student teachers of composition struggle to "name" the power they have been granted through the institution, as well as their (un)easiness with residual conceptions of the ownership of this power, as a borderline-tangible property.

\section{Allowance and Authorization as Conditions of Generic Function}

In terms of exploring the nature of power-as-property as an identity-centered function of graduate student teachers of composition through the course of collecting data 
for my study, and through the process of writing this dissertation, I have discovered the extent to which the concept of "residuals" plays into readings of course syllabi, themselves composed of transitional, operationalizing genres. In Chapter Two, I argue that past conceptions of genre - including limitations of genre practiced and defined as a limited mode of classification, as well as the relationships between conceptions of genre and of intertextuality - affect current conceptions of genre, stemming from Catherine Schryer, as a form of social action. Recalling one of Bawarshi's central definitions of genre as a set of "conceptual realms within which individuals recognize and experience situations at the same time as they are the rhetorical instruments by and through which individuals participate within and enact situations" (Genre 113), I struggled to negotiate explorations, examinations, and analyses of these syllabi without dismissing every detail of textual or rhetorical nuance as an element specific to this genre of academic writing. I also grappled with how best to maintain Bawarshi's elements of the specific here-andnow of genre with the effects of antecedent genres on our conceptions of current iterations ${ }^{1}$. The genre of the course syllabus - specifically as constructed and disseminated through the multiple stakeholder positions operational within identities of graduate student instructors of composition - falls in the spaces between "now" and "then," even if some of the graduate students involved in my study had never taught before, implying a function of genre both in the acting and in the reading/writing of a given text, just as I have claimed in Chapter One that the course syllabus operates as a student's initial and self-defined college-level reading assignment.

In order to move into the next stage of my study, and to engage these syllabi on the level(s) of genre, I need to address the generic multiplicity called for in responses to 
Schryer's conception of genre as that which can only be "stabilized-for-now." In "A Closer Look at the 'Fuzzy' Concept of Genre," Catherine Matsuo argues for a "recalibration of emphasis" on genre (239), so that we better understand how "the very act of explaining 'freezes' something that by its very nature is constantly evolving" (241). Stressing the need to "abandon the Western reflex of representing issues in terms of antagonistic dualities," Matsuo advocates a perception of genre embracing "the dynamic and the stable $[\ldots]$, process and product; and the actions of the individual within the structure of society and institutions" (241). In this section, as part of a method for examining the genre of the course syllabus as encompassing these dualities, I explore the frequency with which the graduate student teachers who submitted syllabi for this study avail themselves of what I call a rhetorical vocabulary of conditionality. These uses of conditional language (including but not limited to uses of "may," "might," and other individual terms suggesting possibilities over certainties) function in ways that announce the syllabus as a genre of academic writing, an "operationalizing" one which, as I have noted in Chapter Two, helps us see this text as both enabled and enabling, creating and preserving boundaries, through forms of temporal de- and re-contextualization.

This rhetorical vocabulary of the conditional gets negotiated between two contrary yet interrelated purposes - responding to the general unpredictability of day-today events in any given course in a university environment, and responding to a similar unpredictability of how one's authority (especially vis-à-vis establishments of policies and consequences) should be conducted, expressed, and perceived in the classroom. In both of these cases, examining these uses of conditional language in these composition course syllabi helps reveal both conditions of allowance, in terms of making 
considerations for possibilities or of modifying circumstances, as well as conditions of authorization, in terms of the interactions between the instructor and institutional sanctions, and the extent to which these struggles reveal the intertextual relationships between conceptions of authority and genre.

In Chapter One, I made the claim that the sequentiality of the course syllabus represents, to a significant extent, the canonicality of its form, and that an understanding of the syllabus as a narrative text suggests the interconnectivity between instructors' perceptions of chronology, emphasis, and control. Of course, it is within this narrative framework that we encounter the equally inherent incompleteness of the "story" tentatively told through our course syllabi. Instructors understandably negotiate this sense of incompleteness by engaging in this rhetorically conditional vocabulary, and the syllabi collected for this study bear out a scale of this vocabulary in this regard. This scale ranges from the more expansive (signaling a placement of the individual course and students enrolled within larger constructions of "the university," or of "college life" as a general concept) to the more course-specific (expressing a degree of uncertainty as to how the entirety of the course will "work out"). In the first instance, graduate student instructors who submitted syllabi were more likely to connect their individual iteration of the course to its assigned title. One instructor writes, "In the course of WAC 101, students may encounter materials that differ from and perhaps challenge their understanding of reality, their ideas, and their beliefs." Such a statement suggests that the course itself - and not merely this particular instructor's version of the course - might, and, as suggested through the instructor's tone here, hopefully will, present essential ideological confrontations to students, confrontations that appear part of the intrinsic nature of the course itself. 
Another instructor announces the potentially combative nature of student expectations, explaining, "If you prefer or learn better from traditional classes, this may not be the most helpful class for you." Implying that students have enough experience with both "traditional" and "non-traditional" courses to recognize a preference, although these terms are not explained or defined in this statement, this example appears to reiterate the complexities between conceptions of anxiety-reduction and questionreduction that I made mention of in Chapter One. To the extent that this statement operates as one of pre-emptive admonishment, statements of which I have admitted to employing in my own syllabi earlier in Chapter Two, this warning also operates as a condition of the genre of the course syllabus. Since this instructor employs the genre of the course syllabus in order to classify the course in general as something labeled nontraditional, this embeddedness of the "surface genre" (the syllabus as a common academic text) demonstrates the interconnectivity of classification ("non/traditional"), preservation (of the notion, perhaps, of challenge), and regulation (determinations of who will and will not find the class "helpful").

Further instances of these more expansive uses of conditional language focus more explicitly on uncertainties within a specific course section, and how it will play out through the academic term. Such instances are far more common than those I have previously discussed, and it is this very commonality that signals the genre of the course syllabus as distinctive in its awareness of itself, within the confines of textual classification, as a document responding to the duality of conservation and transformation, simultaneously preserving a record of the academic term and transformatively participating in the creation of this term. This very level of self- 
awareness reveals itself through these uses of conditional vocabulary. Many of these course syllabi make allowances for temporal limitations and uncertainties associated with performing a class in an academic term, including those that announce that "(there may be assignments or other changes not listed on the syllabus)," "additional readings may be posted," and that part of a student's grade will come from "readings, which you may have to write responses about" (all emphasis mine). In these instances, I might be too tempted to suggest that these uses of the conditional simply surface more in the syllabi produced by newer instructors, or at least as a result of these instructors' self-consciousness towards their neophyte status; however, this overlooks a key component of the course syllabus as a genre of academic writing. Recalling Barthes' austere depiction of a teacher in "Writers, Intellectuals, Teachers" as one who "puts out a discourse, never knowing how that discourse is received" (194), and his notion in $S / Z$ of texts "controlled by a principle of non-contradiction" (156), these instances of the conditional appear to recognize both the presence of this classification and the need to combat it by taking advantage of the multiple layers of performance embedded in this genre.

To this extent, other graduate teaching assistants employ the conditional in a more definitional context, including one that notes, "[h]omework includes any writing assignments beyond the four major papers. This may include more informal responses and reflections, online discussions, reading quizzes, and paperwork from peer workshops." In this instance, options for defining what qualifies as "homework" in this course are deliberately and consciously left open in what I argue represents an acknowledgement of how this genre must resist "ideal, prefabricated, homological audiences" (Eberly 175). Simultaneously, since these definitions are left open by the 
instructor, such conditional language in this case also indicates the extent to which these definitions and qualifications appear to fall under the purview of the instructor's conception of his or her authority in the classroom through the composition of his or her course syllabus. In clarifying one aspect of coursework, "extra credit opportunities" which "may be offered for arranged missed classes (before class is missed)," another instructor's use of the conditional demonstrates how the conditional itself and the authoritative are not mutually exclusive, making allowances for the possibility of extra credit work only if the other predetermined criteria of pre-arrangement is met. Of course, none of these uses of this rhetorically conditional vocabulary is meant to be taken as unusual, or an out-of-bounds experience for any entering graduate student teacher. The significance of these kinds of conditionals is that they are commonplace as a function of the course syllabus as an academic genre. Elena Afros and Catherine Schryer explore the genre of the syllabus as one that "offers instructors a constellation of rhetorical strategies to describe the course, its goals and objectives, its structure and its correlation with other courses within the program, classroom, and institutional policies as well as general logistical and procedural information" (2). Taken together with their understanding of the "flexibility and plasticity of the genre of the syllabus" (7), we can see the syllabus as a genre performing a multitude of often conflicting and sometimes contradictory functions. The uses of the conditional in these cases reflects an admission of, and in some cases a reliance on, allowances made by and through this "plastic" genre.

While the above instances reflect a more commonplace response to perceived tensions between a genre-on-paper and a genre-in-performance - the more commonly understood idea that what is scheduled to happen in the text of the course syllabus might 
not occur as such through the performance of the class in real time - other instructors who submitted syllabi for this study appear to take advantage of this kind of conditional vocabulary as a mode of authorization. This vocabulary reflects both a more explicit struggle with their own senses of authority and their hesitations towards course-specific policy creation. In more than a quarter of the syllabi submitted, instructors exhibited at least one significant moment of this conditional authorization, defined as affecting course policy decisions. These instances include references to provisional consequences associated with accusations of plagiarism, as I have already discussed in this chapter, as well as more conditional statements such as "your case may be reported to the College of Arts and Sciences," which also often appears as a part of plagiarism statements. In the examinations that follow, the majority of the cases where instructors employed this kind of conditional language involved more course-specific (rather than department- or university-mandated) policies and sets of consequences, or expressions of the ambiguities therein.

Nearly all of these uses of the conditional are associated with issues of attendance or penalties for coursework submitted late. Most common are instances such as this example, where an instructor notes that "more than nine absences may result in failure of this course," followed almost immediately by the provision that "this penalty may be waived." This functions as a case of dual-conditionality - this penalty may or may not be enforced, and if it is, it may in fact be waived. The desire (or presumed need) to represent oneself as an authoritarian, in the pejorative definition of the term as is most often connected to absolutist attendance policies such as these, appears to encounter the equally weighted notion that attendance might just be as contextually recognized as plagiarism. 
This desire also encounters an acknowledgement of the multiple audiences in play concerning the genre of the course syllabus. The provisional language functions here as an operation of the genre itself, serving in a more simplified way "the class" as a specific unit, while also striving to recognize the individual cases that may or may not make up this unit.

This struggle, expressed as imprecision, reveals itself to varying degrees as these graduate student instructors of composition write themselves into their course syllabi. Another instructor admits that "more than four absences will complicate your grade," following this assurance of "complication" with the more ambiguous observation that these same four absences "may constitute failure of the course." One essential point I am making in examining these cases is that the ways in which entering graduate student instructors of composition recognize the spatiotemporal limitations of the course syllabus as a genre of academic text tend to affect how they construct their authority in the classroom. In the case of the instructor who writes, "I might excuse up to 3 pre-informed and/or reasonable absences without penalty," the statement of provisional acceptance itself acknowledges that discussions of what qualifies as "pre-informed" (notification one class day before the absence? one week?) or "reasonable" (death in the family? car accident?) are not only helpful but required for this particular policy to be implemented. Also required is an understanding that the limited space of the syllabus cannot possibly address each individual case for each student, and that the genre must leave these terms open, or conditional, for later discussions through the performance of the class. In a rare case regarding the use of conditional language in discussions of attendance policies in the course syllabus, one graduate student instructor makes a more explicit reference to the 
contextuality of presence in the classroom, noting, "depending on the circumstances, I might excuse up to six absences."

While I am certainly not arguing for airtight attendance policies (since even the most strict, authoritarian, all-or-nothing policies I have ever included as part of my course syllabus have all inherently been subject to the contextual circumstances of the individual student in a particular course, at a particular time, at a particular institution), I am arguing that these uses of the conditional under such circumstances signal an intrinsic relationship between conceptions of authority and conceptions of genre. One instructor manages to balance this most effectively, noting, "If you reach four or more absences, you'll have to visit me during office hours so that we can come up with a plan to get you back on track. That might entail makeup work, extended deadlines, etc. It just depends on what your needs are." Apart from being the only instructor who submitted a syllabus to this study who phrased the attendance policy as an "if"-centered possibility (meaning the entire issue of attendance might in fact not become an issue at all), this individual manages to position the declaration of a requirement as an element of teacherly authority ("you'll have to visit me") with a focus on the individual student's needs, using the conditional in a limited fashion to refer to possibilities of those needs.

I encountered many other instances of the conditional in suggesting penalties beyond attendance, including the penalty of being denied further presence in the classroom. Common enough were warnings such as, "No cell phones or pagers should be used in class, nor should they be openly displayed. If yours rings during class, or if you are using class time for text-messaging or game-playing, you may be asked to leave," or "You are absolutely expected to bring a rough draft to the conference - you may be asked 
to leave, and receive a ' 0 ' participation grade for the peer review, if you arrive with no written draft." What is most intriguing about these examples is that the absolute requirement comes into direct contact with the conditional consequence. While examples of the conditional explored earlier in this section make certain allowances for temporal limitations in a given academic term, these conflicts explored in these cases demonstrate struggles of authorization as conditions of the syllabus-as-genre, the intertextual relationship between conceptions of authority and of genre, through the instructors' various struggles between definition and reception, between the genre of the syllabus as it appears on paper and the genre as it becomes performed in the real-time environment of the classroom.

\section{Gesturing Towards "Community" - Beyond the "We"}

These struggles and sets of interrelationships represent, of course, a signature challenge and limitation of my dissertation. Early in Chapter One, in developing both formal and operational definitional distinctions between the course syllabus and a more institutionally-centered text like the course description as developed for departmental websites and university handbooks, and in most cases updated not nearly as often as a more transformational and responsive text like the syllabus, I made the claim that disparities between what a course says it should do as a course and what a specific section of that course will actually do are out of bounds for this particular study. My earlier claim of "inevitability," in regards to what an instructor plans for a course in the text of the syllabus and what actually occurs on a day-to-day basis, is not meant to be taken lightly. I feel that an inherent distinction between a text like the syllabus and one 
like the university- or department-sponsored course description is that these tensions coexist within the same text in the syllabus. In other words, the course syllabus must deal with the coexistence of the course description in its construction, dissemination, operation, and performance, but this textual relationship is decidedly not reciprocal.

Under these circumstances, the genre of the course syllabus, as both adjacent to and separate from other representations of a course, inevitably encompasses these tensions. Since observing individual classes from those instructors submitting course syllabi was not a part of this study, I prefer instead to focus on the extent to which tensions between what I call (in Chapter One) the "should" and the "will" reveal themselves in these course syllabi, particularly in gestures seeking to establish a sense of community, both broadly and more narrowly defined and conceived. Although this analysis will necessarily explore ways these syllabi make use of, or defer, the pronoun "we" as a version or extension of "you," this section will also move beyond these pronoun usages, so that we might better explore these textual employments of "community" in the composition course syllabus.

In my last chapter, I made note of how often composition scholarship makes use of static conditions of "the individual" and "the social," despite our inclinations and theorizations to the contrary. Linda Adler-Kassner and Susanmarie Harrington, in their introduction to Questioning Authority: Stories Told in School, remark with ease how "this tension between the individual and the community is an important force in the classroom" (7). While the encapsulation of this tension in such oppositional terms appears convenient on its surface as a distillation of conflict at work in the composition classroom, such a comment suggests the idea that "the individual" and "the community" are unified enough 
to be at odds with one another in the first place. Such placement of opposition seems to deflate Joseph Harris' critique of David Bartholomae's "Inventing the University," particularly how this tension itself, especially in terms of explorations of discourse communities, is often expressed as a function of the evolving encountering (and conflicting with) the fixed. In this section, I do not intend to re-raise issues of consensus and dissensus, which I have already explored to some degree through analyses of email communications from composition program directors. Also, I do not intend to recapitulate debates between the desired fixedness and fluidity of conceptions of community in the classroom and in the last three decades of composition theory. In this section, I wish to engage these moments in these course syllabi submitted for this study these moments of community reference or invocation - in order to better speculate about what types of communities these graduate student instructors of composition are advocating, and for what pedagogical, ideological, and institutional purposes. In this section, I wish to critically engage concepts of genre embeddedness, focusing on more recent works from Carolyn Miller, Glenn Stillar, Elizabeth Wardle, Stephen Owen, and Trish Roberts-Miller, to better explore the ways in which graduate student instructors' conceptions of "community" get used through the genre of the course syllabus.

As a way of getting into these various employments of "community," allow me a moment of disciplinary and pedagogical nostalgia. I point to Robert Sutherland's "Letting Students Be: Report on a Continuing Experiment in Education," in which he elaborates on his current (in 1971) "local situation" at Illinois State University, described as a "public, four-year institution with a variety of master's degree programs and several doctoral programs either established or in process" (733). Throughout his explorations of 
this experiment -the additions of three courses including Linguistics, Growth and Structure of the English Language, and Introduction to Descriptive Linguistics Sutherland enumerates certain pedagogical assumptions he had across these individual courses. Among them, he had hypothesized that "[a] community of colleagues can be established only if students and teachers accept each other and each other's ideas with respect and trust; openness can be achieved only if the classroom context is free from fear: teachers must not fear students, and students must not fear teachers; all must be free to be themselves" (734), as well as the assumption that "a community of learning can succeed only if all members work actively for its establishment and maintenance" (735). Accepting the extent to which the last thirty years or so of composition scholarship have worked to complicate the idea of a community, we can also accept the conditions that affect these and other assumptions of "community" in this regard.

These assumptions seem to indicate a more generalizable understanding of the writer's apparently autonomous cognition (Bawarshi Genre 5), through subsequent problematizing of conceptions like "respect" and "trust," but even more the dissolution of an accepted unified notion of being "free" from fear. Whether graduate student instructors deliberately and consciously choose an invocation of community (under the auspices of "discourse" or not) as a move towards exclusionary consensus as means of polarizing the individual and society, or as a move towards inclusionary collaboration, ${ }^{2}$ is ultimately beyond the scope of this study, as I would be compelled not only to inquire of each submitter their individual purpose in invoking a sense of community in their course syllabus but also to accept their explanations as wholly valid. Just as I have mentioned in an earlier section of this chapter, my goal in this section will not be to overlay my own 
sense of pedagogical judgment on these employments of "community;" rather, I intend to use instances of community invocation in composition course syllabi to explore what Julia Kristeva calls the "intersection of textual surfaces" ("Word, Dialogue, and Novel" 36).

Although Diann Baecker in "Uncovering the Rhetoric of the Syllabus" reminds us that instructors of all disciplines will often use the "we" pronoun in their course syllabi both to "soften" the authority we accept as a given and to maintain our own versions or visions of academic discourse communities (60) - invoking a "we" as both a general and a specific instance of concordance - I argue that, more essentially and more immediately, the use of "we," when not employed in a more direct and obvious disguise of a directive, serves to reinforce conceptions of community through the instrument of the genre. Through my analysis of the course syllabi submitted for this dissertation study, I did not find many uses of "we" as a direct substitute for "you," as in the classic example, "We will write four papers in this class," when the implication obvious to both teacher and student is that only the latter will be doing the actual writing of papers. In these cases, which I must reiterate were few and far between among the data I collected, the desire to establish some sense of community (often through the acknowledgement of the "work" of writing) becomes overshadowed by a desire to enforce or impose a one-word version of community by the mere application of the word "we." These senses of community in these cases backfire, I argue, because they arise not through the teacher's careful and deliberate use of his or her authority in the composition classroom, but through the imposition of its supposed intrinsic value. Rather than these cases of direct imposition substantiations of Joseph Harris' warnings against inculcating our students "as members 
of some abstract, organic, disciplinary community" ("Beyond Community" 4-5) - I instead prefer to focus on those moments of community invocation that border on concepts of immersion through the use of organizational or disciplinary genres in which we "constitute social structures (in professional, institutional, and organizational contexts) and simultaneously reproduce these structures" (Berkenkotter and Huckin Genre Knowledge 17, original emphasis).

While I have argued earlier in Chapter One against dismissing the genre of the course syllabus as a transparently instrumental one, this is of course not to say that it does not operate to achieve an instrumental purpose as a common genre of academic discourse. The first two instances of community invocation present in these syllabi offer moments of clarification as to what type of community is really involved here. One graduate student instructor, following a list of basic course and contact information, opens the syllabus with a gesture towards a specific kind of community, explaining, "We live together in a world that values the way we communicate. Often, the difference between success and failure is determined by how well we can communicate that which we expect someone else to accept, or how well we can judge the communication that someone else presents for our acceptance." Another instructor adopts the "we-as-I" stance, commenting to students that "you may have great ideas in your head, but if you can't put them in writing eloquently, they will go unnoticed. We want your thoughts to be noticed by their clear expression! [...] We believe that developing your writing skills will have a positive impact in many areas of your life." This last phrase, an expression of the composition course's value beyond the more immediate, appears quite frequently throughout these syllabi. Variations of these value expressions include the idea that 
"strong writing skills will help you succeed in most of your courses," as well as the desire to "set you [the student] on the road to the kind of competency that will be necessary for a successful professional career." These two example syllabi particularly demonstrate the extent to which the invocation of "community" in the composition classroom functions as a decidedly complicated and complex enterprise.

One the one hand, the first syllabus here offers a connection to a reading of community that implies a sharing of interests, pursuits, or goals that are distinct from a more general definition of society. When the instructor notes that "we live together in a world that values the way we communicate," there is an implicit acknowledgment that the "world" in this case is that of academia, punctuated by the use of a success/failure binary through a framework of acceptance. The second instructor in this example offers the distinction between thought and written expression, clearly acknowledging the superiority of the latter over the former, and stressing the significance of the latter both through the adoption of the "we" to represent the instructor in this case, as well as the suggestion that the community to which the instructor belongs (and into which students are entering) admits to the cultural capital contained within modes of written expression over other modes. Carolyn Miller defines a rhetorical community as a kind of "virtual entity, a discursive projection, a rhetorical construct," the community "as invoked, represented, presupposed, or developed in rhetorical discourse," and "constituted by attributions of characteristic joint rhetorical actions, genres of interaction, ways of getting things done, including reproducing itself" ("Rhetorical Community" 73). I argue that the composition course syllabus operates as a "genre of interaction" compelling an encounter between possibly conflicting representations of community, as a function of values, 
definitions of success, failure, even as a definition of operation within that community itself. The "reproducible social action" to which Miller refers (74) indeed functions as a connection between "us" and "them" through the conditions of the "we."

Other more complicated and layered moments of community invocation occur in these sample syllabi as well. One instructor makes a clearer distinction between selfrepresentation as a member of "we" and also as an individual "I," through a specialized section of college composition taught in the fall semester of 2008 , during this historical presidential election. Choosing to focus the course on uses and implementations of political rhetoric, this instructor notes that political rhetoric "is particularly potent and deserving of examination as it concerns the communities in which we live. My hope is that through this engagement with political discourse you will not only become better writers and readers but also more aware as citizens, residency in this country being one thing we all have in common." What is most intriguing about this explanation or justification of this special topic-centered version of freshman composition is the use of the genre of the course syllabus as an intermediary of interconnectivity. This interconnectivity acknowledges that which, in the instructor's estimation, connects us all as citizens, while simultaneously relying on a qualitative difference of experience with reading and interpreting this rhetoric, connecting the novice(s) and the expert(ise), through a supposedly common thread of residency - although this may not necessarily be the case, depending on a reading of "residency" as either a reference to physical location or a more precise definition of immigration status. This instance recalls Glenn Stillar's observations on the contained multiplicities inherent in any formulation of discourse community structures. In his Analyzing Everyday Texts: Discourse, Rhetoric, and Social 
Perspectives, Stillar recognizes the extent to which "discoursal practice is both constrained and enabled by past, present, and projected discourse; it is inserted in and productive of history. It peers, Janus-headed, at two dynamic and ever-evolving horizons: one way, toward the other actual discourses and discourse conventions it relies on for relevance; the other way, toward the multiple, only semi-stable systems of resources it draws on to construct relevance" (5). In the case of the syllabus above, the discoursal practice of community invocation offers itself as "Janus-headed" in this regard, relying on an expressed and assumed relevance of (in this case) political discourse, while at the same time gesturing towards the "semi-stable systems of resources" inherent in the assumption of residency.

On a more meta-discursive note, one syllabus in particular takes advantage of recognizing itself as a modus operandi of the more general institutional frameworks at play in its inception, taking the opportunity to comment on its own course description and the complex word choices embedded within. What follows is an excerpt from that course syllabus, with identifying information expurgated:

On first glance, the course description for ENG [...] appears simple, even straightforward. "Study" and "practice" are familiar terms; at the very least they seem to be terms appropriate to a class that is a [...] Plan foundation requirement course. Yes, on second glance, they do appear safe, so let's move on. What of the terms "explanatory," "expressive," and "persuasive," let alone the troubling term "effective?" Additionally, did you notice that the description is not quite a sentence? And can we move beyond the text: who created this description? What does it say about the university and your continued progress in it? [...] Suddenly - and without too much digging - we are moving to territory that may be unfamiliar. In a sense, the unfamiliarity that was quickly revealed in this course description reveals our critical objective in this class. In this class we will try to invent and reinvent for ourselves what these terms mean and how they apply to us now and as we move forward as writers. 
Such self-interrogating techniques offer an invocation of community beyond the superficial declaration thereof, and the written struggles towards unpacking "our critical objective in this class" offers a subtle spin on more traditional "we-as-you" constructions. In other words, in this case, the instructor does not simply declare the classroom as a writing community, a community of learners, or other similar formulations - through the actions of commenting on the course's specific and general relationships to the assigned course description, and through questioning the appearance of simplicity and safety in these word choices, this instructor chooses to demonstrate the actions of a (discourse) community rather than merely ascribing a label and assuming everyone will act accordingly on the basis of this label alone.

Focusing on the actions of community as opposed to whether the label of community is being applied capriciously, we can better begin to make these essential distinctions through a more thorough understanding of what Vijay Bhatia, in Analysing Genre: Language Use in Professional Settings, calls the placement of the "genre-text [...] intuitively in a situational context," including "the background knowledge of the discipline one gets from his/her association with, and training within, the professional community," as well as "the knowledge of the communicative conventions one gets from his/her prior experience of similar texts" (22). Bridging the gap between understandings, conceptions, and associations of genre and those of power and authority as acquired and adapted through encounters with disciplinary knowledge(s), Bhatia's emphasis on the "genre-text," and more specifically, on our own struggles to place this "genre-text" within our own experiences, couples with Elizabeth Wardle's more recent depiction of "enculturation" as a process requiring "neophytes to engage in new practices - including 
new written practices" - which "may ask them to give up some measure of authority to which they believe they are entitled" ( 11 ). The result, as a way of engaging conceptions of "community" as they relate to the conception, construction, and dissemination of the composition course syllabus, is the notion of "resources."

In a sample syllabus already examined earlier in this section, in which the graduate student instructor refers to a desire to set the student "on the road to the kind of competency that will be necessary for a successful professional career," the instructor then offers a suggestion towards the kinds of genre- and authority-based definitions of competency without saying as much. Shifting from an institutional "we" to the more localized "we" of the specific classroom community (simply put as teacher-plusstudents), the syllabus invokes the notion of resources to two differing degrees, noting in quick succession that "we will not have time in class to exhaust all of the textbook resources, but feel free to explore them on your own," and, in deference to their first assignment, requiring students to "bring to class one example of something you consider to be 'good' writing (an excerpt from a novel, short story, newspaper, song, etc., etc." Wardle reminds us that learning to write in new settings - whether relevant for students learning to write for college or for new graduate student instructors of composition learning to write as a representative of the institution - is a process of "involvement in communities, of identifying with certain groups, of choosing certain practices over others; a process strongly influenced by power relationships - a process, in effect, bound up tightly with identity, authority, and experience" (\$ 39). In this sense of identifying writing practices in conjunction with negotiations of authorities, genres, and communities, the juxtaposition of offering up the textbook used in this particular course 
as a potentially exhaustible set of resources if not for the temporal limitations of the academic term, along with the more revealing assumption that examples of "'good' writing" exist in a realm separate or disconnected from students' own writing (noticeably not listed in the syllabus's original parenthetical), offers a more distanced, or perhaps detached, sense of resources in this regard.

On the contrary, another pair of examples from these course syllabi offers a more direct implementation of "resources" as they pertain to parallel suggestions of community construction and development in the composition classroom. After gesturing towards "maturity" as a point of spatiotemporal communal intersection with the comment, "we are all adults in this course together, so remember to give the same respect that you expect to receive from others," a rhetorical move I encountered frequently among the composition course syllabi I received, one instructor in particular notes simply, "I am your first resource for writing assistance." What's most interesting about this use of "resource" in this context is that it simultaneously invokes and polarizes conceptions of community. On the one hand, such a statement assuages students' apprehensions towards their relationship with the instructor; on the other, as I read this statement located in the course syllabus shortly after the statement regarding maturity, I began to wonder how often students might interpret "first resource" as "only resource," thereby deflating its original intention. While I have already discussed both the inevitability and the difficulties of examining disconnections between the ways in which instructors intend their policies and statements in their course syllabi and the ways their students might receive them, in this specific instance, the invocation of "resource" presents itself in a way that directly affects perceptions of authority and community through the genre of the course syllabus. 
Another instructor makes a more deliberate attempt to shift the role as a member of the class community, specifically labeling a section of the syllabus "Resources." Under this heading, the instructor delineates different resources available in the class, including, "Your classmates: Rely on one another for the questions you have regarding the readings, the work we're doing in class, software we may be using, etc. You all, both individually and as a collective, embody a vast bank of knowledge and experiences. $\mathrm{Me}$ : I will do all I can to assist you in succeeding in this course." In this case, the instructor employs the notion of resources in a more deliberately calculated fashion, so as to become hierarchically repositioned as a member of the class community rather than as one expressly responsible for its creation and implementation.

Identifying the students in this class on both an individual and a collective basis allows this instructor to interact with multiple invocations of "you" in terms of community co-creation, and consistent references to the specificities of this individual section of composition suggests an acceptance of, and reliance on, the temporary nature of classroom community constructions. The distinction between the first example, announcing, "I am your first resource," and the second, suggesting, "I will do all I can to assist you," demonstrates the genre of the course syllabus as a platform or the potential integration of conceptions of authority, power, and community. In "Genres in Motion," Stephen Owen notes that genre functions as a "sediment of contingencies and changing motives" (1391). In this instance, Owen's suggestion that genre operates as a signifier of particular options ineluctably tied to conditions of location and the need to be located easily suggests the notion of "community" as well. When Owen claims, "The local configurations of genre differ sharply in their shapes and in the sharpness of the 
boundaries between them; still, some idea of genre seems to be a commonality" (1392), replacing the term "genre" with the term "community" reveals strikingly similar results. In this case, Owen's general theme of genres as textual structures and modes of taxonomic categorizations and locations that "enable the enterprise" of genre (1393) reflect ways in which instructors employ and invoke a sense or definition of community through the course syllabus.

As a final note to this section on implications of community invocation in the composition course syllabus, I point to Trish Roberts-Miller's "Discursive Conflict in Communities and Classrooms," in which she discusses what she sees as the central point of contention with concepts of communities of discourse, "that it is not at all clear what constitutes successful discourse, other than some vague sense of people remaining cordial" (538). Responses to this inherent "fuzziness" of what constitutes a community (recalling Matsuo's explorations of genre in a similar fashion) reveal themselves in these graduate student instructors' composition course syllabi, particularly represented as one instructor notes, "Because this is a small writing class, it is important that each student is able to communicate openly and honestly. To ensure this class atmosphere, it is essential that all students treat each other with the utmost respect. Therefore, any disruptive or unprofessional behavior will not be tolerated." Versions of these kinds of comments appear quite frequently in the data, from the above - a recognition characteristic of the usually smaller enrollments of composition classes when compared to other larger, auditorium-sized core courses - to the more formal, including instructors delineating variations of "student academic rights" in conjunction with "instructor expectations, class conduct, and student academic responsibilities," as well as the case of one instructor in 
particular, who has students sign a "Classroom Civility Contract" attached to the end of the course syllabus.

Of course, these kinds of gestures - particularly this "Classroom Civility Contract," which refers to "the undersigned student," and describes various forms of "disruptive behaviors," including eating and cell phone usage in the classroom - reiterate the problems associated with the contractual metaphors of the course syllabus I discuss earlier in Chapter One. More than this, however, these gestures towards community encounter an essential problem of potential reduction as encapsulated by Roberts-Miller, as she explains how, "at one end of the spectrum, 'communities of discourse' means little more than genre conventions, with the implication that people can move easily from one community to another; at the other end, the term becomes determinist, with the implication that communities of discourse so shape one's ability to know that discourse among communities is impossible or 'incommensurable'" (553-54). While I agree with Roberts-Miller in the extent to which conceptions of "community" can become as overused and oversimplified as our typical associations with conventions of genre, I am not so sure that genre conventions themselves imply an inherent and comparable level of passage or movement from one to another.

More to the point, while Roberts-Miller sets up the determinist threat of community in opposition to the malleability of genre conventions, threats of deflating the functions and operations of these "communities of discourse" are in fact determinist on both ends of the spectrum, limiting our engagement with genre conventions to rigid formulations of taxonomic responses as well as pre-shaped conditions of the communities themselves. In the case of presenting "respect" and resistance to "disruptive or 
unprofessional behavior" as pre-qualifying conditions for entering into and engaging with this specific, limited classroom community, or in the more extreme case of presenting these conditions of elements of a contractual obligation students must sign before they are allowed to engage in this community in the first place, the deterministic threat of conceptions of community represents itself as that which simply is, and thus itself becomes removed from the field of conversation, discussion, and engagement. The reasoning becomes circular - we are a community because communities follow these general sets of ethical and social guidelines, and we will follow these sets of ethical and social guidelines because we are a community.

\section{The Authority of Deferment and the Deferment of Authority}

While gestures towards the formulation and maintenance of some version of community in the composition course syllabus are both fairly common and inherently problematic, the final rhetorical move I wish to examine in this chapter appears more direct, and has become more commonplace in recent years, as a representation of more modern syllabi operating within multiple institutional structures simultaneously. In this section, I will examine the ways in which some of these sample composition course syllabi engage in moments of authority deferment, rather than deflection, often through gestures towards policies and regulations both external to the specific course section and internal to the more general institutional structure in which it operates. Linda AdlerKassner and Susanmarie Harrington write that the authority we bring into the classroom "manifests itself in classroom ranks and titles, writing program hierarchies and policies; in the texts we read, write, teach, and study; and in the formal and informal settings for 
sharing our professional expertise" (2), and it is within the latter, these "formal and informal settings," that these deferments of authority most often take place. Throughout this section, I wish to examine how newer entering graduate student teachers of composition negotiate these settings in their deferments of their authority through the institutional-wide policies as established, taking primarily as my framework for these analyses Xin Liu Gale's descriptions of what she calls authorities of expertise in Teachers, Discourses, and Authority in the Postmodern Classroom. Through her explorations of both the authority of expertise and institutionally-sanctioned authority, particularly the ways in which these function in a strange, symbiotically suppressive relationship, we can begin to see how newer instructors of composition occupying multiple overlapping stakeholder positions use the course syllabus as a participatory, functional (rather than transparently instrumental) genre of academic discourse.

Gale acknowledges the extent to which we prefer to rely on the authority of expertise because, "since the teacher's expertise is what students need in life, authority based on expertise must also be good for students" (47). The assumptions buried in this preference, however, include the tendency of this assumption to ignore both "the teacher's relation to the academic institution and to the job of teaching" as well as "the power relations implicated in the authority of expertise" (47). What is most interesting about Gale's observations from this perspective, from its applicability to composition as an academic discipline, and from its eventual interactivity in the genre of the course syllabus, is that she appears to make an association between the authority of expertise and the authority of substantial, accreted disciplinary knowledge. In the case of the examples of what I call this deferment of authority embedded within these sample syllabi, the 
conditions of the authority of expertise become relegated to, or deferred by, structures specifically outside the realm of discipline-specific knowledge, and more into the realm of broader institutional structures of indemnification.

The question in this section of my dissertation ultimately becomes, how do these newer instructors of composition negotiate the multiple stakeholder positions evident in their placements within the institutional structure of higher education? How do they negotiate what might be described as a paradox of status, the fact that, according to Bruce Horner, many writing teachers have an interest "in claiming professional expertise and membership in an academic discipline," while at the same time wrestling with the understanding that "it is through subjecting traditional knowledge and practices to written critique that such status is acquired" ("Traditions and Professionalization" 369)? In this same piece, Horner argues that "we need to insist that the significance of an institutional form or structure cannot be read outside the specificity of its material instantiation or use" (392), and, as I will discuss next in this section, I argue that these moments of authoritative deferment serve to complicate our understandings of both institutional forms and structures and the extent of their material instantiation.

First, I need to clarify just what I am referring to, those moments in the composition course syllabi I examined for this dissertation where these deferments take place. Specifically, I will be discussing the moves instructors make to refer their students to administrative rules and regulations, inter- and extra-departmental policies which at least partially govern the specific instantiation of the course as it operationalizes itself under the structure of the institution. ${ }^{3}$ These moments take on two distinct forms - those calling for awareness, and those calling for accountability. Together, these moves serve 
to complicate the authority of expertise, especially for entering graduate instructors of composition. What I have termed moments of awareness present themselves in a rather innocuous way, allowing students to familiarize themselves with writing program or departmental policies at their own pace and on their own times, suggesting that the discourse community in the classroom must and should move outside the physical environment dedicated for the performance of the course itself. These moves towards awareness are almost categorically presented as suggestions for "additional information," implying enhancement rather than direct applicability. Given the proliferation of general university-wide and departmental/program-specific information available online, these moves offer an alternative to more traditional verbatim recapitulations of "boiler-plate" policy language. So, rather than restating the Writing Program's policies, one instructor chooses instead to direct students to websites that list and explain these policies. Another instructor provides a list of websites related to course-specific and institution-wide resources, which include explanations of "academic integrity," the program's website describing the nature of the First-Year Writing Requirement, the "Library Online Basic Orientation tutorial," and contact information for the Reference Staff at the university's main library.

These gestures in particular are not limited to those seeking to bolster the coursespecific manifestations of composition through referrals to broader policies and interconnected informational websites. In some cases, these acts of de/referral function more as operators of disciplinary legitimacy. One instructor prefaces a formal attendance policy with a gesture towards those in authority beyond the specific classroom, noting, "The Writing Program attendance policy, approved by the Department Chair and the 
Dean's Office, states that [...]." Also, this instructor makes deliberate reference to university-wide policy as a method of indemnification, recognizing that, "According to the 2006-08 Catalog, [...] you must take a final exam for this course, and you must take the exam when it is scheduled by the University." Speaking from personal experience, I can attest to the number of students each semester seeking to reschedule final exams for times more appropriate to their personal end-of-term plans, and this "according to" gesture allows this particular instructor to not necessarily sidestep but rather absorb potential problems and confusion later in the term. Other rhetorical moves of similar import include the instructor who notes, in drastic bold type, that "students enrolled in this section will be expected to adhere strictly to the English Department's Attendance Policy," as well as the instructor who seems to acknowledge the conscious role as a bridge between departmental regulations and individual students' responses to those regulations, announcing, "my department provides a standard attendance policy, and I reproduce relevant parts for you below." While these types of gestures do, in large quantities, or presented as disembodied lists of policies rather than incorporations thereof, run the risk of moving the course syllabus away from anxiety reduction and more towards question reduction (as I have already discussed in Chapter One), they also succeed in establishing the instructor as only one of many "authors" of this text called the syllabus.

Beyond gestures of deferment operating on more informational levels, a significant percentage of instructors who submitted course syllabi also engage in similar gestures calling instead for an acknowledgement of responsibility, in acts of accountability. More than one-quarter of the graduate student instructors involved in this study include at least one of these gestures in their course syllabus, most often related to 
constructions of "student codes of conduct," or in more specific terms, plagiarism. While I certainly do not intend to explore the myriad ramifications and implementations of various plagiarism policies enacted in composition classrooms, or within broader structures of institutionally-mandated policies within the limited confines of what remains of this chapter, ${ }^{4}$ it is worth noting that the subject of plagiarism - especially, and regardless of the specific institution, as it relates to broader understandings and "authorizations" of student codes of conduct - presents itself most often as the signature subject for this act of deferment. In "Rescuing the Discourse of Community," Gregory Clark recognizes our classrooms as "part of a competitive public realm where individuals must develop the expertise that demonstrates their practical competence" (71), but in the case of these rhetorical moves wherein instructors of composition refer students elsewhere via a web address, this development of expertise becomes curiously suspended.

When one instructor, for example, notes that "students are responsible for knowing and abiding by University and Writing Programs' policies," or when another asserts that students are "expected to know and abide by [the university's] Commitment to Community" (presented in hyperlink format), or when yet another instructor advises students to "consult the Code of Student Rights and Responsibilities," followed by a web address, they effectively shift receptions of expertise in the composition classroom, as the individual section of composition they teach relates to the larger structure of universitymandated policies. I am not denouncing these activities of deferment in any way. On the contrary, I feel these gestures, particularly as they manifest themselves through links to departmental or university websites, offer ways for newer instructors of composition to 
engage in conversations relevant to disciplinary authority and the layers thereof, and how their syllabi are in fact multifaceted, multi-authored, and multi-genred texts responsible to a number of different authoritative entities. While this deferment of expertise does at times make perfect sense - declaring, "I am not an expert on plagiarism, so I am taking the opportunity in the syllabus to refer you to people with connections to the department who claim these positions" - I do wonder how often these gestures of deferment succeed in suspending or vacuuming these potential conversations about disciplinary authorities in the writing classroom, rather than serving as opportunities for further investigation. In any case, these moments of deferment appear most intriguing in my study, especially the multiple significances imbedded in a seemingly innocuous or beneficial gesture as a reference to a website seeking to provide further information or make students aware of policies by which, through their presence in the course, they have implicitly agreed to abide.

These moments of deferment, in conjunction with residual conceptions of poweras-property, rhetorics of conditionality, and gestures towards community construction in the composition classroom, all contribute to the ways in which readings of the composition course syllabus serve both to acknowledge and subvert graduate student teachers' multiple stakeholder positions. In this chapter, I have explored a small but essential aspect of teacher identity construction, and the extent to which the course syllabus attempts to bridge gaps between understandings, conceptions, and associations of genre and those of power and authority as acquired and adapted through encounters with disciplinary knowledge(s). The analyses explored in this chapter offer a rhetorical road map for the ways in which newer instructors of composition negotiate these 
newfound authorities, granted through the academic institution the authority to perform acts of de-contextualization and re-contextualization through the construction and dissemination of a course syllabus. Seeking to establish a sense of developing teacherly authority, through the genre of the course syllabus as operating between temporal constructions of "now" and "then," focusing on ideological assumptions of "community," new(er) graduate student instructors of composition employ these texts as delegations of their struggle for institutional-personal representations of their own identity constructions as teachers. In my next and final chapter, I will explore ways in which these retheorizations of the course syllabus's roles in the discipline composition can help refashion the graduate student teaching practicum as a more explicit opportunity to develop, examine, and explore conceptions and depictions of the syllabus as a representative institutional, personal, and pedagogical document. 
${ }^{1}$ See also Bazerman's "What Written Knowledge Does," Berkenkotter and Huckin's Genre Knowledge in Disciplinary Communication, and Brenton Faber's "Discourse and Regulation," all playing to an extent on Schryer's depiction of genre as "stabilized-fornow," coupled with discussions of antecedent genres in Bawarshi's earlier "The Genre Function," Amy Devitt's Writing Genres, and Irene Clark's "A Genre Approach to Writing Assignments."

${ }^{2}$ For more on the problems associated with employments of "community" in the classroom in this context, see specifically Peter Vandenberg and Colette Morrow's "Intertextuality or Intratextuality? Rethinking Discourse Community Pedagogy." The Writing Instructor 14 (Fall 1994): 17-24.

${ }^{3}$ For more on the implications of the use of the term "operationalizing," see my discussions of "Genre and the Exigence of Social Action," in Chapter Two.

${ }^{4}$ While the disciplinary bibliography on plagiarism vis-à-vis composition is enormous, Perspectives on Plagiarism and Intellectual Property in a Postmodern World (Eds. Lise Buranen and Alice Roy) as well as Rebecca Moore Howard's Standing in the Shadow of Giants: Plagiarists, Authors, Collaborators offer exceedingly beneficial ways into the enormity of literature available on this subject, particularly as plagiarism reveals itself as a subject of disciplinary conversations at the beginning of the twenty-first century. 


\section{CHAPTER V}

\section{THE COURSE SYLLABUS AND THE GRADUATE STUDENT COMPOSITION}

\section{TEACHING PRACTICUM - TOWARDS A METHOD OF UNDERSTANDING}

Our most basic message here is this: when teachers question received authority about composition, they promote generative change; when teachers grapple with the complex relations among theory, practice, narrative, and authority, they make teaching possible. However, we argue that the questioning must begin locally - with ourselves, with our programs, in our institutions, and develop outward from there. Linda Adler Kassner and Susanmarie Harrington, "Stories, Authority, Teaching: Making a Difference in the Composition Classroom" (13-14)

In the previous chapter, I explored the extent to which new(er) graduate student teachers of composition seek to establish their identities as teachers through the academic genre of the course syllabus. Accomplishing these goals often through exhibitions of power-as-property, conditional phrases, a desire to create a version of community in the composition classroom, and moments of authority-deferment, these graduate student teachers strive to reconcile their own conceptions of their identities as students with their emerging identities as teachers. In doing so, or rather in the struggles of these attempted reconciliations, these new(er) teachers of composition demonstrate a keen awareness of their own multiple stakeholder positions, both within specific disciplinary frameworks of composition and within the larger socio-temporal structures of academics. In this concluding chapter, I will explore the extent to which a re-invigoration of the course syllabus as a subject (rather than a transparently instrumental object) of composition can 
contribute to a reciprocal and re-constitutive reexamination of the composition course practicum.

First, I explore historical conceptions of the graduate student teacher, and by extension, earlier conceptions of composition as an emerging and self-conscious academic discipline, moving swiftly from the early 1950 s to the mid-1980s. Although this section is not meant to be an encyclopedic historical overview of the figure of the graduate student teacher in developments of the discipline of composition, I use these historical signposts, or moments of nostalgia, to lead up to texts like William Irmscher's "TA Training: A Period of Discovery" and Helen Rothschild Ewald's "Waiting for Answerability: Bakhtin and Composition Studies." I argue that these two texts, published in the mid-1980s and early 1990s respectively, function as an operational shift in the understanding (as well as misconceptions) of both the discipline of composition and the graduate student teacher's place within that discipline. Next, I examine more recent characterizations of the composition practicum, including Bill Bolin and Peter Vandenberg's edited collection "A Forum on Doctoral Pedagogy" and selections from Sidney Dobrin's Don't Call it That - The Composition Practicum. Finally, I return to the data I explored in my previous chapter, this time focusing on the follow-up responses I received from individual graduate student teaching assistants, detailing their program or institution's theoretical frameworks guiding their understandings of their course syllabi. Ultimately in this chapter, I argue that the composition practicum, focusing on implications inherent in the construction, dissemination, and performances of the course syllabus, can help to reconceptualize this text as an operationalizing genre of academic writing. Further, this reconceptualization helps position the syllabus as a subject of 
composition, as a pedagogical exigency essential to contributions of our understandings of teacher identity constructions and negotiations.

\section{A Narrative of Germination - The (Re)Birth of a Notion}

I began this dissertation project in the fall of 2005, upon my return to graduate school after a five year hiatus, during which I served as an adjunct instructor of English at three different institutions simultaneously. Sitting in Debra Journet's Narrative Theory course, I struggled initially with the entire "work" of graduate school - it had indeed been some time since I had to read 500-600 pages of texts each week, and negotiate my own presence in class discussions, weekly responses, and seminar papers. It took me a while to remember the role of student I had previously held, while slipping more comfortably (than a number of my cohorts with considerably less teaching experience) back into the role of teacher, only this time, teacher-plus-student. No longer able to define myself through one single stakeholder position (and my students as collectively through another single position), and no longer able to focus my time and energy solely on this single identity-position, I began to see the syllabus as something more than a list of events, something more than a series of goals to be accomplished.

As the development of the idea of syllabus-as-narrative began to take shape, I searched for an opening to this particular seminar paper, one with a decidedly personal and conversational tone, so as best to combat the otherwise densely theoretical language the remainder of the paper engaged. After struggling with ways to enter into the subject of the syllabus as a narrative text, I opened the paper that would eventually generate into this dissertation with the phrase, "Orientation is always a hassle." From there, I went on 
to describe my own place in this university, my own encounters with these recently reestablished multiple stakeholder positions, and eventually my own reconsiderations of the course syllabi I had been producing as a writing teacher. As I have discussed earlier, the syllabus has been a primary fascination of mine, leading to the subsequent need to employ a reexamination of these kinds of texts to concurrently reinvigorate discussions of teacher identity formations and transmissions. It was not by coincidence or accident, then, that the way I approached the idea of the syllabus in the initial ruminations for this dissertation, in the seminar paper for Narrative Theory so many years ago, mirrored the way I saw myself as (re)entering the discipline of composition as a multiple stakeholder through the concept of the graduate student teaching practicum.

Consequently, I entered the subject of composition through a label of "new." Amongst a group in any orientation, you are labeled "new." Orientation for teachers of composition is no exception, though the label is all the more uncomfortable in the sticky heat of August, positioned at the beginning of the fall semester. I can recall sitting in a circle in a refreshingly frigid room on the second floor of the Bingham Humanities Building at the University of Louisville. I could not help feeling a bit smug, not to the detriment of my cohorts, but perhaps as a counteractive measure to balance the other telltale signs of "newness" - from a folder jam-packed with important numbers, passwords, information of all kinds, emblazoned with the University logo, to the perpetual stop-and-go motions of negotiating the campus between consultations of map kiosks placed outside of nearly every virtually identical building. When I started the doctoral program here, I had already been teaching - "basic writing," freshman composition and sophomore American literature courses - for six years. Unlike proper 
parking procedures, when certain on-campus restaurants were open, or negotiating the Watterson Expressway, teaching was something I understood. Despite my place in the orientation group, I felt I was not "new."

This confidence, which I perceive now as a mask for my own sense of feeling simultaneously in and out of place, was shaken by the end of the week, the day we began to discuss syllabus construction. We were handed a list of items we were required to include in the syllabus to varying degrees of compliance with University procedures and guidelines. While most of these seemed obvious enough - office location, office hours, contact phone number and email, grade distributions (the plus-minus system here) further down the list were elements of a more legalistic nature, concerning disability statements, plagiarism definitions, sexual harassment clauses. In that moment, I began to see how I had seen my syllabi over the years as a mere calendar of events, a series of points in the plot of the semester, a chronological indication of assignments, tests, readings, discussions - nothing more.

Ultimately, the lens through which I began to (re)view the syllabi I had been writing for six years prior, and for the next five years here at the University of Louisville, was forged through my experiences in the composition practicum. This experience was a significant before/after moment, as I recalled sitting in a similarly-constructed circle of brand-new teachers of composition the week before beginning the Masters program at the University of Alabama. The teaching practicum there (back in 1999) was a two-semester course, Teaching College English I and II, preceded by what was referred to by the administration, the instructor, and graduate students alike as "boot camp" - and not always in a good-natured way. Whether we discussed the training practicum as "boot 
camp," being consistently referred to as "new recruits," developing a "battle plan" for contentious or disruptive students, our place as graduate students "on the front lines" of college education, or even the presence of the general debate of composition as a "service" discipline, these militaristic metaphors were not lost on me, even in the early stages of my teaching career. We were being drafted. ${ }^{1}$ These militaristic metaphors raise significant questions concerning our methods of bringing graduate student teachers into composition, questions that have been at the forefront of disciplinary conversations for quite some time.

Eight years prior to the formation of the Conference on College Composition and Communication, Herbert Weisinger pierced the heart of insecurities about composition as a legitimate (and legitimated) academic discipline, noting that "as soon as the teacher of composition tries to collect suitable materials for his course he discovers that English composition has no subject matter. Whatever the subjects of discussion he chooses, he is informed that he is poaching on the preserves of the economics teacher or political science teacher or science teacher" (688). A form of militaristic metaphor occurs here through the use of "poaching," hunting outside the boundaries of the law, "on the preserves" of disciplinary turf, under the cover of darkness, in the style of a mercenary. Further acquiescing to the idea that "the very nature of freshman composition forces the teacher to accept the task of the larger intellectual orientation of the first-year student" (689), Weisinger hints at later conversations regarding composition's (dis)placement as a service course - conversations more fully realized through Albert Kitzhaber, Bob Connors, and more recently Sharon Crowley. In proposing a freshman composition course focusing on theories of democracy, Weisinger recognizes that "certainly the 
freshman instructor, who is usually a graduate student, is able to handle the history of ideas as part of his professional training and ought to be able to deal with contemporary problems simply in his capacity as an educated man" (692). Of course, a central point of contention for future generations of composition theorists and instructors lies in equating an understanding of "the history of ideas" with being a professionally trained teacher.

Ten years later, Robert Hunting, in his "A Training Course for Teachers of Composition," cynically acknowledges that while "the graduate student looks forward to being a full-time instructor, $[\ldots]$ both the graduate student and the instructor are early made aware of the fact that one usually cannot afford to take such an interest in freshman composition that he becomes a recognized authority on the subject" (3). Simultaneously, opportunities to become such a "recognized authority" (however apparently misconceived in 1951) are themselves de-emphasized through the placement of the graduate student teaching practicum within the larger curricular framework of the university. Hunting opines, "It is my impression that the [freshman composition teacher training] course should be a non-credit one. It should be non-credit because it really involves extracurricular work. A graduate school of liberal arts should not pretend to be a trade or a professional school. To give credit for training in a trade or profession would be to betray its purposes. Such training must always be a felicitous, but incidental, increment to graduate studies" (6). The suggestion of the teaching practicum as a non-credit course positions both the subject(s) of freshman composition and those primarily charged with teaching it in a significantly precarious position - not quite a disciplinary insider, not quite a disciplinary outsider either. 
Further, the status of the graduate student teaching practicum as a non-credit course forces an artificial separation between the development of content-based knowledge and the development of teaching. The graduate student him- or herself becomes placed in a position where his or her place in the freshman composition classroom is necessary, but the path towards that place does not yet count. In "The Graduate Student and the Freshman English Student," Dudley Bailey characterizes these earlier stages of academic insecurity in the graduate student teacher of freshman composition more elaborately:

A great deal of freshman English is being taught these days by graduate students. They daily have their noses rubbed in undergraduate illiteracy. And anyone who expects for a moment that they find balm in their administrator's preoccupation with normalizing their grading curves, or with checking their derivations from a syllabus, or with articulating their work with a high school course of study that may or may not make any sense, or with protecting their students from their impatience with laziness and stupidity, or with protecting a board of trustees from the conceivable embarrassment or a gratuitous or irregular comment, or with the jealous guarding of the sacro-sanctity of a none-too-clearly conceived 'in-service training program' - anyone who suspects anything of the sort is very seriously disoriented. (38)

Such a disheartening description of the graduate student teacher's average daily plight in deference to the administration recalls Barthes's bleak depiction of a teacher in "Writers, Intellectuals, Teachers" as one who "under cover of setting out a body of knowledge, puts out a discourse, never knowing how that discourse is received" (194, original emphasis). A palpable sense of dejection, disconnection, and disassociation permeates these earlier descriptions of the graduate student teacher's place in this strangely developing disciplinary location of composition.

These characterizations abound. In "The Role of TA's in the English Department," a 1971 workshop report from College Composition and Communication, one graduate 
student teacher in particular explains how, "teaching two classes, attending three classes myself, studying for the M.A., reading for my tests," she feels "like a bull that has been hurried on to the trailer of a cattle truck $[\ldots]$ where I am constantly bumping into other bulls who are in the same position" (277). Lori Erickson, in her mid-1980s reflective piece, "The Graduate Student: Forty-Five Years Later," notes how "an air of unreality seems to pervade graduate school," especially the extent to which, "busy through jumping through the various hoops, as graduate students we become so concerned with details that we miss the greater picture" (854). Countless informal chats I have had with Masters and $\mathrm{PhD}$ students as well as responses to my follow-up questions as part of my research for this dissertation indicate that these broad strokes of conditions have changed little in the last twenty years, or forty for that matter. Through these admittedly brief windows into these historical layers of depiction, I argue that, while those in composition do indeed recognize our operations within a number of different and overlapping discourse communities, and while threats of static reduction ("I" the teacher and "you" the students) run the possibility of repeating themselves in my collective references to "graduate students," evidence of the extent to which history appears to repeat itself in regards to the graduate student teacher of composition both in research and anecdotally cannot be underestimated or discounted.

These moments of nostalgia are not, of course, meant to imply that such characterizations have gone by the wayside through further theorization and modernization of the components of this equation - the discipline of composition, the graduate student teacher, the composition teaching practicum, and the university. In the last decade, Scott Miller and others explore the nature of "graduate students colliding 
with the unpleasant realities of the profession as it exists with institutional structures: the university, the field and its position within academe, higher education and its currently appalling job market" (398). Marcy Taylor and Jennifer Holberg, in an essay tellingly titled "'Tales of Neglect and Sadism:' Disciplinarity and the Figuring of the Graduate Student in Composition," discuss conditions of "exploitation, fear, and dislocation" (608), while Diana Royer, et al., point out that graduate student teachers are most likely, "in the worst case scenario, to be scapegoated both within and beyond the department for not teaching Jennifer and Johnny how to write in two semesters" (34). Thus, the placement of the graduate student teacher should not be considered a problem related only to earlier disciplinary formations of composition.

My narrative of germination, the development of my own sense of the graduate student's placement in various incarnations of the composition classroom and in the composition teaching practicum, reached a sort of sociodynamic critical mass through repositioning myself in stakeholder positions in the university structure. Patricia Sullivan notes that, absent of any self-conscious theorization, a new teacher "often arrives at the scene of the practicum with a commonsense understanding of teaching writing," often drawn "from personal memories, vague cultural expectations, and other non-theoretical sources" (W35-36). Although these experiences appear to fall in line with what Stephen North calls practitioner inquiry, concerning "what has worked, is working, or might work in teaching, doing, or learning writing" (23), I prefer to categorize them in the lesscategorizable context Elizabeth Rankin assigns in questioning North's definitions in this regard, as she asks, "But how do we know 'what works'? And what does that mean anyway? For example, at what point does my declaration that writing groups 'work' in the 
classroom leave the domain of hollow assertion and enter into the realm of 'knowledge'? On what grounds do we distinguish valid claims of practitioner knowledge from all the doubtful claims we've read and heard and produced ourselves over the years?" ("Taking" 261, original emphasis). While Rankin never specifically discusses graduate student teaching assistants, and focuses instead on problematizing North's conceptions of what qualifies as knowledge, her questions here reveal an equally problematic concern - where do those who don't feel like practitioners fall into the space of practitioner inquiry?

In my capacity as a Masters student, an adjunct instructor, and then as a $\mathrm{PhD}$ student, I've spoken with a number of colleagues in a variety of informal environments, primarily outside of whatever building, smoking cigarettes and making small talk, but through the haze of tobacco smoke, and in the insignificance of chatting about the weather, parking, and whatnot, there emerged an overall sense of discomfort that went beyond the ordinary, that which is usually characterized by any general situation in which we are called upon to act in a certain way while feeling unprepared, uncertain as to how that "way to act" should present itself. One way into these characterizations of both the graduate student teacher and the composition teaching practicum, and to practice a more thorough, reflective examination of these conditions, is through the course syllabus as a genre of academic writing - through this text which functions both as the freshman composition student's initial college-level reading assignment and a textual declaration of the graduate student adopting the stakeholder position of teacher in the university. I argue that re-positioning the syllabus as a more explicit subject of the discipline, as an institutional and pedagogical immediacy, would place both the details and the greater picture of being a graduate student teacher of composition more at the forefront of 
conversations concerning placements into their disciplinary identities. This re-positioning can be especially valuable during the transition from strictly-student to student-plusteacher, the time of "unreality" in graduate school, in which we can so often and so quickly, in Erickson's words, "become so concerned with details that we miss the greater picture."

I do not mean to imply that these feelings of discomfiture can or should be eliminated from the graduate student teaching experience. Indeed, I argue that these feelings of uncertainty directly contribute to the sense of ourselves as teachers, while forming a natural bond with other members of the graduate teaching practicum. Just as Lee Ann Carroll describes the syllabus itself as a "grid of blank squares" ("Pomo Blues" 919), so are graduate student teachers entering the classroom and the practicum for the first time - not in the style of a tabula rasa, or in terms of Friere's "banking" concept, but rather in the sense that graduate student teachers of composition are partially shaped by their own experiences coupled with a necessarily generalized and generalizable set of assumptions as to what defines feeling like a teacher, and that these assumptions (the "squares" in this sense) come in contact and conflict with the realities of day-to-day teaching. Thus, as the syllabus is shaped as an academic genre by antecedent versions and assumptions of itself, so the graduate student teacher is shaped both by the space, time, and room provided by the university, as well as the discomforting experiences occurring within these spaces. 


\section{Discovery, Answerability, a Forum, and "Don't Call it That"}

Though my own experiences in multiple stakeholder positions have collectively served to develop my interests in graduate student teachers of composition as acutely aware of their own multiple stakeholder positions within the university, it was only after becoming a doctoral student that I was able to effectively separate my theoretical investigations from my own physical daily activities in the classroom. While I certainly acknowledge that praxis, the intersection of theory and practice, really is the only way we in composition can begin to more thoroughly investigate what we do and how we do it when it comes to the writing classroom, I also recognize the limitations of approaching praxis as an already-entangled set of concepts. In other words, I had to take apart both theory and practice in order to better understand how they worked together. After I arrived at the University of Louisville, enrolled in our English 602 course, the college composition teaching practicum, I spent a great deal of free time wandering Ekstrom Library in search of books that would help better clarify what I was (supposed to be) doing in the writing classroom beyond the day-to-day, more (in my mind at that time, anyway) "adjunct"-defined concerns.

Coming across a collection of essays entitled Training the New Teacher of College Composition, I felt both elated and vaguely emasculated - glad to know that there were texts at least superficially designed to help those in my situation, frustrated that I was once again classified as a "new teacher of college composition." It was here when I first encountered William Irmscher's essay, "TA Training: A Period of Discovery," and became particularly attracted to his descriptions of the ways in which multiple emotional responses are at work in acts of teaching. Irmscher explains, "Almost 
without exception, teaching assistants I have known (and I now have a roster accumulated over a period of twenty-eight years) approach their duties with enthusiasm. With fear and trembling, too, but with the same kind of anxiety that characterizes any bold adventure" (27-28). This particular description applying the natural intersection of enthusiasm and anxiety struck an entirely different chord by the end of my first semester teaching composition here at the University of Louisville, after I received copies of our teacher evaluation forms. One of the first departmental questions, outside of the standard multiple choice responses, asks students to describe the enthusiasm of their instructor $-\mathbf{a}$ question that still remains on their composition program evaluations. Apart from the leading nature of such an open request for commentary - in the sense that in the last four years of teaching here, so many students have used the term "enthusiastic," I argue primarily as a result of the more traditional method of rephrasing the question to begin the answer - I began to think more about this part of the teacher evaluation in terms of Irmscher's descriptions, particularly the extent to which perceptions of enthusiasm and perceptions of anxiety become indecipherable from one another.

I do still take issue with some of Irmscher's characterizations of graduate student instructors, however, and maintain that these contentions help explain why the course syllabus should take more of a primary position in the role of the development of the graduate student instructor within the boundaries of the practicum course. Irmscher notes that he never discourages teaching assistants "from telling students exactly who they are and what their status is" (28), and in this case, I wholeheartedly agree. In the last four years, as my status as a doctoral student has intersected with my status as a teacher of composition, I never hesitated to bring up current projects or papers I was working on as 
subjects of conversation with my students. I strive to make clear to them that struggling with writing is not a condition to which only freshmen are susceptible, and that each new genre (a progression of seminar papers, exam proposals, prospectus drafts, dissertation chapters) forces encounters with new challenges and new audiences, new roles to adopt as writers.

Soon afterwards, however, is where I take issue with Irmscher's struggles towards re-creating the graduate student teacher as student first, teacher second, as he notes how freshmen composition students and teaching assistants "are engaged in a common enterprise of learning and that can be an important bond of identification. They live in the same world; they do their work in the same places," and while students often perceive professors as somehow living "in a different world of learning, seemingly more remote, more theoretical, more specialized, more settled," students do not often project the same level of disconnection onto graduate student teaching assistants (28). While I agree that a certain "bond of identification" can be reached through the work to establish a status, I am not so sure I agree with Irmscher's declaration of students and graduate student teachers engaged in a "common enterprise of learning," especially as he relates this commonality to the condition of place, of location.

Though it might be tempting to link freshman students of composition to graduate student teachers in this regard, especially in terms of what William Coles once described as an intense desire "to know who he is supposed to be in relation to what he thinks is wanted of him $[s i c]$," a brand of "threatening unfamiliarity" ("Freshman Composition" 138), this sort of connection allows an overly simplistic view of location as it pertains to conditions of power, authority, and status, as well as perceptions of the same. In the most 
immediate sense of location, for example, in the last four years here at the University of Louisville, I have taught freshman composition in the Humanities, Life Sciences, Natural Sciences, Education, and even ROTC buildings, yet I have never attended a graduate level course (in composition or in literature) outside of the centralized Humanities building. Not only are the disciplinary locations physically different, but both students and graduate student teachers of composition are fundamentally aware of these most immediate and obvious differences.

Beyond what might be termed an over-idealization of the desire to connect freshman students of composition with graduate students assigned to teach these courses, I wish to move on to Irmscher's description of "a coherent scheme for thinking about teaching," beginning with an orientation course that "should bring to a level of conscious awareness may of the assumptions on which they [graduate student teachers of composition] operate" (28-29). While this implies that graduate student teachers are somehow outside "a level of conscious awareness" prior to their introduction to the composition teaching practicum, suggesting a "trickle down" theory of inculcation in which "teachers-to-be are blank slates upon which a pedagogy gets written" (Blakemore 139), I prefer to focus instead on Irmscher's use of "scheme" in this capacity. While Irmscher discusses how all new TAs in his department teach the same course, how "during the orientation, they receive a general syllabus for that course setting forth the objectives, requirements, and an overall teaching plan for the entire quarter" (31), he also appears careful to note how these syllabi, while "not prescriptive in the sense that they direct everyone to be on pages 59-63 on a particular Wednesday, [...] do expect everyone to be teaching the same topic for the week, perhaps prewriting, paragraphing, or sentence 
variety" (32). I do not necessarily wish to reiterate discussions and debates over model syllabi I have already broached to a certain extent in Chapter Three. At the same time, however, I am compelled to compare Irmscher's establishment of graduate student teacher communities to another almost diametrically opposed conception.

Peter Blakemore, in his "An Intentionally Ecological Approach to Teacher Training," describes his own experiences of having been "tossed overboard" as a teaching assistant, conditions which, as he puts it, "may have gotten me and my friends who engaged in our subversive teaching to realize the strength and value of teaching communities" (144). In opposition to Irmscher's topic-based commonalities, in which a particular form of consensus forms the basis for a community of graduate student teachers of composition, Blakemore points to a sense of paralysis, "the terror of being twenty-five years old, standing jaw agape, realizing that the lesson plan out of your Manual took up only 15 minutes out of an 80-minute period" (144). While he recognizes that many of his colleagues probably developed disdain of teaching through these experiences, it is difficult to downplay the significance such experiences have on both the development of one's pedagogy and one's sense of identification as a teacher.

So, while Irmscher argues that an orientation course for new teachers of composition should provide "a coherent scheme for thinking about teaching," the question becomes, to what extent does the genre of the course syllabus - itself a coherent scheme of sorts - function within the framework of the intentions of the composition practicum? While Vijay Bhatia argues that the placement of the "genre-text" needs to occur "intuitively in a situational context by looking at one's prior experience, the internal clues in the text and the encyclopaedic knowledge of the world that one already has," 
including "the writer's previous experience and background knowledge of the specialist discipline as well as that of the communicative conventions typically associated with it" (22), how is the composition teaching practicum best able to enhance the (collaborative) creation of "genre-texts" like the course syllabus when engaging those with minimal to no prior disciplinary experiences or knowledge of generic expectations? An answer lies in the concept of answerability, what Helen Rothschild Ewald describes as an exchange of "ethical action and response" ("Waiting" 331). Playing on Mikhail Bakhtin's notions set forth in his "Discourse in the Novel," Ewald notes that while an utterance "has meaning only in relationship to a complex, ever-shifting network of other utterances," heteroglossia, "the situational dynamic underpinning discourse" is fundamentally "sponsored by differentiation in genre, profession, social stratum, age, and region" (331336). Ultimately, Ewald's claim that a teacher's responses to classroom procedures "are themselves responses to certain theoretical assumptions" calls for a manner of teaching "within the framework of $[\ldots]$ answerability," and the "need to examine the ethical implications of our pedagogies," primarily through addressing "the students' need for us to articulate the assumptions underpinning our content selections and/or pedagogical procedures" (343).

Part of the responsibility of instructors is to respond to students' need for our own pedagogical articulation. As a genre of academic writing, the composition course syllabus works as a more-than-functional discursive utterance of operating in response to other utterances, to other networks of how we understand the syllabus. Taken together as both responsibility and operational discourse, the "coherent scheme" offered in Irmscher's case does indeed begin to resemble more of the "trickle down" theory Blakemore critiques it 
as. Further, Ewald's description of pedagogical answerability belies the otherwise structured nature of a more traditional model syllabus, or treating the syllabus as such within the framework of the graduate student teaching practicum. Beyond the more immediate sense - how are we to "articulate the assumptions underpinning our content selections and/or pedagogical procedures" if these are decisions removed from our discretion? - placing the challenges of the course syllabus directly as a subject of conversation for the composition teaching practicum reorients our understanding of the functions of heteroglossia in the development of teacher identities through this text. The composition teaching practicum, then, through a focus on this essential text as a representation of a teacher's in-process identity, can become a medium for these (in Ewald's terms) sponsorships of differentiations in graduate students' "professions, social stratum, age, region," and most certainly, differentiations in their understandings of the genre of the course syllabus.

These differentiations, particularly conceived through conceptions of the course syllabus, figure heavily into Bill Bolin and Peter Vandenberg's issue-length collection of composition teaching practica, which includes both the actual syllabi from these courses from universities across the country, as well as explanatory rationale for the course as submitted by directors of composition and/or department chairs. This collection establishes how different conceptions of the composition teaching practicum lead to different conceptions of the status of the graduate student teacher within the framework of the department, the university, and broader strata of authority. A few examples from this forum play out these differences. While my intention is not to re-catalogue descriptions of the teaching practicum from these various programs, these snapshots of 
practica taken together offer suggestions as to the placement of the course syllabus within this essential course. Edwina Helton and Jeffery Sommers from Miami University (Ohio) offer the suggestion that graduate student teachers of composition might be classified as such only on a temporary basis, noting, "whatever your plans, you are about to become a teacher for the next few semesters, and you have an obligation to do that job in a professional manner" (52). Helton and Sommers operate simultaneously on the supposition that the definition of "graduate student teacher" encompasses different gradations of identity. They allude to the co-taught composition teaching practicum, recognizing that the two instructors "demonstrate in their own discourse different orientations to teaching," primarily through occupying "different locations in terms of age, race, gender, and power positions: one instructor is a full professor, well established in the profession, while the second instructor is an advanced $\mathrm{PhD}$ candidate working through the professionalization process" (57-58). In this case, the composition teaching practicum functions as a direct representation of the differentiations within these identities struggling to find, achieve, or maintain a place within the particular disciplinary and institutional structure.

Described as "a highly-charged and conflictual institutional 'space'" (73), Kathleen Dixon from the University of North Dakota-Grand Forks characterizes the teaching practicum as a pivotal course for disciplinary development, acknowledging that, at least at this institution, "many who decide to specialize in composition make their decisions after the required composition study they undertake in their first year as graduate student teaching assistants" (75). Signaling a particular set of conditions of what has often been referred to as the "conversion metaphor" in composition, ${ }^{2}$ the decision to 
specialize in Rhetoric and Composition as a function of the composition teaching practicum demonstrates the extent to which this particular course operates as an essential factor in the development of the graduate student teachers' multiple stakeholder positions, as well as emergent teacher identity structures and roles.

Joseph Harris from the University of Pittsburgh describes the seminar of the teaching practicum as a course designed to help graduate students "form a stance as a teacher in relation to $[\ldots]$ competing voices and authorities" (78), while Richard Marback from Wayne State University describes the course as an opportunity for graduate student teachers "to announce their positions on what they think writing teaches and how they would teach it, providing some examples of this through brief sample syllabi," which in turn "reflect positions taken on current debates, and draw on the vocabularies of the profession, to give expression to critically informed teaching practices" (98-99). The distinction between the end results of the composition teaching practicum in this regard, between "forming a stance" and "announcing a position," appears principally significant, especially considering teacher identities as highly contextualized, relational structures as opposed to pre-formulated constructions proffered up exclusively in response to a decidedly temporary formulation of "what they think writing teaches." In the case of these two depictions of the composition course practicum, I argue that the course syllabus - especially for the entering graduate student teacher of composition - functions as the middle ground between the formation of a disciplinary and institutional "stance" and the representation of an "announced position" through the (always and only) temporarily stable genre of the syllabus itself. 
Finally, in regards to examining more current iterations of the composition teaching practicum, I wish to explore selections from Sidney Dobrin's recent collection, Don't Call it That - The Composition Practicum. Dobrin spends the majority of his introduction characterizing the essentially problematic nature of the course, "not only in terms of definition, but also in terms of its role in composition studies and larger university communities, its function as a training mechanism, and its share in the propagation of composition studies' cultural capital" (1). Dobrin's introduction essentially shies away from traditional conceptions of a service discipline, and thus by extension perceptions of the practicum "as a how-to course" (2). This entire collection ultimately seeks to move beyond conceptions of the composition practicum as "a negative space, one that controls identities - programmatic and individual - in improper ways," offering those of us embedded in the discipline further opportunities to see this course "not merely as the required course in professionalization, but also as one of the most powerful sites in composition studies and English studies" (28).

Dobrin's introduction, "Finding Space for the Composition Practicum," indicates the troubled and troubling conditions of institutional and disciplinary location as they pertain to this course that should succeed beyond a how-to course, pointing out that "even in the early inceptions of the composition practicum," speaking of Albert Kitzhaber's "Rhetorical Background of Written English" course at the University of Kansas in 1950, "compositionists recognized the power such a course had for disseminating a particular (political) view of what teaching composition is" (11). This early indication of the significance of the composition practicum course appears coupled with movements in the 1960s and 1970s towards theories of writing that Dobrin notes "attended to practical and 
pedagogical approaches," including "the advent of cognitivism and process approaches to writing [which] provided writing teachers with specific methodologies of how to teaching writing students how to write" (17). Although Dobrin never mentions the term specifically, the struggle between the identifiable influences of the composition practicum course coupled with desires to develop and maintain concrete (or concretized) pedagogical methodologies in the composition classroom lies in the struggle of praxis itself. In these terms, in the battle between what Dobrin calls the dominant push towards the inclusion of theory in graduate level teacher training and "conventional wisdom grounded in process paradigrn" (17), we should refocus the graduate student composition teaching practicum course around the development of the course syllabus as a contributory genre in the construction of teacherly identities - one that is active both in the theoretical perceptions of composition as an academic discipline and in the practical methodological implications of the day-to-day realities of the composition classroom.

In the spirit of a sense of praxis, and reflecting upon their experiences in the English department at the University of Washington at Seattle, Juan Guerra and Anis Bawarshi's contribution to Don't Call it That, "Managing Transitions: Reorienting Perceptions in a Practicum Course," seeks to reevaluate the circumstances under which the study and teaching of writing operate, "within the disciplinary, institutional, political, and material conditions in which it takes place" (44). An essential component of this reevaluation lies in making the connections between composition theory and practice more overt, more deliberate, and more conscious in the actions of graduate student teachers. Addressing this specific audience directly, they argue that "knowing why you ask your students to perform particular tasks and what those tasks might mean in a 
broader, social framework should mean more thoughtful, more enjoyable teaching;" further, they note how, "realistically, you will be asked about your teaching practices and philosophy when you go on the job market. [...] So in your first job, your ability to articulate what you do in the classroom becomes critical in the search" (57). In this instance, Guerra and Bawarshi argue that the conception of transition, for the graduate student in composition, should not be limited to the more overt transition from student to student-teacher, but should encompass the more overarching transition from graduate student teacher to disciplinary professional.

On a personal note, I can attest to the value of having engaged more in both the theoretical and pedagogical-practical elements of the composition course syllabus as it pertains to the construction and development of my own statement of teaching philosophy, a ubiquitous document in the graduate student dossier. The experience of the academic job market has offered me a lucid opportunity to see the implications of articulation in action. While sample course syllabi themselves were often a part of documents requested from various universities seeking to hire newly-graduated assistant professors of composition (particularly in the later stages of review), these documents were nowhere near as commonly requested - in my experiences - as statements of teaching philosophy. This paradoxically indicates not only a tendency to overlook the course syllabus as a potentially revealing representation or partial demonstration of a teacher's conception of him- or herself as a teacher (a condition I have addressed previously in this dissertation, through the limitations of treating the course syllabus as a purely functional, transparently instrumental genre), but also a desire to connect texts like the syllabus to markedly more valuable notions of articulation. Here, the place of the 
course syllabus in the composition practicum further mirrors the place of this text in the praxis-based formation of the graduate student teacher's transitional identity.

\section{Mixed Emotions - Graduate Students (Don't) Speak of the Practicum}

In my last chapter, I examined what I call "moments of awareness" present in the composition course syllabi submitted from graduate student teachers as part of my study. These moments include when graduate student teachers recognize the need for students to familiarize themselves with writing program and departmental policies at their own pace - including links to program websites, departmental websites describing the goals of first-year writing programs, and even basic university library tutorial websites - operating as a set of "see also" or "for additional information" moves. I see these types of moves as beneficial for the evolution of the genre of the academic course syllabus, particularly as they pertain to introductory composition courses. These moments can also move discussions of the course syllabus as an academic genre and partial representation of teacher identity more fully into theoretical and practical discussions in the composition teaching practicum course.

As I have mentioned earlier in Chapter Two, composition's preoccupations and struggles with its own disciplinary status - as a function both of historical interpretation and pedagogical implementation - are not an explicit focus of my dissertation; ${ }^{3}$ however, I feel that characterizations of composition's relationship to its own service identity (particularly as explored by Sidney Dobrin, Bob Connors, and Sharon Crowley) reveal themselves in these sorts of "see also" or "for additional information" moves, those becoming more and more common in composition course syllabi. Further, and more 
appropriate to these examinations of the syllabus' potential place in the composition practicum - as a microcosmic reflection of the practicum's "place" in the discipline of composition, perhaps - these moves towards "additional information," which I described earlier as having implications of enhancement rather than direct applicability, suggest graduate student teachers' conscious manipulation of "boiler-plate" policy language. This in turn offers an indication of how the course syllabus can operate as a text of articulation, in Guerra and Bawarshi's words, one which can more accurately reflect the graduate student's adaptive and transitional multi-stakeholder positions within the discipline of composition as well as the university.

In her contribution to Don't Call it That, bonnie kyburz characterizes the composition teaching practicum as a traditionally disenchanting, coercive, and constraining course (67-75), coupling the implication of "training" in terms of what she calls the "narrow conceptualizations of the roles of composition courses" with the notion of "defining" first-year composition as a necessarily constraining act (69). The degree to which these generally negative conceptions of the composition practicum have the potential to come to fruition relies primarily, I argue, on the degree to which the composition course syllabus as a function of the graduate student teacher's identity becomes a more prominent source of dialogue in the practicum course. This way, a semblance of community could be offered in the practicum course that moves beyond what kyburz calls "a disambiguating screen through which we could enact the strange alliances we pretended towards," citing Joe Harris's A Teaching Subject: Composition Since 1966 as she recapitulates how the workings of her communities tended to operate "at a vague remove from actual experience" (70). The space between a sense of 
disambiguation (of striving to establish a semblance single grammatical and semantic interpretation) and a sense of a "vague remove from actual experience" helps characterize an element of intermediacy inherent in the construction and performance of the composition practicum course.

This sense of the transitional recalls Kenneth Burke's explanation of "an intermediate area of expression that is not wholly deliberate, yet not wholly unconscious," functioning "midway between aimless utterance and speech directly purposive," and identifying "private ambitions with the good of the community [as both] partly justified [and] partly unjustified" (Rhetoric of Motives 521). Interpretations of "intermediate" in this regard more concretely reveal graduate student teachers of composition as multiple stakeholders in the discipline - not only in the sense of maintaining (or being placed into) a middle position, but also from a chemical point of view, "intermediate" in the sense of a substance necessary to the creation of a desired final product. So, in a sense, graduate student teachers become "intermediates" in-process as well as in-product, as in "Professing at the Fault-Lines: Composition at Open Admissions Institutions," in which Cynthia Lewiecki-Wilson and Jeff Sommers explain how a 1998-1999 assessment of graduate Rhetoric and Composition programs "locates the discipline in the (re)production of graduate teachers of rhetoric and composition, not in undergraduate writing courses" (438). This sense of intermediacy can be seen as a lens through which we can more thoroughly investigate graduate student teachers' placement in and against both departmental and institutional requirements pertaining to the construction, dissemination, and documentation of their course syllabi. 
Through these explorations, characterizations of the composition teaching practicum - though often minimal and palpably hesitant - reveal the extent to which graduate student teachers have (and have not) considered the course syllabus as a representational function of themselves as instructors, and the institution that serves as a space in which to create the instructor as such. Of the 25 original respondents enrolled in graduate work at the time of this study at institutions which offer at least a Masters degree in Rhetoric and/or Composition, submitting a total of 43 course syllabi for my study between August 2008 to January 2009 (of which 40 represented variously designated versions of an introductory or first-year writing course), only thirteen responded to my follow-up questions asking them to characterize their programs in further detail. ${ }^{4}$ In and of itself, this less-than-expected turnout reveals more than merely a temporal differential between emailing an attachment of one's course syllabus and composing answers to survey questions. Although this differential is certainly a tangible factor, especially given the chaotic schedule of most graduate students (regardless of discipline and whether they also teach), this significant drop in further participation might also signal an underlying assumption that texts like the course syllabus "speak for themselves" without the need of further contextual elaboration. This suggestion recalls the distinction I explore in Chapter One between the fundamentalistic and relativistic tendencies of narrative, in the sense that the reliance on the text to speak for itself in some fashion mirrors the reliance on a dominant (fundamentalistic) narrative, a presumption of a "common story" relevant to the text's representation of the teacher's identity.

What is most intriguing about the decline in response between submitting a sample composition course syllabus and submitting responses to the brief questionnaire is 
that the proportions of respondents remain parallel. Of the 25 individual participants in this study, 19 were $\mathrm{PhD}$ students at the time of their submission of their course syllabi, and six were Masters students (doctoral students representing $76 \%$ of the total). Of the 13 respondents to the additional follow-up questions, 10 were $\mathrm{PhD}$ students and three were Masters students (doctoral students in this case representing roughly $77 \%$ of the total). This oddly proportionate decrease in participation, regardless of one's location in the hierarchy of graduate education, represents what Richard Ohmann describes as a combination of "the intimidating weight of professional expectations, the crush of daily labor, the monumental anxieties produced by qualifying exams, [and] the impossibility as it seemed, of producing a discourse of 300 pages or so that some human being would care to read" (247). In other words, the investment (in this case, of time) transformed fundamentally between the submission of an already-created composition course syllabus and a set of yet-to-be-created responses to my questionnaire.

These combinations of institutional, disciplinary and personal pressures are of course not unique in any professionalizing environment, and are certainly not unique to composition over and above other academic disciplines; however, I argue that the graduate student teacher of composition is placed (or perhaps located) in a tenuous authorial position of professionalization, as a contributory member of the pedagogical preservation of that discipline. Brian Bly, in his "Uneasy Transitions: The Graduate Teaching Assistant in the Composition Program," clarifies this tenuousness as a contributor to the compilation In Our Own Voice: Graduate Students Teach Writing. Bly explores the difficulties of graduate student instructors facing "a fundamental conflict between the position of authority they possess as composition professors and the lack of 
authority inherent in their roles as students in a graduate program" (2). While my earlier explorations of the subtleties entailed in these kinds of relationships, displays, and assumptions of authority tend to contest his binary supposition of a possession/lack of authority in the daily operations of the graduate student teacher - particularly in the ways in which I employ the term "multiple stakeholder" to challenge characterizations of authority as a possession - I do agree with Bly's depiction of the role of the graduate student teacher of composition as one replete with conflict.

These conflicts manifest themselves in terms not only of definitions and practical applications of authority in the classroom, but also in what Bly, through a survey he conducted in 1997 as part of his own practicum course, calls "an undercurrent of dissatisfaction with their preparation, particularly a wish for more instruction in pedagogy and in practical applications of composition theory in the classroom" (4). Bly's observations point to the interconnectivity between internal conceptions of graduate student teachers' own sense of authority and their external sense of their place in the practicum course. This interconnectivity signals what Stacia Dunn Neely (another graduate student contributor to In Our Own Voice) calls the need "to look more closely at the training and working conditions of graduate instructors with a commitment to improving their situations as beginning teachers who have the potential to offer new ways to envision the teaching of writing," in the sense that "graduate instructors do have a part in defining the field of composition studies" (20). Further, Neely acknowledges the inherent complications of the graduate student's role in the university structure, particularly focusing on titles - including "student," "assistant," and the often "misappropriated" title of "Professor So-and-So" when it comes to addresses from their 
students - and the fact that, given these immediate exterior representations of themselves, "it is not surprising, then, that the TA should be concerned with issues of subjectivity, identity politics, and role conflict" (21). This exteriority, this critical reflection of self-asteacher rather than the often frightened (particularly in the earlier stages of one's teaching career) performance of self-as-teacher, reveals itself more completely through the practicum course, the desired - if not often produced - interactions between composition theory and practice. Exploring the theoretical and practical implications of the composition course syllabus in the practicum course would, by extension, help both the practicum course as well as the discipline of composition (in terms of its relationships with graduate student teachers) refocus this struggle of praxis as a necessary development of professional and disciplinary identities.

The essential dilemma, then, becomes not whether issues associated with the construction and dissemination of the composition course syllabus should be a central tenet of the practicum course, but how the syllabus should present itself as a subject of conversation and discussion within this framework. Although I have discussed conceptions of the model syllabus and its various implications in my third chapter, specifically in terms of how views of "the model" filter through the composition program directors I encountered in my data collection, I do wish to revisit the issue of the model syllabus briefly, particularly in the context of its perception in the composition practicum. Of the 13 respondents to my questionnaire asking for further characterization of their individual program, none of the respondents claimed they were required to use a model syllabus provided as part of the practicum course; six responded that they were offered a model syllabus; six claimed that they were not offered a model syllabus; and one claimed 
both, referring to two separate teaching practicum experiences at two different institutions.

The respondents, ranging (at the time the survey was conducted, between August 2008 and January 2009) from less than three months to more than ten years of collegelevel teaching experience, also expressed similarly divided sentiments in regards to the efficacy and other associated implications of using the model syllabus provided in the practicum course. Not including the one respondent to the survey who referred to multiple practicum experiences, half of the respondents expressed positive sentiments concerning even the presence of a model syllabus in the composition teaching practicum course, while half framed this offering in a more negative light. Most of the positive comments can be characterized in terms of ease, assuaging fears early in one's teaching career, and providing opportunities to examine genre expectations - avoiding the temptation to, as one graduate student teacher put it, "re-invent the wheel." Negative comments directed towards model syllabi offered in the practicum course concentrated more on the generic nature of its construction resulting in, as one graduate student teacher explained, "a lot of redundant or repeated text" which "took more time cutting/revising [...] than simply coming up with my own [syllabus]."

Risa Gorelick, in "'Read My Lips' and Other Rhetoric: A Qualitative Ethical Study of TAs Using Standardized Syllabi in First-Year Composition Classes," acknowledges that "the assumption $[\ldots]$ that the teacher presenting the syllabus has designed it and feels invested in its goals" is indeed often a faulty one (1). Her explorations of the literature that variously characterizes teaching syllabi "that pursue a particular social agenda" as "transformative, socially responsible, political, politically 
correct, unethical, and immoral" (1), curiously overlook the most basic, immediate, visceral element of all of this - the potentially overwhelming stress on an entering graduate student teacher's time. I have already mentioned in Chapter Three that my intention here, both in these particular investigations and in the dissertation as a whole, is not to disparage the concept of offering a model syllabus in its entirety. Simultaneously, I do wish to reiterate that, especially in programs in which a large majority of the introductory composition courses are taught by graduate student teaching assistants with a wide range of pedagogical and institutional experiences (often outside the realm of the English department), ${ }^{5}$ the concept of the model syllabus as presented in the context of the practicum course designed (presumably) to more carefully associate practical and theoretical teaching concerns cannot and should not be relegated solely to conditions of ownership. Overarching ethical and authorial concerns, in this instance, come into conflict with more immediate, basic concerns of time - time which suddenly becomes an overtly operational element of the emerging graduate student teacher's identity, a further point of subjective negotiation.

This contributory factor of temporality serves to complicate the reception of the syllabus as an academic genre. Not unlike the genre of the graduate seminar papermany a graduate student has submitted work with which he or she was not entirely satisfied, simply because the external temporality of the academic term assigns a due date to which they are invariably held accountable - the syllabus as an academic genre becomes further complicated by the notion of limited time. One feels compelled (if not required) to begin the term with something resembling a syllabus, a plan, a schedule, a set of policies to begin to structure the course as a miniaturized, highly temporalized 
academic discourse community. Brenton Faber, in "Rhetoric in Competition: The Formation of Organizational Discourse in the Conference on College Composition and Communication Abstracts," examines conference abstracts as "a genre of writing that academic organizations produce, support, and legitimate," through what he calls "a disciplining process" (356). Further, Faber employs Chantal Mouffe's "Hegemony and New Political Subjects: Toward a New Concept of Democracy" in examining CCCC as a process of discipline construction that "creates various social tensions among participating members as the organization works to establish 'relatively stable social forms' within its boundaries" (361). In this sense, the relative stability of genre as a social form realizes itself, at least partially, through the relative stability of time itself, the temporality through which any genre takes place.

Kristeva reminds us that processes of intertextuality occur to some extent "through a combination of displacement and condensation" ("Revolution" 111), and these processes of passage, of transposition, occur through an inherently temporal medium. The ways in which conference abstracts, for instance, come into being through processes of production, authentication, and legitimation are acted upon by an overriding awareness of temporality - in the case of the conference abstract, the ubiquitous deadline. Although Faber focuses on deliberately limited and specific examples of academic discourse constructions and disseminations, his parallels between the "disciplining process" of conference abstracts and composition course syllabi reinvigorate my earlier examinations of the course syllabus as an inherently intertextual document (in Chapter Two), as well as my earlier claim that this intertextuality ought to be made a more deliberate point of discussion in the composition practicum. 
Faber's observations remind us not only that academic disciplines are under constant reproduction and reconstruction but also that the "apparently naturalized boundaries" of academic organizations are just that - apparently. Through the parallel of these "disciplining processes," the model syllabus can function more in a conversation about the conditionality and multiplicity of the syllabus as a genre, rather than in an either/or position in regards to its presence or use in the composition practicum. In this regard, the question in my survey which asks, "If you are offered/required to use a "model" syllabus, do you work against it in other ways?" partially contributes to this binary supposition, in terms of juxtaposing conditions of offering with those of requiring. At the same time, this question offers graduate student teachers a way into these discussions of the syllabus as an intertextual genre, the model as a set of opportunities to explore what to do and what not to do in the graduate student's own version of the composition classroom.

Finally, Faber's analysis of conference abstracts as functional representations of the ways in which academic disciplines "produce, support, and legitimate" themselves in order to establish "relatively stable social forms" mirrors Catherine Schryer's observation on genres as "stabilized-for-now" (in her "The Lab vs. The Clinic"). More appropriately, this sense of relative stability recalls Amy Devitt's observation that "if each text always participates in multiple genres, then even in that text a genre is moving, shifting, and becoming destabilized" ("Integrating" 713). Thus, if we can make even the presence of the model syllabus in the composition teaching practicum a subject of conversations concerning the syllabus in general as an intertextual academic genre, competitively operating between notions of stability and destabilization, we can in turn begin to use the 
practicum as a forum for examining the composition course syllabus as a socially reconstitutive text in the reconstructions and reorganizations of teacher identity structures.

\section{Re: Re: Re: The Syllabus, the Practicum, and Processes of Becoming}

These repetitions of "re-" phrases above are not accidental. What can help make the composition practicum less of an exclusively "how-to" course, and more concerned with productive intersections of day-to-day teaching goals and broader theoretical understandings of the teaching of writing, involves envisioning the practicum as a forum for examining the syllabus as a deliberately unoriginal document, a genre of academic writing that, like all other genres of academic writing, proceeds along a not-always linear path of development and evolution. Although perhaps conceptions of the model syllabus are easily established as a collective whipping-boy in this regard, we should be more open to the notion that examining different kinds of syllabi from different courses - not just different literature and composition courses from within the English department, but syllabi from mathematics, history, hard sciences, and foreign language courses as well, for instance - can offer beginning teachers of composition opportunities to discuss the extent to which this text serves as a continually shifting, operationalizing representation of their teacherly identities in deference to their academic discipline.

In "Developing Pedagogies: Learning the Teaching of English," Shari Stenberg and Amy Lee narrativize their respective experiences as a first time teacher and the director of writing at the University of Minnesota's General College (described as "an open admissions program within the university"), specifically engaging Shari's initial 
encounters with developing a composition course syllabus as an impetus for hierarchical and institutional conflict. Through their descriptions of their meetings to discuss perceived problems with Stenberg's syllabus, Lee notes how she posed a number of questions "intended to help Shari examine the assumptions informing the syllabus," including, "What are your reasons for choosing the texts that you did? What role should published texts serve in a writing class? How do they work in relation to students' own writing projects?" (332). Lee explains that her intention was "not to help Shari 'fix' the syllabus, but to encourage a particular mode of reading - one that would render visible the pedagogy in the syllabus" (332). Processes of rendering pedagogy visible reflect Sternberg and Lee's desire to see the "possibility in recognizing where we fall short of the visions we are working to achieve; it is how we revise and grow" - arguing that "teaching can never be finally mastered," they argue the same "about striving to enact a group that positions teachers of different experiential levels in collaboration" (345). Employing the subject of the course syllabus within the forum of the composition practicum allows for a more direct, overt path towards understanding the need for making our pedagogies more visible, not only to our students but to ourselves as well - further exploring the possibilities of this pedagogical visibility, the continual reshaping of composition as an academic discipline, and the boundaries of collaboration to include the textual beyond the physical.

Of course, I agree with Margaret Marshall in her Response to ReformComposition and the Professionalization of Teaching when she admits that "a single seminar cannot begin to provide the intellectual foundation necessary for making fully informed curricular or pedagogical choices required of those who would purport to be 
'professional' teachers at the university level" (89). At the same time, however, shifting the course syllabus to a primary position in the process of the development of teacher identities would help extend the spirit of the practicum beyond its one- or two-term limited structure, helping to quash the assumption that teaching operates as a master-able skill. Referring to her observations at the University of Michigan in Fall 2001, Marshall expresses concerns about the overly ad hoc representation of the composition practicum course. She points out how "[t]he 'issues' covered in the course are thus not issues of teaching that concern all faculty, but rather the issues of teaching assistants, issues that need not be revisited once the doctoral degree is obtained and the graduate student assumes the role of becoming a professor" (89). In the short term, inherent in the construction of the practicum course as a course, lies the problem of its eventual completion, and the concomitant presumption that one is now "finished" with teacher training.

In between, in the space between beginning the course labeled a substrata of "teacher training" and the completion of the degree, as David Smit observes in The End of Composition Studies, many students "may consider writing instructors, especially if they are graduate teaching assistants or part-time instructors, as the opposite of a model: they may consider writing instructors people in training to be experts, people who have not yet acquired the credentials necessary for giving appropriate advice" (175). It is, in fact, this very awareness of being "in training to be experts" that commits graduate student teachers to so many conditional and tentative phrases, as I have observed in Chapter Four, through my investigations of what I have called moments of authorial deferment. A significant amount of my observations from my study of graduate student 
teachers' composition course syllabi can be linked in one fashion or another to their collective consciousness of their own sense of transition, a sense of transition clearly yet artificially marked by the end of the practicum or "teacher training" course. These moments where the conditions of the authority of expertise are relegated or subjected to structures of authority outside discipline-specific knowledge, most often broader institutional structures, in cases resulting in what I have referred to earlier as a "paradox of status," are marked by an awareness of their own status, their own multiple stakeholder positions. While I cannot logistically argue that the formal, schedule-designated and university-funded composition practicum course continue for the graduate student teacher's entire career, as a graduate student teacher and beyond, I do maintain that the mentality of the practicum as a temporally-limited "teacher training" course with explicit markers of beginnings and endings to one's "training" as a teacher of writing, can begin to be overcome through the text of the course syllabus.

Examining this text as a continually shifting (yet "stabilized-for-now") representation of one's own identity as a teacher of writing, graduate student teachers enrolled in a version of the composition practicum can begin to treat both pedagogical and theoretical expertise more as processes of accretion, and not as finalizable goals. While I disagree with Darlene Habanek's assertions in her "An Examination of the Integrity of the Syllabus" that the syllabus should function as a model of accountability, I do agree with her citation of Cliff Davidson and Susan Ambrose's The New Professor's Handbook, in the seemingly obvious and unadorned declaration that "a syllabus tells students a lot about the instructor [...] and leaves a lasting first impression" (64). While I acknowledge both halves of this particular phrase, I do argue that repositioning the 
conception, construction, dissemination, and ultimately revision of the course syllabus at the forefront of the practicum will help re-imagine the development of the graduate student teacher of composition not in structurally sound but theoretically shaky terms of "training," in preparation for the day that the badge labeled "trainee" comes off, but in terms of a continual process of becoming. These re-theorizations of the course syllabus's roles in the discipline of composition can help refashion the graduate student teaching practicum as a more explicit opportunity to develop, examine, and explore conceptions and depictions of the syllabus as a representative institutional, personal, and pedagogical document. Yes, the syllabus tells students quite a bit about the instructor as an instructor, and as a multiple stakeholder in the institution, and yes, the syllabus has the potential at least to leave a lasting impression; however, both of these conditions are in a constant state of periodic flux, subject to the institutional, classroom, and course conditions from academic term to academic term. They are subject to change. 
${ }^{1}$ Military metaphors of composition - including but not limited to the teaching practicum - became the subject of a multi-thread discussion on the WPA-L listserv in the early part of June 2007, questioning both the efficacy of such metaphors already mentioned in this chapter, as well as the militaristic implications of more tangential observations, such as the ubiquitous use of the phrase "bullet points." While these metaphoric explorations as a whole fall outside the scope of my dissertation, I do argue in the early stages of this chapter that the ways we talk about graduate student teachers of composition implicitly contributes to the way we perceive the discipline of composition in general.

${ }^{2}$ While not all-inclusive, this "conversion metaphor" has been elaborated upon both in and out of the discipline in Kenneth Burke's Permanence and Change: An Anatomy of Purpose, as well as in Wendy Bishop's "Against The Odds in Composition and Rhetoric."

${ }^{3}$ Regarding composition's historical sense of its own disciplinarity, Julie Jung, in Revisionary Rhetoric, Feminist Pedagogy, and Multigenre Texts (Carbondale: Southern Illinois University Press, 2005), notes that, "Because rhetoric and composition studies in some sense has always been a discipline that does not quite 'fit in,' and indeed because so many of us see ourselves as misfits, it makes sense that it is we who might forge new ways of listening, new strategies for fostering cross-boundary discourse. Although there is pain in not belonging, we need to recognize we have had a hand in shaping our outsider status. It is here, on the borders of belonging, that revisionary work gets done" (55). Here, the location of the discipline of Rhetoric and Composition directly parallels the spatial, physical, ideological, and authorial placement of graduate students within the discipline.

${ }^{4}$ For the questionnaire, see Appendix 7, Amended Follow-Up Questions for Graduate Student Teachers Participating in Syllabus Request (IRB Approval 08.0273).

${ }^{5}$ One of my colleagues at the University of Louisville, for example, arrived at the $\mathrm{PhD}$ program in Rhetoric and Composition directly from a Masters program in Economics. Although his is arguably an unusual case, it is hardly sui generis, and the assumption that graduate student teachers have spent a majority of their professional(izing) academic career within the discursive boundaries of an English department (in literature and/or composition studies) is primarily faulty. Such an assumption does much to both artificially characterize graduate student teachers as components of a more externally homogenized academic discourse community and point to the dangers inherent in using the model syllabus to reinforce this artificiality at the expense of exploring the opportunity to make theoretical and pedagogical use of varied academic and social experiences prior to their arrival in a Rhetoric and Composition program. 


\section{CONCLUSION}

\section{SEE PAGE ONE - THE OBJECT AS SUBJECT AGAIN}

The problems that it [composition] tries to deal with are difficult, complex, and of long standing, and the particular combinations of solutions proposed for these problems are almost without number. Albert Kitzhaber, "Freshman English: A Prognosis" (476)

Evolving theories of authority, genre, and discourse community construction have collectively had a growing impact on both conceptions of composition as an academic discipline and the ways in which we in that discipline construct our course syllabi. I believe my analysis of course syllabi submitted by graduate student teachers of composition represents an attempt at a praxis of theory and pedagogy in introductory composition courses, heavily influenced by approaches to teacher identity. No longer, for instance, is the composition practicum course thought of only as a "nuts-and-bolts" or "how-to" course. The very question of entering and multiple stakeholders' identities, and the extent to which the texts they produce operate as reflections of these identities, reformat disciplinary responses to this course to ask what else takes place in this course, or what else should be taking place. These evolutions in turn reflect broader trends in composition as a discipline, complicating our understandings of what we want, need, and are compelled to teach in introductory writing courses. My impetus for pursuing this dissertation ultimately came out of negotiations of my own stakeholder positions through the last decade or so of my various experiences teaching writing courses of all kinds. 
In "Freshman English: A Prognosis," Kitzhaber reminds us of composition's propensity towards problematization. Nearly fifty years after his predictions of development, in which he calls for "abandon[ing] the service concept of the freshman course" (482), the problems facing our discipline have not diminished in complexity or in the ways we attempt to "solve" them. My dissertation operates on a fine line between merely contributing to this discipline's inclination towards complications and offering presumably over-simplified solutions to this very condition. Just as I argue that the composition teaching practicum must be a partial response to its own perceptions as a "how-to" course, the composition course syllabus must be able to respond to assumptions of its generic function as a contract, a map, an inert object (as I have explored in Chapter One), while simultaneously acknowledging that it cannot be purely reduced to a set of prescriptive generic moves. Bruce McComiskey recognizes how those students in freshman composition courses who "focus on cultural categories [...], popular artifacts $[\ldots]$, and/or institutions $[\ldots]$ benefit from rhetorical and cultural strategies that teach them to avoid the paralyzing either/or logic of identity/difference binary oppositions," ultimately working "to negotiate cultural identities and differences" (362, original emphasis). In this sense, treatments of the composition course syllabus as intersections of McComiskey's discursive foci - as intersecting representatives of cultural categories, of a "popular," disciplinary, or material (in Donna LeCourt's terms) artifact, and of the institution to which it is ultimately responsible - by extension offers these "rhetorical and cultural strategies" both to students and teachers of introductory composition courses. These interpretive and discursive layers across ranges of audience receptions offer a more carefully articulated explanation of what our course syllabi are doing, in addition to 
offering purely functional information. This dissertation does not represent a single way to read the syllabus - just as it does not argue for monolithic conceptions of authority, genre, or discourse community; rather, it represents ways to read the syllabus, and the implications of these readings for our discipline, our graduate student teachers, and our students.

Further analysis of other related texts would enhance this study. Syllabi from composition practicum courses as well as from courses tangentially related to composition as an academic discipline - including but not limited to literature survey courses, foreign languages courses, and business/technical communication courses would offer further points of analysis on syllabus writing conventions in a variety of academic disciplinary settings. These texts, as well as course descriptions authored by those with entirely different sets of stakeholder positions in the university structure, could be examined to explore rhetorical strategies employed across disciplinary conventions, further adding to analyses of the relationships between conceptions of authority and conceptions of genre. The syllabus is (and is more than) a disciplinary product, and expanding this study to include these texts would offer more descriptions of the syllabus from the perspectives of different sets of stakeholders.

Such expansions could allow me to locate more tropes of progression associated with syllabus production. Rather than focusing exclusively on graduate student teachers of composition, expanding the variety of texts received would allow a more evolutionary exploration of the syllabus through the progression of authorships. This study could be simultaneously focused and expanded upon, through a more directly defined case study of one writing teacher's syllabus evolution, from graduate student to assistant or associate 
professor and beyond. Course syllabi function as point-blank representatives of one's teacherly identity most explicitly, perhaps, as one enters the academic job market, marking another transition of "stakeholdership" from graduate student to emerging professional, and placing this transitional identity most in conflict with the syllabus serving (as an augmentation to other job documents - the application letter, curriculum vitae, statement of teaching philosophy, and the like) as a temporary, or perhaps "stabilized-for-now" substitution. This position of the syllabus as a "stand-in" or a shorthand version of teacher and student identity expectations demonstrates the extent to which both entering instructors as well as entering students of college composition courses can benefit from examining the syllabi to which they are both inherently held responsible in a relational context, including elements of physical design as well as theoretical implications of this reduced self-representation.

I believe this dissertation's investigative approach to the course syllabus can be redirected or expanded upon in several different ways. First, as mentioned above, more emphasis should be placed on these elements of layout and design - including negotiations of white spaces, typefaces, fonts, and other aspects of visual style. Both teachers and students implicitly understand that a particular policy, due date, or other associated requirement must be of significant importance if it is underlined, italicized, or in bold on the course syllabus. Beyond these more immediate indicators, however, teachers of writing would benefit from exploring how receptions of the visual packaging of a text factors into the very text they construct to deliver a list of these readings to students in the first place. Second, tracing the developments of various visual elements of the syllabus, centering on those of layout and design, would allow for a more natural 
progression to the next evolutionary stage of the course syllabus as a genre of academic writing - the online syllabus. I am not speaking of PDF or Microsoft Word versions of print syllabi that are merely available online, but exclusively-online syllabi, designed for exclusively (or at least primarily) online courses. This inevitable next stage in the syllabus's progression as a pedagogical, theoretical, and personal representation of a teacher's identity would help further demonstrate the complexities of location in determining perceptions of authority, the functional operations of textual genres, as well as the co-construction of discourse communities in an environment not based on an understanding of physical location.

Third, contrasting the creation, production, and dissemination of course syllabi from introductory writing courses and those from more advanced writing courses including undergraduate and graduate - would help identify the extent to which teachers of writing construct themselves in deference to pre-determined understandings and conceptions of the discourse communities they and their students enter into, and where these pre-determined understandings originate. The differences in the degrees of attention paid to consequences, for example (in content, form, and scope), could expand my initial observations on authority, since instructors of upper-level or graduate-level English courses might presumably spend less time in their syllabi explaining elements such as attendance and plagiarism than instructors of introductory composition courses. Such contrasting moves might lead to a re-assembly of my observations on stakeholder positions in composition, since I deliberately limit myself to graduate students in this dissertation. Finally, each chapter could be expanded to analyze more instances where the composition course syllabus' role demonstrates the continual re-construction of the 
teacher of writing through personal, pedagogical, theoretical, and institutional frameworks.

Since Kitzhaber's "prognosis" for the future of composition more than suggests a preoccupation with problems associated with a burgeoning academic discipline problems still fundamentally affecting composition's depiction of itself through its own disciplinary historical narratives - we can always gain new stories in composition. People new to the discipline will always have associations and models in mind about what makes a teacher, what defines the role, the performance they have at one time seen "on stage," but have never been behind the scenes of production until now. Because we will always have new teachers, new syllabi, new narratives, and new subjects of composition, we will also always strive towards accretion, new ways to see, to make a presumably inert object of our discipline the subject once again. 


\section{REFERENCES}

Adler-Kassner, Linda. "Ownership Revisited: An Exploration in Progressive Era and Expressivist Era Composition Scholarship." College Composition and Communication 49.2 (May 1998): 208-233.

Afros, Elena, and Catherine F. Schryer. "The Genre of Syllabus in Higher Education." Journal of English for Academic Purposes 20 (2009): 1-10.

Aronowitz, Stanley, and Henry Giroux. Education Under Siege: The Conservative, Liberal and Radical Debate Over Schooling. London: Routledge, 1986.

Atkinson, Dennis. "Theorising How Student Teachers Form their Identities in Initial Teacher Education." British Educational Research Journal 30.3 (June 2004): $379-394$.

Baecker, Diann. "Uncovering the Rhetoric of the Syllabus: The Case of the Missing I." College Teaching 46.2 (Spring 1998): 58-63.

Bailey, Dudley. "The Graduate Assistant and the Freshman English Student." College Composition and Communication 5.1 (February 1954): 37-40.

Bakhtin, Mikhail M. Speech Genres and Other Late Essays. Trans. V. W. McGee. Austin: University of Texas Press, 1986.

---. The Dialogic Imagination: Four Essays. Ed. Michael Holquist. Trans. Caryl Emerson and Michael Holquist. Austin: University of Texas Press, 1981. Barthes, Roland. S/Z. Trans. Richard Miller. New York: Hill and Wang, 1974. 
---. "Writers, Intellectuals, Teachers." Image-Music-Text. Trans. Stephen Heath. New York: Hill and Wang, 1977. 190-215.

Bartholomae, David. "Inventing the University" When a Writer Can't Write - Studies in Writer's Block and Other Composing-Process Problems. Ed. Mike Rose. New York: Guilford Press, 1985. 134-165.

---. "Writing Assignments: Where Writing Begins." Fforum 4 (1982): 300-312.

Bawarshi, Anis. Genre and the Invention of the Writer: Reconsidering the Place of Invention in Composition. Utah State University Press, 2003.

---. "The Genre Function." College English 62.3 (January 2000): 335-360.

Bazerman, Charles. Constructing Experience. Carbondale: Southern Illinois University Press, 1994.

---. "What Written Knowledge Does: Three Examples of Academic Discourse." Philosophy of the Social Sciences 11 (September 1981): 361-87.

Bennett, W. Lance. "Storytelling in Criminal Trials: A Model of Social Judgment." 1978. Memory, Identity, Community - The Idea of Narrative in the Human Sciences. Ed. Lewis P. Hinchman and Sandra K. Hinchman. Albany: SUNY Press, 2001. 72-103.

Berlin, James. "Composition Studies and Cultural Studies: Collapsing Boundaires." Into the Field: Sites of Composition Studies. Ed. Anne Ruggles Gere. New York: MLA, 1993. 99-116.

---. "Rhetoric and Ideology in the Writing Class." College English 50.5 (September 1988): 477-494. 
Berkenkotter, Carol, and Thomas Huckin. Genre Knowledge in Disciplinary

Communication: Cognition/Culture/Power. Hillsdale, NJ: Lawrence Erlbaum, 1995.

Bhatia, Vijay K. Analysing Genre: Language Use in Professional Settings. London: Longman, 1993. 13-4.1.

Bishop, Wendy. "Against the Odds in Composition and Rhetoric." CCC. 53.2 (2001): $322-335$.

Bizzell, Patricia. "Power, Authority, and Critical Pedagogy." Journal of Basic Writing 10.2 (1991): 54-70.

---. "The Intellectual Work of 'Mixed' Forms in Academic Discourses." Alt Dis Alternative Discourses in the Academy. Eds. Christopher Schroder, Helen Fox, Patricia Bizzell. Portsmouth: Heineman, 2002. 1-10.

Blakemore, Peter. "An Intentionally Ecological Approach to Teacher Training." WPA 21.2-3 (Spring 1998): 137-149.

Bleich, David. "In Case of Fire, Throw In (What to Do with Textbooks Once You Switch to Sourcebooks)." (Re)Visioning Composition Textbooks: Conflicts of Culture, Ideology, and Pedagogy. Eds. Xin Liu Gale and Frederic G. Gale. Albany: SUNY University Press, 1999. 14-42.

Bly, Brian K. "Uneasy Transitions: The Graduate Teaching Assistant in the Composition Program." In Our Own Voice: Graduate Students Teach Writing. Eds. Tina Lavonne Good and Leanne B. Warshauer. Needham Heights, MA: Allyn \& Bacon, 2000. 2-9. 
Boland, Mary R. "The Stakes of Not Staking Our Claim: Academic Freedom and the Subject of Composition." College English 70.1 (September 2007): 32-51.

Bolin, Bill, Peter Vandenberg, et al. "A Forum on Doctoral Pedagogy." Composition Studies/Freshman English News 23.2 (Fall 1995): 4-103.

Bourdieu, Pierre. Outline of a Theory of Practice. 1972. Trans. R. Nice. Volume 16. Cambridge: Cambridge University Press, 1977.

Branaman, Ann. "Reconsidering Kenneth Burke: His Contributions to the Identity Controversy." The Sociological Quarterly 35.3 (1994): 443-455.

Briggs, Charles L. and R. Bauman. "Genre, Intertextuality and Social Power." Journal of Linguistic Anthropology 2 (1992): 131-172.

Brodkey, Linda. Writing Permitted in Designated Areas Only. Minneapolis: University of Minnesota Press, 1996.

Bruffee, Kenneth. "Collaborative Learning and the 'Conversation of Mankind."' College English 46.7 (November 1984): 635-652.

---. "Social Construction, Language, and the Authority of Knowledge: A Bibliographical Essay." College English 48.8 (December 1986): 773-790.

Bruner, Jerome. Acts of Meaning. Cambridge/London: Harvard University Press, 1990.

Buranen, Lise, and Alice Roy, eds. Perspectives on Plagiarism and Intellectual Property in a Postmodern World. Albany: SUNY University Press, 1999. Burbules, Nicholas. "A Theory of Power in Education." Educational Theory 36.2 (Spring 1986): 95-114. 
Burke, Kenneth. A Grammar of Motives and a Rhetoric of Motives. 1945/1950.

Cleveland/ New York: Meridian, 1962.

--.. Permanence and Change: An Anatomy of Purpose. 1935. Berkeley: University of California Press, 1984.

Butler, Paul. "Style in the Diaspora of Composition Studies." Rhetoric Review 26.1 (2007): 5-24.

Carroll, Lee Ann. "Pomo Blues: Stories from First-Year Composition." College English 59.8 (December 1997): 916-933.

Carter, Michael. "Ways of Knowing, Doing, and Writing in the Disciplines." College Composition and Communication 58.3 (February 2007): 385-418.

Cherry, Robert D. "Ethos Versus Persona - Self-Representation in Written Discourse." Written Communication 5.3 (July 1988): 251-276.

Christie, Francis. "Curriculum Macrogenres as Forms of Initiation into a Culture." Genre and Institutions: Social Processes in the Workplace and School. Eds. Francis Christie and J.R. Martin. London: Cassell, 1997. 134-160.

Clark, Gregory. "Rescuing the Discourse of Community." College Composition and Communication 45.1 (February 1994): 61-74.

Clark, Irene. "A Genre Approach to Writing Assignments." Composition Forum 14.2 (Fall 2005): 1-14.

---. "Reconsideration of Genre." Visions and Revisions: Continuity and Change in Rhetoric and Composition. Ed. James D. Williams. Carbondale: Southern Illinois University Press, 2002. 89-108. 
Coles, William E. "Freshman Composition: The Circle of Unbelief." College English 31.2 (November 1969): 134-142.

Connors, Robert J. "Composition History and Disciplinarity." History, Reflection, Narrative: The Professionalization of Composition 1963-1983. Ed. Mary Rosner, Beth Boehm, and Debra Journet. Westport, Connecticut: Ablex Publishing, 1999. 3-21.

Cook-Sather, Alison. "Education as Translation: Students Transforming Notions of Narrative and Self." College Composition and Communication 55.1 (September 2003): 91-114.

Crowley, Sharon. Composition in the University: Historical and Polemical Essays. Pittsburgh: University of Pittsburgh Press, 1998.

Danielewicz, Jane. "Personal Genres, Public Voices." College Composition and Communication 59.3 (February 2008): 420-450.

Davidson, Cliff, and Susan Ambrose. The New Professor's Handbook. Bolton, MA: Anker Publishing, 1994.

Derrida, Jacques. "The Law of Genre." Trans. Avital Ronell. Critical Inquiry 7.1 (Autumn1980): 55-81.

Devitt, Amy J., Anis Bawarshi, and Mary Jo Reiff. "Materiality and Genre in the Study of Discourse Communities." College English 65 (May 2003): 541-558.

---. "Generalizing about Genre: New Conceptions of an Old Concept." College Composition and Communication 44.4 (December 1993): 573-586.

--.. "Integrating Rhetorical and Literary Theories of Genre." College English 62.6 (July 2000): 696-718. 
---. Writing Genres. Carbondale: Southern Illinois University Press, 2004.

Dobrin, Sidney. Constructing Knowledges - The Politics of Theory-Building and Pedagogy in Composition. Albany: SUNY Press, 1997.

---. "Finding Space for the Composition Practicum." Don't Call it That - The Composition Practicum. Urbana, Illinois: NCTE, 2005. 1-34.

Dorwick, Keith. "The Last Bastion: Student Self-Determination and the Making of a Syllabus." CCCC Presentation; Washington, DC, 25 March 1995.

Downs, Douglas, and Elizabeth Wardle. "Teaching about Writing, Righting Misconceptions: (Re)Envisioning 'First-Year Composition' as 'Introduction to Writing Studies'." College Composition and Communication 58.4 (June 2007): 552-584.

Dudley, Fred A. "The Success of Freshman English." College English 1.1 (October 1939): 22-30.

Duff, David. "Intertextuality Versus Genre Theory: Bakhtin, Kristeva and the Question of Genre." Paragraph 25.1 (March 2002): 54-74.

Eberly, Rosa. "From Writers, Audiences, and Communities to Publics: Writing Classrooms as Protopublic Spaces." Rhetoric Review 18.1 (Autumn 1999): $165-178$.

Ede, Lisa. Situating Composition - Composition Studies and the Politics of Location. Carbondale: Southern Illinois University Press, 2004.

Ede, Lisa, and Andrea Lunsford. "Audience Addressed / Audience Invoked: The Role of Audience in Composition Theory and Pedagogy." College Composition and Communication 35.2 (May 1984): 155-171. 
---. Singular Texts/Plural Authors: Perspectives on Collaborative Writing.

Carbondale: Southern Illinois University Press, 1990.

Erickson, Bette LaSere, and Diane Weltner Strommer. "Preparing a Syllabus and Meeting the First Class." Teaching College Freshmen. San Francisco: JosseyBass Publishers, 1991. 81-92.

Erickson, Lori. "The Graduate Student: Forty-Five Years Later." College English 47.8 (December 1985): 852-855.

Ewald, Helen Rothschild. "Waiting for Answerability: Bakhtin and Composition Studies." College Composition and Communication 44.3 (1993): 331-348.

Faber, Brenton. "Discourse and Regulation: Critical Text Analysis and the Linguistic Turn in Workplace Studies." Communicative Practices in Workplaces and the Professions. Eds. Mark Zachry and Charlotte Thralls. Amityville, NY:

Baywood, 2007. 203-218.

---. "Rhetoric in Competition: The Formation of Organizational Discourse in the Conference on College Composition and Communication Abstracts." Written Communication 13.3 (July 1996): 355-384.

Fairclough, Norman. Discourse and Social Change. Cambridge: Polity Press, 1992.

Fishelov, David. Metaphors of Genre: The Role of Analogies in Genre Theory. University Park, PA: Pennsylvania State University Press, 1993.

Fisher, Walter. "Narration, Reason, and Community." 1992. Memory, Identity, Community - The Idea of Narrative in the Human Sciences. Ed. Lewis P. Hinchman and Sandra K. Hinchman. Albany: SUNY Press, 2001, 307-27 
Fishman, Stephen M., and Lucille Parkinson McCarthy. "Is Expressivism Dead? Its Romantic Roots and Its Relation to Social Constructionism." College English 54.6 (October 1992): 647-661.

Foster, Dennis A. "Interpretation and Betrayal: Talking with Authority." Reclaiming Pedagogy: The Rhetoric of the Classroom. Eds. Patricia Donahue and Ellen Quandahl. Carbondale: Southern Illinois University Press, 1989. 35-48.

Fox, Thomas. "Basic Writing as Cultural Conflict." Journal of Education 172.1 (1990): 65-83.

--. The Social Uses of Writing - Politics and Pedagogy. Westport, CT: Greenwood Publishing Group, 1990.

Freadman, Anne. "Anyone for Tennis?" The Place of Genre in Learning: Recent Debates. Ian Reid, ed. Deakin University: Geelong, 1987. 91-124.

Freedman, Aviva. "The What, Where, When, Why, and How of Classroom Genres." Reconceiving Writing, Rethinking Writing Instruction. Ed. Joseph Petraglia. Hillsdale, NJ: Lawrence Erlbaum Associates, 1995. 121-144.

Freire, Paulo. Pedagogy of the Oppressed. 1968. New York: Continuum, 2000.

Gale, Xin Liu, and Frederic G. Gale, eds. (Re)Visioning Composition Textbooks: Conflicts of Culture, Ideology, and Pedagogy. Albany: SUNY University Press, 1999. 3-13.

Gale, Xin Liu. Teachers, Discourses, and Authority in the Postmodern Composition Classroom. Albany: SUNY University Press, 1996.

Giroux, Henry. Schooling and the Struggle for Public Life. University of Minnesota Press, 1988. 
Giuliano, Cheryl Fallon. "The Writing Connection: Composing the Learner's Classroom." Pedagogy 1:2 (2001): 387-398.

Gore, Jennifer. "What We Can Do For You! What Can 'We' Do For 'You'? Struggling Over Empowerment in Critical and Feminist Pedagogy." Feminisms and Critical Pedagogy. Eds. Carmen Luke and Jennifer Gore. New York:

Routledge, 1992. 54-73.

Gorelick, Risa. "'Read My Lips' and Other Rhetoric: A Qualitative Ethical Study of TAs Using Standardized Syllabi in First-Year Composition Classes." CCCC Presentation; Washington, DC, March 23-25, 1995.

Greer, Jane. "Refiguring Authorship, Ownership, and Textual Commodities: Meridel Le Sueur's Pedagogical Legacy." College English 65.6 (July 2003): 607-625.

Guerra, Juan, and Anis Bawarshi. "Managing Transitions: Reorienting Perceptions in a Practicum Course." Don't Call it That - The Composition Practicum. Ed. Sidney Dobrin. Urbana, Illinois: NCTE, 2005. 43-66.

Habanek, Darlene. "An Examination of the Integrity of the Syllabus." College Teaching 53.2 (2005): 62-64.

Halasek, Kay. "The Subject as 'Hero,' Genre, and Authority in Written Discourse." A Pedagogy of Possibility: Bakhtinian Perspectives on Composition Studies. Carbondale: Southern Illinois University Press, 1999. 83-110.

Hamilton, Edward W. "Let's Teach Composition!" College English 6.3 (December 1944): 159-164.

Hardin, Joe Marshall. Opening Spaces: Critical Pedagogy and Resistance Theory in Composition. Albany: SUNY Press, 2001. 
Harrington, Susanmarie, and Linda Adler-Kassner. "Stories, Authority, Teaching: Making a Difference in the Composition Classroom." Questioning Authority: Stories Told in School. Eds. Linda Adler-Kassner and Susanmarie Harrington. Ann Arbor: University of Michigan Press, 2001. 1-19.

Harris, Joseph. A Teaching Subject: Composition Since 1966. Upper Saddle River, NJ: Prentice Hall, 1997.

---. "Beyond Community: From the Social to the Material." Journal of Basic Writing 20.2 (Fall 2001): 3-15.

---. "The Idea of Community in the Study of Writing." College Composition \& Communication 40 (February 1989): 11-22.

Herrington, Anne, and John Moran. "The Idea of Genre in Theory and Practice: An Overview of the Work in Genre in the Fields of Composition and Rhetoric and New Genre Studies." Genre Across the Curriculum. Eds. Anne Harrington and John Moran. Logan: Utah State University Press, 2005. 1-20.

Hesse, Douglas D. "2005 CCCC Chair's Address: Who Owns Writing?" College Composition and Communication 57.2 (December 2005): 335-357.

Horner, Bruce. "Students, Authorship, and the Work of Composition." College English 59.5 (September 1997): 505-529.

---. "Traditions and Professionalization: Reconceiving Work in Composition." College Composition and Communication 51.3 (February 2000): 366-398. Howard, Rebecca Moore. Standing in the Shadow of Giants: Plagiarists, Authors, Collaborators. Norwood, NJ: Ablex, 1999. 
Hunting, Robert S. "A Training Course for Teachers of Composition." College English 2.3 (October 1951): 3-6.

Hyland, Ken. "Stance and Engagement: A Model of Interaction in Academic Discourse." Discourse Studies 7.2 (2005): 173-192.

Irmscher, William F. "TA Training: A Period of Discovery." Training the New Teacher of College Composition. Ed. Charles W. Bridges. Urbana, IL: NCTE, 1986. 27-36.

Ivanic, Roz. Writing and Identity: The Discoursal Construction of Identity in Academic Writing. Amsterdam; Philadelphia, PA: John Benjamins, 1998.

Johns, Ann. Text, Role, and Context - Developing Academic Literacies. Cambridge University Press, 1997.

Jolliffe, David A. "Discourse, Interdiscursivity, and Composition Instruction." Reconceiving Writing, Rethinking Writing Instruction. Ed. Joseph Petraglia. Hillsdale, NJ: Lawrence Erlbaum Associates, 1995. 197-216.

Jung, Julie. Revisionary Rhetoric, Feminist Pedagogy, and Multigenre Texts. Carbondale: Southern Illinois University Press, 2005.

Kent, Thomas. "On the Very Idea of a Discourse Community." College Composition and Communication 42.4 (December 1991): 425-445.

Kill, Melanie. "Acknowledging the Rough Edges of Resistance: Negotiation of Identities for First-Year Composition." College Composition and Communication 58.2 (December 2006): 213-235. 
Killingsworth, M. Jimmie. "Discourse Communities - Local and Global." Rhetoric Review 11 (Fall 1992): 110-122.

Kitzhaber, Albert. "Freshman English: A Prognosis." College English 23.6 (March 1962): 476-483.

--.. Rhetoric in American Colleges, 1850-1900. Dallas: Southern Methodist University Press, 1990.

Kirsch, Gesa E. "Multi-Vocal Texts and Interpretive Responsibility." College English 59.2 (February 1997): 191-202.

Kristeva, Julia. "Revolution in Poetic Language" (1974). Trans. Margaret Waller. The Kristeva Reader. Ed. Toril Moi. New York: Columbia University Press, 1986. 89-136.

---. Séméotiké: Recherches Pour une Sémanalyse. Paris: Editions du Seuil, 1969. 113.

---. "Word, Dialogue, and Novel" (1967). Trans. Alice Jardine, Thomas Gora, and Léon S. Roudiez. The Kristeva Reader. Ed. Toril Moi. New York: Columbia University Press, 1986, 34-61.

kyburz, bonnie lenore. "Practica, Symposia, and Other Coercive Acts in Composition Studies." Don't Call it That - The Composition Practicum. Ed. Sidney Dobrin. Urbana, Illinois: NCTE, 2005. 67-81.

LeCourt, Donna. Identity Matters: Schooling the Student Body in Academic Discourse. Albany: SUNY Press, 2004.

LeFevre, Karen Burke. Invention as a Social Act. Carbondale: Southern Illinois University Press, 1987. 
Lewiecki-Wilson, Cynthia and Jeff Sommers. "Professing at the Fault-Lines:

Composition at Open Admissions Institutions." College Composition and Communication 50.3 (February 1999): 438-462.

Luke, Allan. "Genres of Power? Literacy Education and the Production of Capital." Literacy in Society. Eds. Ruqaiya Hasan and Geoffrey Williams. New York: Longman, 1996. 308-338.

Luke, Carmen. "Feminist Pedagogy Theory: Reflections on Power and Authority." Educational Theory 46.3 (1996): 283-302.

Lu, Min-Zhan. "Redefining the Legacy of Mina Shaughnessy: A Critique of the Politics of Linguistic Innocence." Journal of Basic Writing 10.1 (Spring 1991): 26-40.

Lunsford, Andrea, and Lisa Ede. "Representing Audience: 'Successful' Discourse and Disciplinary Critique." College Composition and Communication 47.2 (May 1996): $167-179$.

Lunsford, Andrea. "Refiguring Classroom Authority." The Ethics of Writing Instruction: Issues in Theory and Practice. Ed. Michael A. Pemberton. Norwood, NJ: Ablex, 2000. 65-78.

Marshall, Margaret J. Response to Reform - Composition and the Professionalization of Teaching. Carbondale: Southern Illinois University Press, 2004.

Matsuo, Catherine. "A Closer Look at the 'Fuzzy' Concept of Genre." Fukuoka University Review of Literature and Humanities 35.1 (June 2003). 237-263. 
Mauk, Johnathan. "Location, Location, Location: The 'Real' (E)states of Being, Writing, and Thinking in Composition." College English 65.4 (March 2003): 368-388.

McComiskey, Bruce. "Composing Postmodern Subjectivities in the Aporia Between Identity and Difference." Rhetoric Review 15.2 (1997): 350-364.

McGann, Jerome. "'Reading Fiction/Teaching Fiction': A Pedagogical Experiment." Pedagogy 1 (2001): 143-165.

Miller, Carolyn M. "Genre as Social Action." Quarterly Journal of Speech 70 (May 1984): 151-67.

---. "Rhetorical Community: The Cultural Basis of Genre." Genre and the New Rhetoric. Eds. Aviva Freedman and Peter Medway. London; Bristol, PA: Taylor \& Francis, 1994. 67-78.

Miller, Scott, Benda Jo Brueggemann, Bennis Blue, and Deneen M. Shepherd. "Present Perfect and Future Imperfect: Results of a National Survey of Graduate Students in Rhetoric and Composition Programs." College Composition and Communication 48.3 (October 1997): 392-409.

Mortensen, Peter, and Gesa E. Kirsch. "On Authority in the Study of Writing." College Composition and Communication 44.4 (December 1993): 556-72.

Mouffe, Chantal. "Hegemony and New Political Subjects: Toward a New Concept of Democracy." Marxism and the Interpretation of Culture. Eds. Cary Nelson and Lawrence Grossberg. Chicago: University of Chicago Press, 1988. 89104. 
Muhlhausler, Peter and Rom Harre. Pronouns and People: The Linguistic Construction of Social and Personal Identity. Oxford: Basil Blackwell, 1990. Myers, Greg. "Reality, Consensus, and Reform in the Rhetoric of Composition Teaching." College English 48.2 (February 1986): 154-174.

Neely, Stacia Dunn. "'Only Connect...': Graduate Instructors Choosing the Margin." In Our Own Voice: Graduate Students Teach Writing. Eds. Tina Lavonne Good and Leanne B. Warshauer. Needham Heights, MA: Allyn \& Bacon, 2000. 19-27.

North, Stephen. The Making of Knowledge in Composition: Portrait of an Emerging Field. Upper Montclair, New Jersey: Boynton/Cook, 1987.

Nystrand, Martin. What Writers Know: The Language, Process, and Structure of Written Discourse. New York: Academic Press, 1982.

Ochs, Elinor, and Lisa Capps. "Narrating the Self." Annual Review of Anthropology 25

(1996): 19-43.

Ohmann, Richard. "Graduate Students, Professionals, Intellectuals." College English 52.3 (March 1990): 247-257.

Ong, Walter. "The Writer's Audience is Always a Fiction." PMLA (1975): 405-427.

Owen, Stephen. "Genres in Motion." PMLA 122.5 (2007): 1389-1393.

Podis, JoAnne, and Leonard Podis. "Pedagogical In Loco Parentis: Reflecting on Power and Parental Authority in the Writing Classroom." College English 70.2 (November 2007): 121-143. 
Porter, James. Audience and Rhetoric: An Archeological Composition of the Discourse Community. New Jersey: Prentice Hall, 1992.

---. "Intertextuality and the Discourse Community." Rhetoric Review 5.1 (1986): 3447.

Pratt, Mary Louise. "Arts of the Contact Zone." Profession 91 (1991): 33-40. Mass Culture and Everyday Life. Ed. Peter Gibian. New York: Routledge, 1997. 6172.

Rankin, Elizabeth. "From Simple to Complex: Ideas of Order in Assignment Sequences." Journal of Advanced Composition 10.1 (Jan/Feb 1990): 126-135.

-.-. "Taking Practitioner Inquiry Seriously: An Argument with Stephen North." Rhetoric Review 8.2 (September 1990): 260-267.

Roberts-Miller, Trish. "Discursive Conflict in Communities and Classrooms." College Composition and Communication 54.4 (June 2003): 536-557.

Rose, Mike. "Speculation on Process Knowledge and the Textbook's Static Page." College Composition and Communication 34.2 (May 1983): 208-213.

Royer, Diana, et al. "Revisiting College Composition Within a Local 'Culture of Writing.'" WPA 26.3 (Spring 2003): 28-48.

Russell, David. Writing in the Academic Disciplines: A Curricular History. Carbondale, Southern Illinois University Press, 2002.

Schryer, Catherine F. "The Lab vs. The Clinic: Sites of Competing Genres." Genre and the New Rhetoric. Eds. Aviva Freedman and Peter Medway. London; Bristol, PA: Taylor \& Francis, 1994. 105-124. 
Schwartz, Nina. "Conversations with the Social Text." Reclaiming Pedagogy: The Rhetoric of the Classroom. Eds. Patricia Donahue and Ellen Quandahl. Carbondale: Southern Illinois University Press, 1989. 60-71.

Scudder, Harold. "A Functional English Course." The Journal of Higher Education 11.8 (November 1940): 412-417.

Shor, Ira. Empowering Education. University of Chicago Press, 1992.

---. When Students Have Power: Negotiating Authority in a Critical Pedagogy. University of Chicago Press, 1996.

Singh, Frances B. "'Teacher, You've Got a Problem', or Recuperating HumptyDumpty." Changing English 11.1 (2004): 19-30.

Smit, David W. The End of Composition Studies. Carbondale: Southern Illinois University Press, 2004.

Stenberg, Shari, and Amy Lee. "Developing Pedagogies: Learning the Teaching of English." College English 64.3 (January 2002): 326-347.

Stillar, Glenn F. Analyzing Everyday Texts: Discourse, Rhetoric, and Social Perspectives. Thousand Oaks, CA: Sage, 1998.

Sullivan, Francis J., Arabella Lyon, Dennis Lebofsky, Susan Wells, and Eli Goldblatt. "Student Needs and Strong Composition: The Dialectics of Writing Program Reform." College Composition and Communication 48.3 (October 1997): $372-391$.

Sullivan, Patricia Suzanne. "Common Sense and Theory in the Teaching of Composition Teachers." College Composition and Communication 60.2 (December 2008): W35-W52. 
Sullivan, Paul, and John McCarthy. "Toward a Dialogical Perspective on Agency." Journal for the Theory of Social Behavior 34.3 (2004): 291-309.

Sutherland, Robert. "Letting Students Be: Report on a Continuing Experiment in Education." College English 32.7 (April 1971): 733-739.

Swales, John. Genre Analysis: English in Academic and Research Settings. Cambridge: Cambridge University Press, 1990.

-... "Occluded Genres in the Academy: The Case of the Submission Letter." Academic Writing: Intercultural and Textual Issues. Eds. Eija Ventold and Anna Mauranen. Amsterdam: John Benjamins, 1996. 45-58.

---. Research Genres: Explorations and Applications. Cambridge/New York: Cambridge University Press, 2004.

Taylor, Marcy, and Jennifer L. Holberg. "'Tales of Neglect and Sadism:' Disciplinarity and the Figuring of the Graduate Student in Composition." College Composition and Communication 50.4 (June 1999): 607-625.

"The Role of TA's in the English Department." College Composition and Communication 22.3 (October 1971): 277-278.

Todorov, Tzvetan. Genres in Discourse. Cambridge: Cambridge University Press, 1990.

Tompkins, Jane. "Pedagogy of the Distressed." College English 52.6 (October 1990): $653-660$.

Townsend, R.C. "Training Teachers for an Open Classroom." College English 31.7 (April 1970): 710-724. 
Trimbur, John. "Composition and the Circulation of Writing." College Composition and Communication 52.2 (December 2000): 188-219.

-... "Consensus and Difference in Collaborative Learning." College English 51.6 (October 1989): 602-616.

van Slyck, Phyllis. "Repositioning Ourselves in the Contact Zone." College English 59 (1997): 149-70.

Vandenberg, Peter, and Colette Morrow. "Intertextuality or Intratextuality?

Rethinking Discourse Community Pedagogy." The Writing Instructor 14 (Fall 1994): 17-24.

Vandenberg, Peter. "Animated Categories: Genre, Action, and Composition." College English 67.5 (May 2005): 532-545.

Wallace, David, and Helen Rothschild Ewald. Mutuality in the Rhetoric and Composition Classroom. Carbondale: Southern Illinois University Press, 2000.

Wardle, Elizabeth. "Identity, Authority, and Learning to Write in New Workplaces." Enculturation 5.2 (2004): http://enculturation.gmu.edu/5_2/wardle.html Weisinger, Herbert. "A Subject for Freshman Composition." College English 2.7 (1941): 688-696.

Welch, Kathleen E. "Ideology and Freshman Textbook Production: The Place of Theory in Writing Pedagogy." College Composition and Communication 38 (1987): 269-82. 
Welch, Nancy. "Revising a Writer's Identity: Reading and 'Re-Modeling' in a Composition Class." College Composition and Communication 47.1 (1996): 41-61.

Williams, Raymond. "Culture is Ordinary." Schooling the Symbolic Animal: Social and Cultural Dimensions of Education. Eds. Bradley A. V. Levinson, et al. Lanham, MD: Rowman and Littlefield, 2000. 31-35.

Yagelski, Robert. "The Ambivalence of Reflection: Critical Pedagogies, Identity, and the Writing Teacher." College Composition and Communication 51.1 (September 1999): 32-50. 


\section{APPENDICES}

Appendix 1

Syllabus (Fall 2003, Birmingham-Southern College, Birmingham, AL)

Christopher Alexander

EH 102-I

TR 8-920am, HC 319

Office: HC 327; Office Phone: I forgot, but I'll tell you Thursday.

Office Hours: TR 930-1030am.

Email: calexand@bsc.edu

Best Email Hours: During office hours, and MTWRF 8-9pm.

\section{COURSE DESCRIPTION}

Principal Texts: Everything's An Argument, 3rd Ed. and The Everyday Writer

Essential: A good dictionary (Oxford, American Heritage). Burn your thesaurus.

The Class: Over the course of the semester, we will discuss various points and methods of argument, and we will learn that almost anything, any subject, is susceptible to debate because of the very nature of language. You will produce several essays and shorter assignments focusing on different techniques, but it is important to realize that these are not entirely separate methods; oftentimes, the most effective argumentative essays employ more than one of these skills. It is important to think of these skills as layers and not individual items. We will be focusing on writing as a process, and also on how elements of argument affect aspects of our lives outside of the college classroom...

Grade Determination: Your grade will be determined on the following scale:

$\begin{array}{lllll}100-98(\mathrm{~A}+) & 89-88(\mathrm{~B}+) & 79-78(\mathrm{C}+) & 69-68(\mathrm{D}+) & 0-59(\mathrm{~F}) \\ 96-93(\mathrm{~A}) & 87-83(\mathrm{~B}) & 77-73(\mathrm{C}) & 67-63(\mathrm{D}) & \\ 92-90(\mathrm{~A}-) & 82-80(\mathrm{~B}-) & 72-70(\mathrm{C}-) & 62-60(\mathrm{D}-) & \end{array}$

I don't round up grades; this means that if your average comes to a 79.9 , it's still a $\mathrm{C}+$, and so on.

Your total grade is made up of the following components:

Six (6) Essays@15\% each

Final Exam@10\%

Total (surprise, surprise): $100 \%$ 
A WORD OF WARNING (NOT KIDDING!): Regarding ALL assignments, LATE=ZERO. An assignment can only be in two places - here or not here.... I don't care if it's one class day late, one hour late, one minute late. Due dates and deadlines are parts of the writing process, and I will expect you to follow these due dates and deadlines. Frat party, hangover, broken leg, court date, dead computer, dead grandmother - I don't care. Unless you're dead; then, we can talk...

Attendance: You are expected to show up. You are allowed three (3) absences, to use entirely at your discretion. I advise you to use them wisely. THERE ARE NO EXCUSED ABSENCES, FOR ANY REASON WHATSOEVER. There will be no make-up opportunities at all. Following the three (3) total absences, I will deduct $1 / 2$ of a letter grade (5 points) from your final grade for each subsequent absence. In other words, if your average is an 84 and you have 4 total absences, it will be reduced to a 79 - what a stupid way to go from a B to a C.... If you miss eight (8) classes, you will not pass, regardless of the quality of coursework. Eight classes missed equals two months missed, and that's ridiculous.

A final word: ASK QUESTIONS. This is the only way to learn anything.... 
Appendix 2

Syllabus (Spring 2009, University of Louisville, Louisville, KY)

Mon/Wed 530-645pm (section 75, DA 209A)

Mon/Wed 7-815pm (section 76, LF 102)

Spring 2009

Syllabus subject to change. I will notify the class of changes at least one class day ahead of time.

Instructor: Christopher Alexander

Office: Humanities 4H (Basement), Carrel 1

Office Hrs: Mon/Wed 3-5pm. I am also available by appointment.

Office Phones: 8520987, 8527068 (these can be unreliable; best bet is email...)

Email: jesusorange@gmail.com

Course prerequisites for English 102:

English 101, approved transfer credit for English 101, or Portfolio Placement into 102.

General Course Goals:

English 102 is focused on helping students to become critical readers and writers.

Students enrolled in English 102 can expect to:

- Continue developing writing processes such as invention, revision, organization, drafting through multiple drafts, editing, adjusting for rhetorical context (purpose, audience, persona). Special emphasis will be placed on more challenging approaches to revision and rhetorical context, so that students can exercise varied and complex rhetorical options.

- Continue producing final products that reflect appropriate academic textual conventions, with special emphasis on generating longer texts (1500-2000 words) for the academic community.

- Continue sharing writing and reading with one another as a means of increasing awareness of rhetorical options and of practicing "strong readings" of both student texts and college-level texts. Emphasis will be placed on readings drawn from a variety of sources and disciplines.

- $\quad$ Continue critical thinking processes with special emphasis on the processes of primary and/or secondary research (how to find, evaluate, incorporate, and document research).

Course Description:

During the course of the semester, we will explore the process of writing research writing from developing research questions and proposals, to gathering and evaluating source materials, to incorporating and using these materials in various drafts.

As a framing device for these general course goals, we will be examining what I would like to call "the rhetorics of revolution," and we will be thinking further about how, why, and to what ends do people construct themselves, their audiences, and their rhetorical and 
contextual situations in their desires to have us "think differently." Some selections from these texts might/will/should provoke or perhaps even offend or shock you - this is understandable, and not to be discouraged in any way. In fact, one of the central tenets of this class will be to learn how to articulate and respond to these provocations and frustrations.

The texts we're reading should be thought of as subjects for rhetorical examination and careful scrutiny, and not as political/philosophical endorsement - though this in and of itself can be a fine and fuzzy line to draw, and hopefully this will become a discussion point in class.

Texts (Required): Steal This Book (Hoffman, 1971), and Rules for Radicals: A Pragmatic Primer for Realistic Radicals (Alinsky, 1971)

In addition, we will read several pieces available on Blackboard at least one week in advance.

It will be your responsibility to print these texts and bring them to class.

Grade Components:

Proposal (25\%)

Annotated Bibliography (25\%)

Research Draft $(25 \%)$

Blackboard Discussions (15\%)

Conference (10\%)

Attendance Policy:

It is a requirement of this course that you submit each assignment when it is due. Late work will not be accepted. If you know you are going to be absent (due to family situations, appointments, or extracurricular functions of any kind), it is entirely your responsibility to inform me of these absences and make plans to submit the work due for class(es) missed AHEAD OF TIME. Should a bona-fide emergency occur, discuss it with me immediately upon your return to class.

If you miss more than 6 classes, you will not pass this class.

A Note: There are wonderful people at the Writing Center waiting to help you on your way to becoming better writers. Their services are free, available to all students, available during finals week; they have computers and plenty of dictionaries, handbooks and stylebooks for additional assistance. University Writing Center, Ekstrom Library \#312 Call to set up an appointment, 8522173, or visit this website:

http://coldfusion.louisville.edu/webs/a-s/writingcenter/index.cfm to schedule an in-person or online appointment

General Course Policies:

General Education Requirement Statement: This course fulfills a General Education Written Communication Requirement. 
Disabilities Modification Statement: Students who have a disability or condition which may impair their ability to complete assignments or otherwise satisfy course criteria are encouraged to meet with their instructor to identify, discuss and document any feasible instructional modification or accommodation. Please inform your instructor about circumstances no later than the second week of the semester or as soon as possible after a disability or condition is diagnosed, whichever occurs earliest. For information and auxiliary assistance, contact the Disabilities Resource Center.

Grievance Procedures: A student who has a question or concern about a grade, the class, or an assignment should see me/contact me as soon as possible. If you are not satisfied with our discussion, you should contact an Assistant Director of Composition (8525919). Plagiarism Policy: The University defines plagiarism as "representing the words or ideas of someone else as one's own in any academic exercise." Thus, all writing you do for this course must be your own and must be exclusively for this course, unless I stipulate differently. Please pay special attention to the quotes, paraphrases, and documentation practices you use in your papers. If you have any questions about plagiarism, please ask me as soon as you think of them. If you plagiarize, I reserve the right to grant you a failure for the course and report your case to the College of Arts and Sciences. Every Wednesday, I will post a question to the COMMUNICATION $\rightarrow$ DISCUSSION BOARD section of Blackboard. You will have until the following Sunday at 11:59pm to post a response to this prompt. You will also need to respond to another student's response by the following Thursday by $11: 59 \mathrm{pm}$. Original Responses should be between 250-300 words; Responses to Another Student's Response should be 150-200 words. $(O Q=$ Original Question, $O R=$ Original Response, $R R=$ Response to Another Student's Response) 
Appendix 3

Syllabus (Fall 2005, University of Louisville, Louisville, KY)

English 101-04 and 101-08

Introduction to College Writing

MWF 8-850am (section 04) and MWF 9-950 (section 08)

FALL 2005

Note: Syllabus subject to change. I will notify the class of changes at least one class day ahead of time.

Instructor: Christopher Alexander

Office: Humanities 204, carrel D

Office Hrs: Mondays and Wednesdays $10 \mathrm{am}-12$ noon. I am also available by appointment. If you make an appointment, keep it, or I will consider you persona non grata. Conference times will be established by sign-up sheet. During Conference Schedule, regular office hours will be kept in the Ekstrom Library and NOT Humanities 204.

Phone: 8525921

Email: c0alex04@louisville.edu (those are ZEROS in the first part of the email address) Best Email Hrs: I'll check my email each weekday, but the best times to reach me for a quick response are Tuesday and Friday afternoons. You are welcome to email me anytime, but bear in mind that I am not a slave to my computer. I will not check my email on Saturdays or Sundays, so if you have an email which needs attention before Monday morning's class, be sure to send it by Friday afternoon. Don't email me Wednesday at $430 \mathrm{am}$ and expect a response before Wednesday morning's class. Be realistic regarding emails.

A piece of advice:

This is your class. If something I'm doing isn't working for you, let me know as soon as possible. If someone is not adequately participating in workshops, or is providing unsubstantial commentary, first discuss the matter (courteously) with the classmate in question. Explain that your performance in the class depends on yourself, your classmates, and me, together. If the matter seems unresolved at this point, discuss the matter with me. Remember, you're all in the same boat, and you should come to rely on each other (and yourselves) as much as, or more than, me.

General Course Goals:

English 101 is an introduction to college-level writing. Students enrolled in English 101 can expect to:

- Practice and develop writing processes such as invention, revision, organization, drafting through multiple drafts, editing, adjusting for rhetorical context (purpose, audience, persona)

- $\quad$ Practice producing readable and interesting finished products that reflect appropriate academic textual conventions of presentation 
- $\quad$ Practice discussing and sharing writing and reading with one another, and develop a rhetorical vocabulary for talking about writing

- Practice critical thinking processes such as abstracting, synthesizing, representing, incorporating, and developing complex structures for ideas, which should include the use of outside sources.

Course Description:

During the course of the semester, we will discuss and practice various points and methods of argument, and we will learn that almost anything, and subject, is susceptible to debate because of the very nature of language. You will produce four essays that will build on each other, and we will discuss transforming one type of essay into another as a central component to the class. It is vital to think of these essays as layers, not as individual items. We will focus on the process and effects of argument, and also on how elements of argument affect aspects of our lives in and out of the college classroom.

Text: Everything's An Argument, 3rd Ed. (without readings, slim volume).

Essential: A good dictionary (Oxford, American Heritage). Bring this to class each day.

Grade Components:

You will write four (4) essays that will build on each other, 4-5 pages each.

Each of the first three (3) essays you turn in to me will be scored out of 10 possible points.

The fourth essay will be scored out of 20 . The fourth essay rewrite will be scored out of 50.

Participation in Workshops, Conferences \& Daily Writing Assignments will be scored out of a total of 100 .

Attendance Policy:

Since Essay One will build into Essay Two, Essay Two into Three and so on, it is a requirement of this course that you submit each essay when they are due. Late work will not be accepted. If you know you are going to be absent (due to family situations, appointments, or extracurricular functions of any kind), it is entirely your responsibility to inform me of these absences and make plans to submit the work due for class(es) missed AHEAD OF TIME. Should a bona-fide emergency occur, discuss it with me immediately upon your return to class. Missing workshops, conferences, and smaller writing assignments throughout the semester will dramatically affect your participation grades in these areas. Do not plan on simply writing four essays and ignoring the other aspects of the class. Notice the essays themselves only count for half your grade.

I know 8am classes can begin to drain you after a while, but if you plan on consistently missing classes or arriving late to class, drop this course now and register for a section more suitable to your time needs.

Your final grade in the course will be determined on the following scale:

$\begin{array}{lllll}100-98(\mathrm{~A}+) & 90-88(\mathrm{~B}+) & 80-78(\mathrm{C}+) & 70-68(\mathrm{D}+) & 60-0(\mathrm{~F})\end{array}$

97-94 (A) $\quad$ 87-84 (B) $\quad$ 77-74 (C) $\quad 67-64$ (D) 
A note:

Writing is not a magic trick. Writing is not some super-secret activity. Writing requires work and, more importantly, people to help you - people, plural. Don't think I'm the only one you can come to for questions concerning your writing for this (or any other) course.

There are wonderful people at the Writing Center waiting to help you on your way to becoming better writers. Their services are free, available to all students, available during finals week; they have computers and plenty of dictionaries, handbooks and stylebooks for additional assistance. Contact info below:

University Writing Center

Ekstrom Library \#312

Hours for Fall/Spring:

MWR: 9am-6pm

TF: $9 \mathrm{am}-4 \mathrm{pm}$

Sat: $1 \mathrm{pm}-4 \mathrm{pm}$

Call to set up an appointment: 8522173

www.writercenter.louisville.edu

General Course Policies:

General Education Requirement Statement: This course fulfills a General Education Written Communication Requirement. It focuses on writing as a process of thinking as well as a mode of expression and communication. Writing will be presented as an integral aspect of thinking and learning and will therefore be a pervasive activity in this class.

Disabilities Modification Statement: Students who have a disability or condition which may impair their ability to complete assignments or otherwise satisfy course criteria are encouraged to meet with their instructor to identify, discuss and document any feasible instructional modification or accommodation. Please inform your instructor about circumstances no later than the second week of the semester or as soon as possible after a disability or condition is diagnosed, whichever occurs earliest. For information and auxiliary assistance, contact the Disabilities Resource Center.

Grievance Procedures: A student who has a question or concern about a grade, the class, or an assignment should see me/contact me as soon as possible. If you are not satisfied with our discussion, you should contact an Assistant Director of Composition (8525919). Plagiarism Policy: The University defines plagiarism as "representing the words or ideas of someone else as one's own in any academic exercise." Thus, all writing you do for this course must be your own and must be exclusively for this course, unless I stipulate differently. Please pay special attention to the quotes, paraphrases, and documentation practices you use in your papers. If you have any questions about plagiarism, please ask me as soon as you think of them. If you plagiarize, I reserve the right to grant you a failure for the course and report your case to the College of Arts and Sciences. 
Appendix 4

Syllabus (Spring 2009, University of Louisville, Louisville, KY)

English 102-75 and 102-76

Mon/Wed 530-645pm (section 75, DA 209A)

Mon/Wed 7-815pm (section 76, LF 102)

Spring 2009

Daily Schedule:

DATE

READING/ASSIGNMENTS DUE ON THAT DATE

JANUARY

7

Introduction to course, syllabus, policies, procedures - On the notion of what it means to read, encounter, explore, develop, and have "(a) style"... What does it mean "to research," to be "a researcher?"

Beginning the Research Proposal - How/Where to Start, Where to Go (Assignment Sheet for the Proposal)

Steal This Book - Introduction, SURVIVE! Chapters 1-2 (iii-xii, 2-

25)

Steal This Book - Chapters 3-4 (26-46)

19

NO CLASS - MARTIN LUTHER KING DAY

21

(Further) Developing the Research Proposal - What Am I Looking At/For, and How am I Looking at It?

26-28

Steal This Book - SURVIVE! Chapters 5-6 (47-57)

Steal This Book - Chapters 7-8 (58-82)

\section{FEBRUARY}

2

(Further) Development of the Research Proposal - How and Why

Should I Deliver (a) Version(s) of My Self?

Steal This Book - SURVIVE! Chapters 9-10 (83-95)

selections from Working (to be posted on Blackboard)

4

Steal This Book - Chapters 11-12 (96-110)

selections from Working (to be posted on Blackboard)

RESEARCH PROPOSALS DUE

- Informal (and Brief) Presentations

- Constructing a (Working) Annotated Bibliography Encountering and Responding to Source Materials (Assignment Sheet for the Annotated Bibliography)

Rules for Radicals - Prologue (xiii-xxvi)

"Origins of the Burkean Parlor" (to be posted on Blackboard)

"The Kentucky Derby is Decadent and Depraved"

(to be posted on Blackboard)

Rules for Radicals - "A Word about Words" (48-62)

Rules for Radicals - "Communication" (81-97)

Steal This Book-FIGHT! Chapter 1 (111-138) selections from Working (to be posted on Blackboard) 
Steal This Book - FIGHT! Chapters 2-3 (139-158)

"A Stand Against Wikipedia" (to be posted on Blackboard) ANNOTATED BIBLIOGRAPHIES DUE

- Informal (and Brief) Presentations on Findings and Source Materials Thus Far

- Moving Towards the Image/Perception of Completion; Moving from a Proposal \& Working Bibliography (Assignment Sheet for the Research Paper)

NO CLASS - CCCC CONFERENCE

SPRING BREAK

SPRING BREAK

Rules for Radicals - "The Purpose" (3-24)

Rules for Radicals - "Tactics" (126-145)

Rules for Radicals - "Tactics" (145-164)

Organization and Outlining of Materials

Methods of Attack/Approach - The Draft

Steal This Book - FIGHT! Chapter 4 (159-169)

Steal This Book - FIGHT! Chapters 5-6 (170-86) \& Chapter 9 (211-214)

Handout on MLA Citation Style (to be posted on Blackboard) Two Sample MLA-Cited Research Papers (to be posted on Blackboard)

CONFERENCES

CONFERENCES

CONFERENCES

RESEARCH PAPERS DUE (in-hand, no email submissions accepted) BY THE END OF YOUR CLASS SECTION 


\section{Appendix 5}

Email Communications with Composition Program Directors (Identifying Information Expurgated)

Hello-- I need to inquire as to whether our IRB will need to review your protocol before the program allows this inquiry. Give me a week or two...

Follow-up: Hello All-- I have received the request appended below, and am forwarding it to all current and past TAs who have taught in Core Writing. I am satisfied that appropriate research precautions have been addressed, and that potential participants will be dealt with responsibly. The IRB at the University of Louisville is also overseeing this study, and you may reach them with questions at the contact information in the informed consent form (attached as a word doc). Your decision to participate or not is entirely up to you--I won't know or be concerned either way! Please consider this request for assistance, which comes from one of your graduate student peers at another institution.

I have a couple of questions which are more about the suitability of our program than it is about your request per se.

We've just installed a new syllabus and a new course reader. Given that these materials are new to all of our instructors I suspect that they will follow the syllabus template fairly closely for this semester before customizing their sections in subsequent semesters.

I wonder if this might skew any data that you might collect from our program? If you do not see a problem I will be happy to forward your request to my staff.

Your project sounds interesting; however, I create the syllabus the TAs use for their introductory course, so they are all the same. We are a very large, multi-section program and our novice instructors all receive prepared materials from me to make their transition to teaching easier.

Best of luck with your project.

My Reply: Would it be possible to receive a copy of the model syllabus you create for the TAs, since model syllabi factor into my study as well? As a follow-up question, are there any opportunities TAs have to individualize their course syllabi (outside of course from their contact information), and are there any concessions or special cases made for more experienced TAs? Thank you so much for responding to my request so quickly -- I really appreciate it.

All requests to conduct research or collect materials in our program need to be approved by the First-Year Writing Council. The Council has its first meeting of the academic year next Tuesday, and I'd be happy to take your request to them at that time. I don't want to hold you up on the collection of your data--will it be a problem to wait until next week for a response from the Council?

Thanks so much for your request to extend your research study to include I brought your request before the First-Year Writing Council at our first meeting of the semester last Tuesday, and we discussed the request at some length. The Council 
approved your request to contact teaching assistants in our program for syllabi, but they raised a couple of concerns about the nature of the study that I wanted to pass along to you. Specifically, the Council agreed that it might be useful for you to have some contextual information about our program and how TAs are prepared for teaching in order to interpret the data. You might find the information about our program that is available in our online faculty handbook to be useful:

I'd be happy to respond to any questions you might have about TA preparation at or the makeup of our graduate student TA population. Graduate students at go through one full year of preparation before teaching their first classes as instructors-ofrecord. It might also be useful to know that TAs only represent about $25 \%$ of our teaching faculty in the First-Year Writing Program, teaching approximately $10 \%$ of the courses offered. The remaining courses are taught primarily by full-time lecturers in the program who are intensely involved in mentoring and preparing the teaching assistants for instruction.

Please let me know if you have any other questions, or if I can provide any further information to help you contact the TAs in our program.

Let me run this by a few people first, and I'll get back to you.

I have stepped down as Director of Composition at , so I am forwarding your email to my successor, She is the person who will be able to approve contacting our instructors.

Thank you for the note. It sounds like an interesting project. I'm working with nine new teachers right now who are crafting their first set of policies (and their identities).

I will forward this to our comp TAs. I think, though, it would be better if I wait a couple weeks to do so. Classes start next week and there's a better chance of it getting their full attention after the craziness of the first week subsides. Hope that's ok with you. Good luck with your project; it sounds really interesting. 


\section{Appendix 6}

Request for Course Syllabi (IRB Approval 08.0273)

We are Karen Kopelson, $\mathrm{PhD}$, a faculty member in the English Department at the University of Louisville, and Christopher Alexander, a graduate student in the $\mathrm{PhD}$ program at the University of Louisville. We are conducting a research project that explores the ways graduate teaching assistants in composition construct their course syllabi for first-year writing (FYW) courses. To this end, we are collecting course syllabi from English graduate students teaching FYW courses. We hope to learn about how those in the discipline of composition perceive and express different aspects of the syllabi on both personal and institutional levels.

If you are a composition instructor who is interested in participating in this study, we invite you to submit copies of your current and/or past FYW course syllabi to Christopher at c0alex04@louisville.edu. We will be reading these documents to discover what threads of similarity exist amongst the ways graduate student teachers represent their teaching styles and experiences. In addition, we may contact you in the future to answer possible follow-up questions.

You may email your syllabi and responses to follow-up questions to Christopher, at c0alex04@louisville.edu. Feel free to attach a copy of the syllabus (or syllabi) to your email, and to copy/paste your responses to follow-up questions directly into the email.

All information that would specifically identify you will be removed immediately when we receive your materials. This study is voluntary, and you may discontinue your participation at any time. Attached to this announcement should be the informed consent document, informing you of your rights and expectations in accordance with the study. Thank you for your time, and if you have any questions regarding participating in this survey, please contact Christopher Alexander at c0alex04@louisville.edu.

Sincerely,

Karen Kopelson

Christopher Alexander

c0alex04@louisville.edu 


\section{Appendix 7}

Amended Follow-Up Questions for Graduate Student Teachers

Participating in Syllabus Request (IRB Approval 08.0273)

Are you a Masters or PhD student? What year?

How many years/months have you been teaching first-year writing (FYW) courses?

Have you taught these courses exclusively while a graduate student, or have you taught FYW before?

Are there departmental and/or institution-wide requirements pertaining to the construction, dissemination, or documentation or filing of your course syllabi? If so, what are they?

Are syllabi required to be submitted to the department by a certain deadline in the term?

Are you required to post your syllabi to a departmental website or a course-specific page (Blackboard, WebCT, etc)?

Are you offered a "skeleton" or "model" syllabus, or are you expected to develop your own syllabi?

How do you feel about this?

If you are offered/required to use a "model" syllabus, do you work against it in other ways?

Does your program offer/require an introductory course for teaching college composition (a teaching practicum or course required of new/entering graduate student teaching assistants)?

How - or to what extent - does such a course make the FYW course syllabus a subject of discussion, debate, or analysis? 
Appendix 8

Syllabus Checklist - [name of institution removed]

The following information should be included in your syllabus. Information with text already provided, such as the Official Course Name or General Education statements, needs to have that text included verbatim. Please attach a copy of this sheet to your syllabus, with the required information checked off, when you turn a copy in to the Composition Program Office.

\begin{tabular}{|c|c|}
\hline Check & Item that must be included: \\
\hline & Name of Instructor \\
\hline & $\begin{array}{l}\text { Official Course Name: } \\
\text { English 101: Introduction to College Writing } \\
\text { English 102: Intermediate College Writing } \\
\text { English 105: Advanced Composition for Freshmen } \\
\text { English 306: Business Writing } \\
\text { English 309: Advanced Academic Writing }\end{array}$ \\
\hline & Course number and section \\
\hline & Year and term \\
\hline & Office room number (and carrel \# if applicable) \\
\hline & $\begin{array}{l}\text { Office hours } \\
\text { *two hours per week for one section and four hours for two ore more sections. } \\
\text { Summer teaching requires three hours per week. It is a good practice to } \\
\text { explicitly indicate that students may make appointments for other times. } \\
\text { NOTE: See further information in the OFFICE HOURS section of handbook. } \\
\text { Also see information on STUDENT CONFERENCES. }\end{array}$ \\
\hline & Phone and e-mail address \\
\hline & $\begin{array}{l}\text { Course goals/ course description } \\
\text { * Provide an overview of the design of your course. Explain the relationships } \\
\text { of writing and reading assignments and other activities to the overall purpose } \\
\text { and goals of the course. } \\
\text { NOTE: See further information on Assignment Sheets in the GRADING } \\
\text { CRITERIA section of handbook. }\end{array}$ \\
\hline & $\begin{array}{l}\text { General overview of required work } \\
\text { * Provide a brief description of the formal writing assignments, informal } \\
\text { writing, participation, and any other work. Indicate the percentage each } \\
\text { contributes to the final grade. }\end{array}$ \\
\hline & $\begin{array}{l}\text { Course prerequisites/ placement criteria } \\
\text { English 101: Open to all incoming students. English 102: Eng. 101, approved } \\
\text { transfer credit for Eng. 101, or Portfolio Placement into 102. English } 105 \text { : } \\
\text { Open only to exceptionally qualified students who have been notified of their } \\
\text { eligibility. } \\
\text { English 303: Eng. } 102 \text { or } 105 \\
\text { English 306: Eng. } 102 \text { or } 105 \\
\text { English 309: Eng. } 102 \text { or } 105\end{array}$ \\
\hline
\end{tabular}




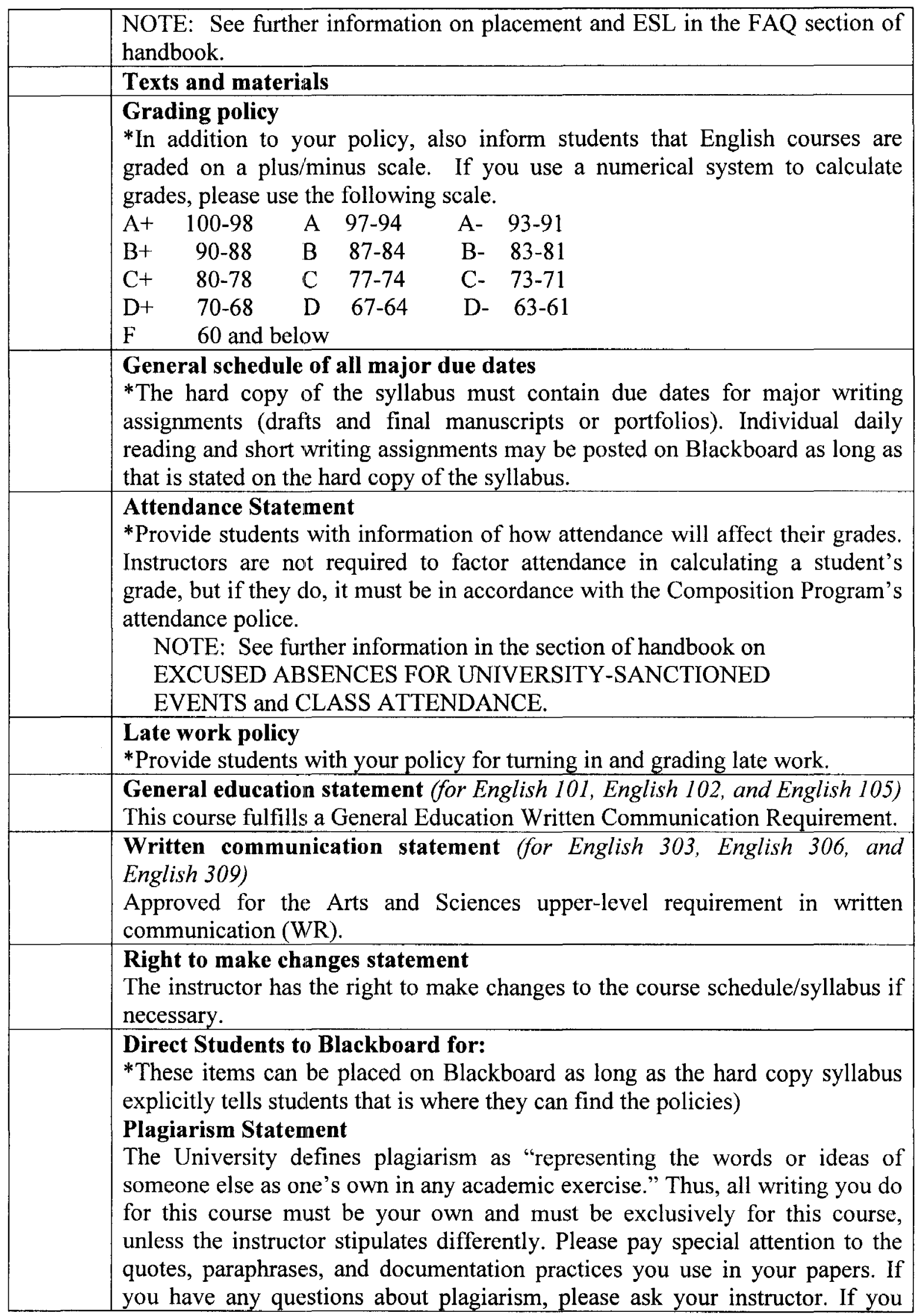




\begin{tabular}{|l|l|}
\hline clagiarize, your instructor reserves the right to grant you a failure for the \\
course and your case may be reported to the College of Arts and Sciences. \\
NOTE: Please see further information in the PLAGIARISM section in the \\
composition handbook. \\
Statement on behalf of students with disabilities \\
Students who have a disability or condition which may impair their ability to \\
complete assignments or otherwise satisfy course criteria are encouraged to \\
meet with the instructor to identify, discuss and document any feasible \\
instructional modifications or accommodations. Please inform instructor about \\
circumstances no later than the second week of the semester or as soon as \\
possible after a disability or condition is diagnosed, whichever occurs earliest. \\
For information and auxiliary assistance, contact the Disabilities Resource \\
Center. \\
Grievance procedure statement \\
Students who have questions or concerns about their grades, the class, or an \\
assignment are encouraged to see their instructor as soon as possible. If not \\
satisfied with that discussion, students may see an assistant director of \\
composition.
\end{tabular}




\section{CURRICULUM VITAE}

NAME:

CHRISTOPHER M. ALEXANDER

ADDRESS: $\quad$ University of Louisville

Department of English

Bingham Humanities Rm. 315

Louisville, KY 40292

DOB:

Memphis, TN - 15 April 1976

EDUCATION: Ph.D. in Rhetoric and Composition

University of Louisville

(2005-2010)

M.A. in English

University of Alabama

(1999-2001)

B.A. in English

University of Alabama

(1994-1998)

TEACHING

EXPERIENCE: Instructor, Department of English, University of Louisville, Louisville, KY (8/2009-present)

Graduate Teaching Assistant, Department of English, University of Louisville, Louisville, KY (08/2005-08/2009)

Instructor, Division of Communications, Jefferson State Community College, Hoover, AL (01/2003-08/2005)

Instructor, Department of English and Classics, BirminghamSouthern College, Birmingham, AL (08/2002-05/2005)

Instructor, Department of English, University of Alabama at Birmingham, Birmingham, AL (08/2001-05/2002) 
Graduate Teaching Assistant, Department of English, University of Alabama, Tuscaloosa, AL (08/1999-05/2001)

PUBLICATIONS: "Audio Reflection and the Materiality of Silence." With Tabetha Adkins, Patrick Corbett, Debra Journet, and Ryan Trauman. "Digital Mirrors: Multimodal Reflection in the Composition Classroom." Computers and Composition Online (Spring 2008): http://www.bgsu.edu/cconline/Digital_Mirrors/

"'I' Walk the Line: Blurred Genres and Selves in the Civil War Memoirs of William G. Stevenson." Kentucky Philological Review 22 (March 2008): 13-25.

WORKS IN

PROGRESS:

"'Click YES to Continue': The Course Syllabus as an End-User Licensing Agreement," co-authored with Stephen Neaderhiser.

CONFERENCES: "What Role(s) Recitation? - A Dialogue Concerning Recitation and Literacy." With Stephen Neaderhiser. Expanding Literacy Studies. Columbus, OH. April 3-5, 2009.

"'Steal This Research Paper:' Rhetorics of Revolution and Teaching Writing from Sources." Conference on College Composition and Communication. San Francisco, CA. March 11-14, 2009.

"The Spaces In Between: Burke's Substantiality, Audio Recording Technology, and Constructions of Reflective Composition." Thomas R. Watson Conference in Rhetoric and Composition. Louisville, KY. October 16-18, 2008.

"Paine's Prefaces to Rights of Man and the (Re)Constructions of the Public Sphere." Kentucky Philological Association. Louisville, KY, March 7-8, 2008.

"Walking the Line: Blurred Genres and Selves in the Civil War Memoirs of William G. Stevenson." Kentucky Philological Association. Barbourville, KY. March 2-3, 2007.

"Drawing Conclusions - John Callahan and the Art of Autobiography." $5^{\text {th }}$ Annual Hawaii International Conference on Arts and Humanities. Honolulu, HI. January 12-15, 2007.

"'Subject to Change:' Syllabus, Narrative Sequentiality, and Dialogic Identity." Thomas R. Watson Conference in Rhetoric and Composition. Louisville, KY. October 5-7, 2006. 
GRADUATE

COURSEWORK

$\mathrm{U}$ of $\mathrm{L}$ :

GRADUATE

COURSEWORK

U of ALABAMA:
Teaching College Composition (B. Williams)

Narrative Theory (D. Journet)

Composition Theory and Practice (K. Kopelson)

Special Topics in Rhetoric: Literacy (D. Brandt)

Research Methods in Composition (D. Journet)

Special Topics in Composition: Basic Writing (B. Horner)

History of Rhetoric II: $18^{\text {th }}$ and $19^{\text {th }}$ Centuries (C. Mattingly)

Digital Media and Composition (D. Journet)

Contemporary Theories of Interpretation (B. Williams)

American Literature: Disability and Culture (R. Miller)

The Civil War and American Culture (S. Ryan)

Romantic Poetry and Prose (K. Hadley)

Teaching College English I (J. Raymond)

Teaching College English II (M. Tuman)

Research and Bibliography (P. Logan)

Critical Prose Workshop (E. Messe)

Special Topics: Petrarch (B. Godorecci)

Structures of Tragedy (G. Wolfe)

Shakespeare: Sexuality and Transvestitism (S. O'Dair)

Milton/Spenser (R. Halli, Jr.)

Seminar in Romantic Literature (W. Ulmer)

Special Topics in American Literature: Moby Dick (R. Rand)

Modern British Drama (G. Wolfe)

PROFESSIONAL ASSOCIATIONS

ACTIVITIES:

Coordinator, IRG (University of Louisville Reading Group)

Sigma Tau Delta, International English Honor Society

PROFESSIONAL INTERESTS:
Composition Theory and Practice

Rhetoric and Rhetorical Studies

Business and Professional Writing

Graduate Student Teacher Training

Genre Studies

British Romantic History and Literature

1970s American Radicalism

Memoir Writing

Disability Studies 